\title{
A Comprehensive Review of Thermoelectric Technology: Materials, Applications, Modelling and Performance Improvement
}

\author{
Ssennoga Twaha ${ }^{1}$, Jie Zhu ${ }^{1 *}$, Yuying Yan $^{1}$, Bo Li ${ }^{1}$ \\ ${ }^{1}$ Department of Architecture and Built Environment, Faculty of Engineering, University of \\ Nottingham NG7 2RD, United Kingdom
}

\begin{abstract}
:
Thermoelectric (TE) technology is regarded as alternative and environmentally friendly technology for harvesting and recovering heat which is directly converted into electrical energy using thermoelectric generators (TEG). Conversely, Peltier coolers and heaters are utilized to convert electrical energy into heat energy for cooling and heating purposes The main challenge lying behind the TE technology is the low efficiency of these devices mainly due to low figure of merit (ZT) of the materials used in making them as well as improper setting of the TE systems. The objective of this work is to carry out a comprehensive review of TE technology encompassing the materials, applications, modelling techniques and performance improvement. The paper has covered a wide range of topics related to TE technology subject area including the output power conditioning techniques. The review reveals some important critical aspects regarding TE device application and performance improvement. It is observed that the intensified research into TE technology has led to an outstanding increase in ZT, rendering the use TE devices in diversified application a reality. Not only does the TE material research and TE device geometrical adjustment contributed to TE device performance improvement, but also the use of advanced TE mathematical models which have facilitated appropriate segmentation TE modules using different materials and design of integrated TE devices. TE devices are observed to have booming applications in cooling, heating, electric power generation as well as hybrid applications. With the generation of electric energy using TEG, not only does the waste heat provide heat source but also other energy sources like solar, geothermal, biomass, infra-red radiation have gained increased utilization in TE based systems. However, the main challenge remains in striking the balance between the conflicting parameters; ZT and power factor, when designing and optimizing advanced TE materials. Hence more research is necessary to overcome this and other challenge so that the performance TE device can be improved further.
\end{abstract}


Keywords: Heating; Cooling; TEG/TEC materials; TEG Structures; TEG Modelling; TEG/TEC Performance improvement.

*Corresponding author: Jie Zhu: Email: lazjz@ nottingham.ac.uk. Tel. +44115 8466141.

\section{Table of contents}

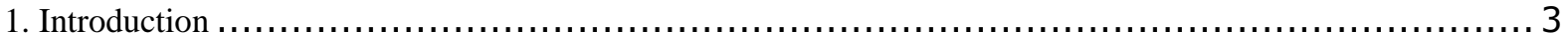

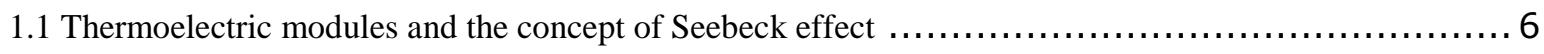

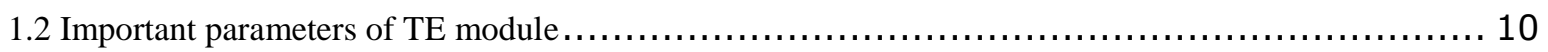

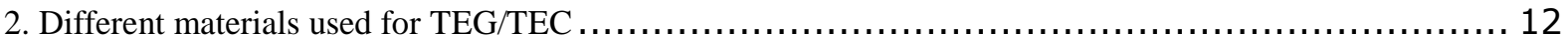

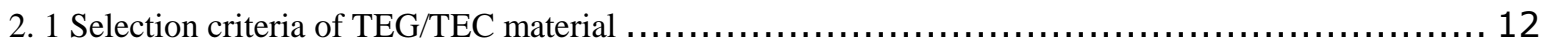

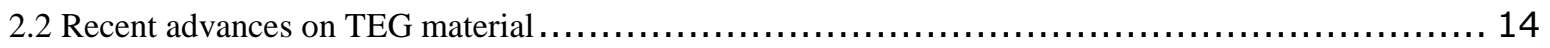

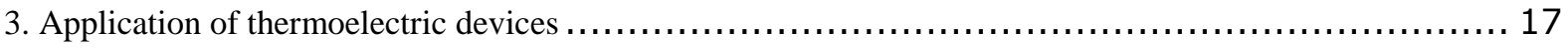

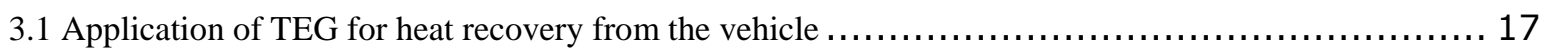

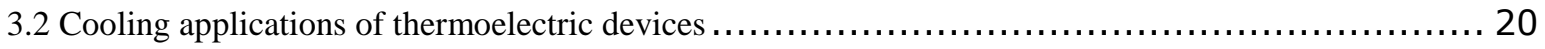

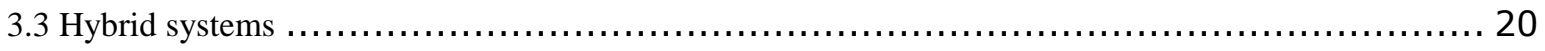

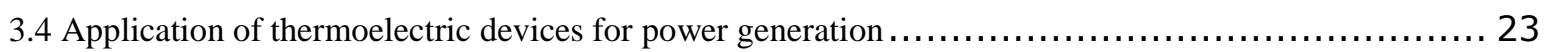

3.4.1 Categories of thermoelectric applications for electric power generation ....................... 23

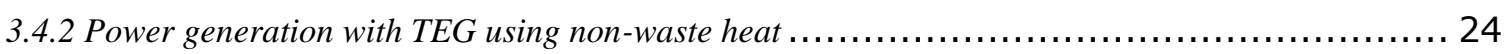

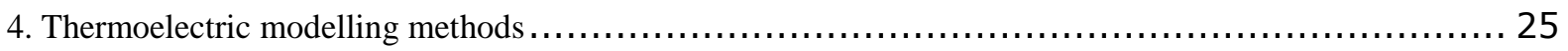

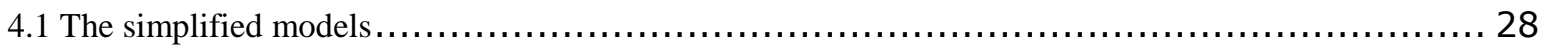

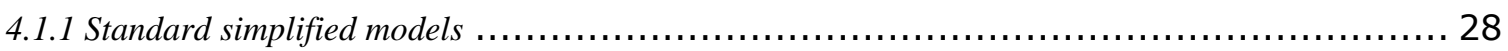

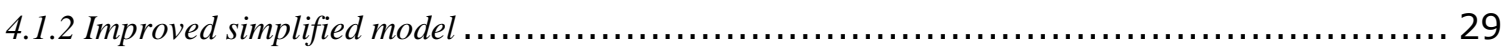

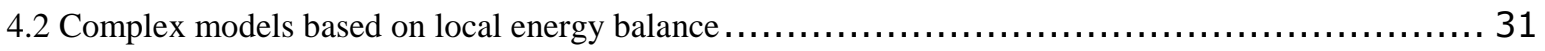

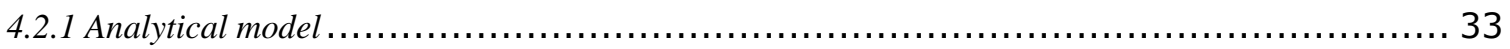

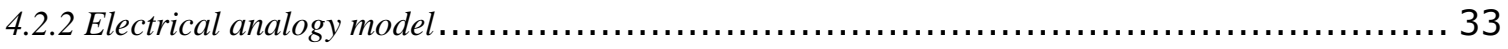

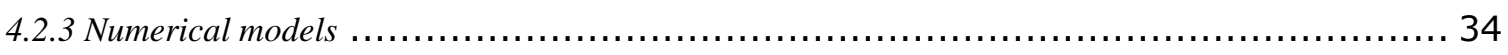

5. Different structures of TEG unit/Module................................................ 35

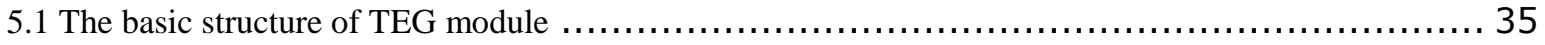

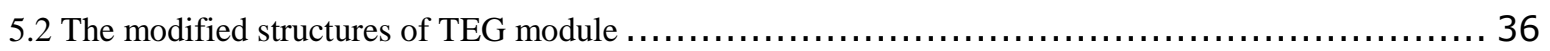

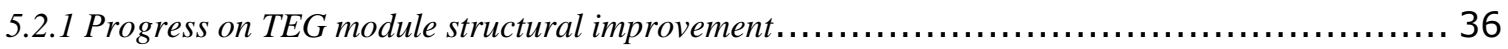

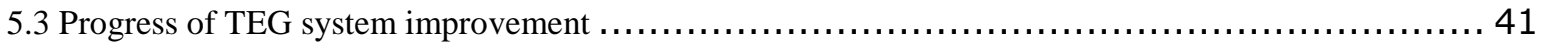

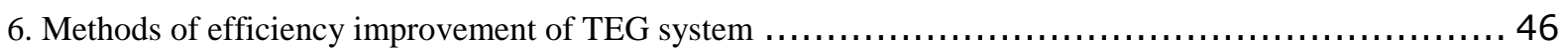

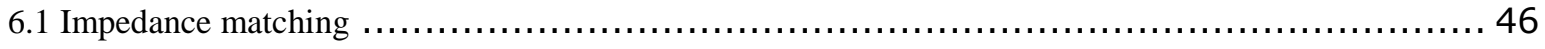

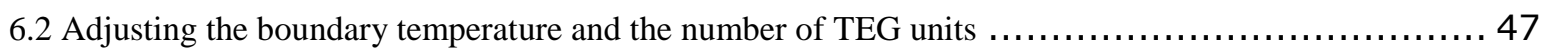

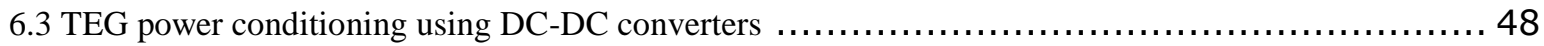

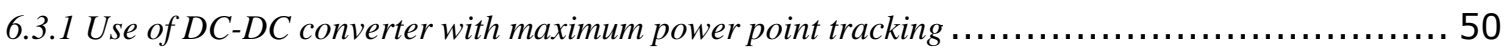

6.3.2 Application of TEG output power regulation with DC-DC C'uk converter...................... 53

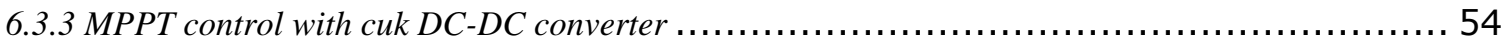


6.3.4 Use of distributed multi-section multilevel DC-DC conversion networks........................ 55

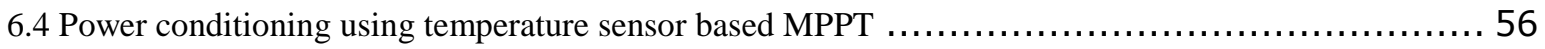

6.5 Other methods to improve the performance of thermoelectric devices ......................... 57

7. Description of the reviews on thermoelectric materials, parameters and applications $\ldots \ldots \ldots \ldots \ldots \ldots \ldots \ldots \ldots \ldots$

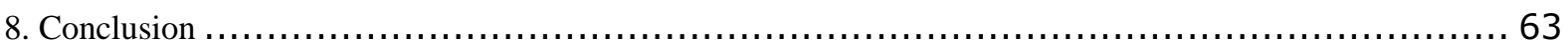

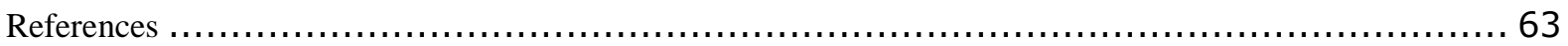

\section{Introduction}

The drastic changes in climate have driven the need for increasing research into alternative sources of energy. Those rapid changes in climate are mainly attributed to the use of fossil fuels for transport and energy generation. Due to climatic challenges, several countries around the world have pledged to reduce primary energy consumption through an increase of efficiency in production, distribution and end-use, limit carbon dioxide emissions and increase the utilization of renewable energy sources [1]. The rapid development of power electronics technologies has enabled the realization of high energy-efficient systems such as electric vehicles [2]. The U.S. Energy Administration in 2011 estimated that almost two-thirds of total demand for petroleum is from the transportation sector. With an assumption that daily production of petroleum holds steady at 63.5 million barrels, global oil reserves are conventionally predicted to last approximately fifty years [3]. In the French industry, $75 \%$ of the final energy is used for thermal purposes such as furnaces, reactors, boilers and dryers. However, around $30 \%$ of this heat is assumed to be wasted in form of discharged hot exhaust gas, cooling water and heated product [4]. Therefore, the recovery and utilization of the waste heat is believed to contribute some amount of energy to the energy needs of the society.

Research and development have been promoted on thermoelectric (TE) modules which convert heat energy directly into electrical energy. TE devices are semiconductor devices that have the ability to either generate a voltage when exposed to a temperature gradient, exploiting the Seebeck effect, or produce a temperature gradient when supplied by electricity, exploiting the Peltier effect [5]. A number of currently available and applicable low-grade waste heat recovery methods include plant/district/water heating, direct power generation (TE and piezoelectric), absorption cooling, indirect power generation (steam and organic Rankine cycle), desalination/clean water and biomass co-location [6]. TE technology is seen as one of the most promising direct power generation technique used to recover waste heat energy because of the direct conversion from thermal energy to electrical energy, unlike the organic 
Rankine cycle, believed to have been discovered more than 150 years ago [7]. Heat energy can be harvested or recovered using two direct electricity generation strategies: thermoelectricity and pyroelectricity. Whereas thermoelectricity is the generation of electricity using thermoelectric harvesting systems which exploit the Seebeck effect for conversion of heat energy i.e., generation of electricity due to difference in temperature of two dissimilar conductors or semiconductors connected together at two junctions, pyroelectricity exploits specific materials whose structures are modified when heat is applied on them and in turn the polarization of the material is changed, thus creating electric potential [8].

TE modules offer low cost electricity, and green energy technology without the use of moving parts or production of environmentally deleterious wastes [9]. However, the optimal performance of TE modules depends on several factors like material selection and operation strategy. A study has used an irreversible model to analyse the performance of a thermoelectric generator (TEG) with external and internal irreversibilities, providing some significant instructions for their optimal operation including the information about optimal device-design parameters, efficiency, maximum power output, etc. [10]. Most of the research by 2005 had concentrated on electronics cooling applications especially on the variation of the geometric features such as shapes, sizes, and orientations to the flow in heat transfer systems but in later years, research on TE technology has gained a lot of momentum [11].

Although energy-related GHG emissions from fossil fuel combustion account for $70 \%$ of total emissions including come from heat supply and electricity generation, a relatively large portion is generated from the transportation industry [12]. Although electric vehicles (EV) powered by renewable energies are seen as a potential solution to curtail GHG from transport industry [13], TE technology is also continuously introduced in low carbon vehicles to extract waste energy from various points of the vehicle. For a typical gasoline-engine vehicle, about $40 \%$ of the fuel energy is discharged from the exhaust pipe; about $30 \%$ is lost into the cooling system, clutch, gearbox and differential [14]. Hence, energy-harvesting systems which recover this heat energy to convert it into electricity with the use of TEGs are being studied and introduced [15][16].

There are challenges surrounding TE technology which call for more research to address them. The assembly of TEG devices is still particularly challenging, and consequently these devices have been applied only in niche applications [17]. With regard to TE materials, there is a problem of wide lattice thermal conductivity whereby nanostructuring has been considered as an effective approach to enhance the TE performance of materials by reducing their lattice thermal conductivity [18]. The introduction of large concentrations of lattice vacancies in 
silicon nano-films is noted for creating more than a 20 -fold reduction in thermal conductivity, while Seebeck coefficient and electrical conductivity are largely maintained [19]. With such challenge in mind, the impact of the substrate on the efficiency of thin film thermoelectric technology is assessed [20]. It is found that as the thickness ratio between substrate and thin film increases, the parameter ZT sharply tends to zero; this effect causes a serious problem to overcome by the thin film TE technology, more especially at nanoscale. Frequency dependency of ZT is another challenge especially in cylindrical thermoelectric nano devices. A study indicates that regarding the relative values of the particles' mean-free path and the characteristic size of the system, the performances of the thermoelectric devices are reduced in those situations [21]. However, it is found that non-local effects may be used as an aiding tool to have less marked reductions in those performances.

With TE Cooling (TEC) devices, cooling hot-spots with high heat flux is becoming one of the most important technical challenges in integrated circuit industry, calling for more aggressive thermal solutions, than those required for uniform heating, to mitigate this problem [22]. One efficient method of hotspot thermal management is to use super lattice TECs which can provide on demand and localized cooling. A detailed 3-D thermal model of a stacked electronic package is developed to investigate the efficacy of TECs in hotspot cooling for 3-D technology where thermal contact resistances between dies inside the TEC module, and between TEC and heat spreader are shown to have a crucial effect on the TEC performance [23]. Regarding TEG devices, product development requires solving coupled challenges in materials development and systems engineering to enable new thermoelectric materials and material performance improvements for development of thermoelectric generators for numerous applications [24].

The objective of this work is to carry out a comprehensive review of thermoelectric technology encompassing the materials, applications, modelling techniques and performance improvement. A brief background of the TEG devices and materials has been covered first followed by the applications of these technologies. The rest of the paper is organised as follow: section 2 deals with different TE materials while section 3 describes the application of TE devices. TE modelling techniques are discussed in section 4 whereas various structures of TEG systems are clarified in section 5. Sections 6 and 7 elaborate the methods of efficiency improvement in TEG and the description of the reviews on TE technology, respectively. The paper ends with a concluding remark. 


\subsection{Thermoelectric modules and the concept of Seebeck effect}

TE modules can be used for either cooling or power generation, as shown in Fig. 1. A TEG is a solid-state device that can convert heat directly into electrical energy when a temperature difference is placed across it [25]. The TE module consists of arrays of $\mathrm{N}$ and $\mathrm{P}$ type semiconductors in which, by applying a heat source on one side and a cooler heat sink to the other side, electric power is produced and vice versa. Electric power can be converted to cooling or heating by reversing the current direction [26].

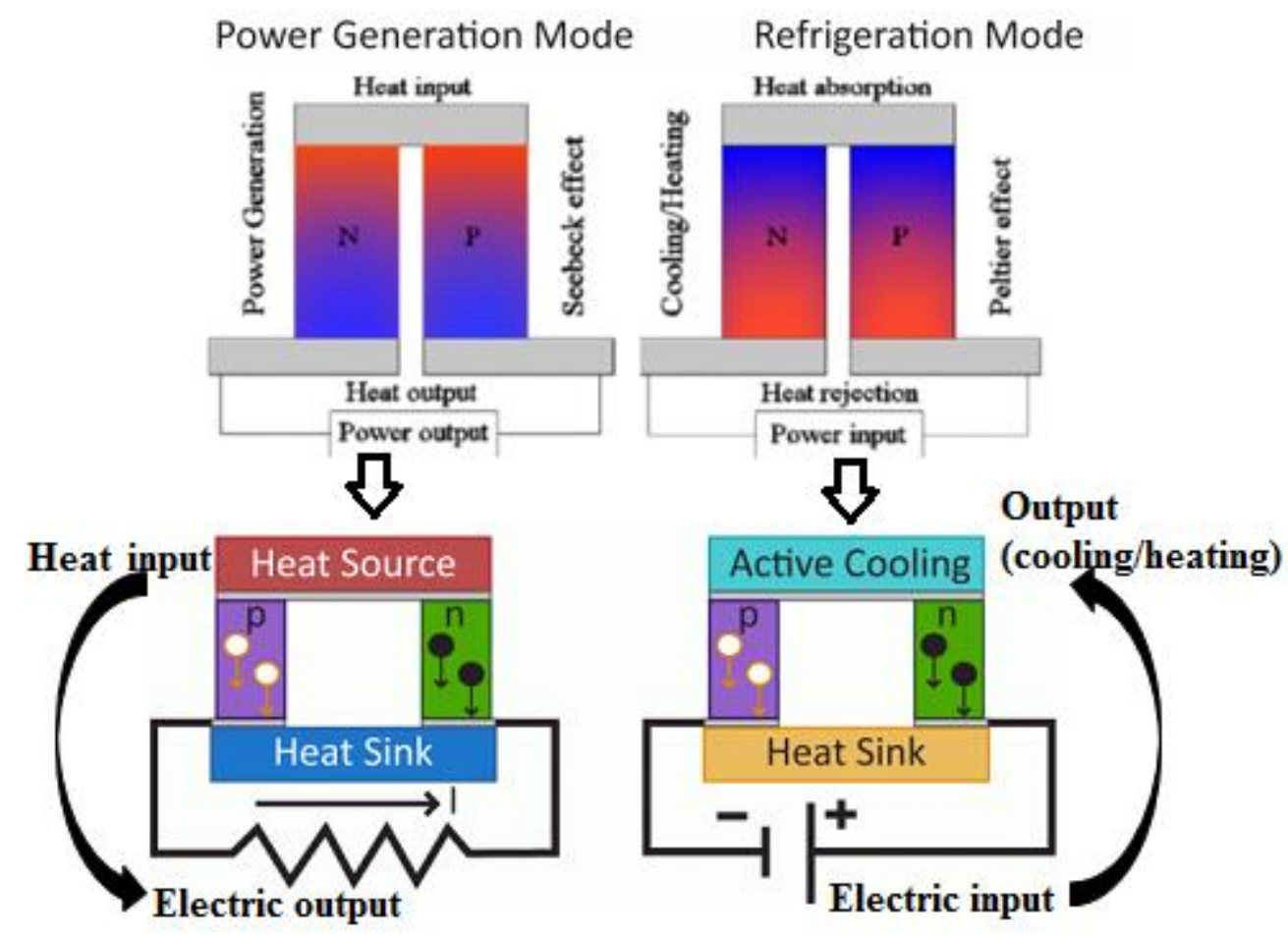

Fig. 1. Power generation and cooling/heating thermoelectric heat engines [26]

While choosing TEGs for application in varying conditions, it is necessary to select an appropriate semiconductor with acceptable performance in the temperature range of that condition [27].

The figure of merit $(Z)$ is a parameter generally used to gauge the performance of a TE material:

$$
Z=\frac{\alpha_{p, n}^{2} \sigma_{p, n}}{\lambda_{p, n}}
$$


Where $\alpha_{p, n}$ is the Seebeck coefficient of n-type or p-type material. $\sigma_{p, n}$ is the electrical conductivity of the material in p-type or n-type in Siemens per meter whereas $\lambda_{p, n}$ is the thermal conductivity [27].

In general, for obtaining maximum efficiency, the important characteristic for thermoelectric material is the dimensionless measurement thermoelectric performance figure of merit ZT [26].

$$
Z T=\frac{\sigma S^{2} T}{\lambda}
$$

Where S, $\sigma, \mathrm{T}$ and $\lambda$ are the Seebeck coefficient, electrical conductivity, absolute temperature and thermal conductivity, respectively. In order to get high thermoelectric efficiency, the figure of merit should be large.

In a thermoelectric material there are free electrons or holes which carry both charge and heat. The electric potential (Voltage) produced by a temperature difference is known as the Seebeck effect and the proportionality constant is called the Seebeck coefficient. If the free charges are positive (the material is p-type), positive charge will build up on the cold end which will have a positive potential. Similarly, negative free charges (n-type material) will produce a negative potential at the cold end [28]. Fig. 2 illustrates the movement of electrons and holes in p- and n-type materials respectively due to Seebeck effect.

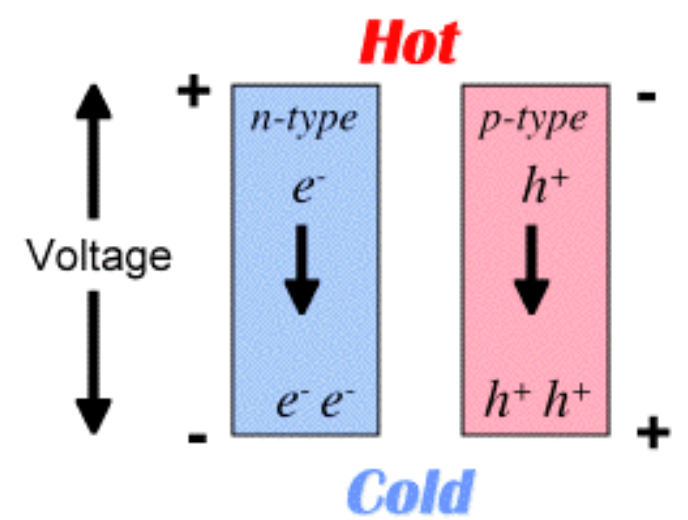

Fig. 2. The movement of electrons and holes in p- and n-type materials.

The features of heat transfer are calculated using the mechanism of the Seebeck effect as shown in Fig. 3. The compressed air heated by a heater with flow rate $F_{H}$, heat transfer coefficient $h_{1}$ and at inlet temperature $T_{i}$ flows through the heat pipe to provide the high/hot 
temperature side of the TE module. Similarly, the jet air at with flow rate $\mathrm{F}_{\mathrm{C}}$, heat transfer coefficient $h_{2}$ and at temperature $T_{j}$ provides cooling to create the cold side of the module. The waste heat energy is transferred to the heat absorber with temperature $T_{i, s}$ by heat convection while the internal heat sink absorbs some of the waste heat energy, and the thermal grease with thermal conductivity $\mathrm{k}_{\mathrm{tg}}$ guides the heat to the hot side of TEG with $\mathrm{T}_{\mathrm{TEG}, \mathrm{H}}$ temperature. The heat collection and heat dissipation distinctly at the hot and cold sides of TEG create the temperature difference between the both sides of the module to generate electricity due to Seebeck effect. Simultaneously, the internal Joule heating happens in the TEG due to the internal electric resistance $\mathrm{R}_{\text {int }}$. More details of the heat transfer mechanism are found in [29].
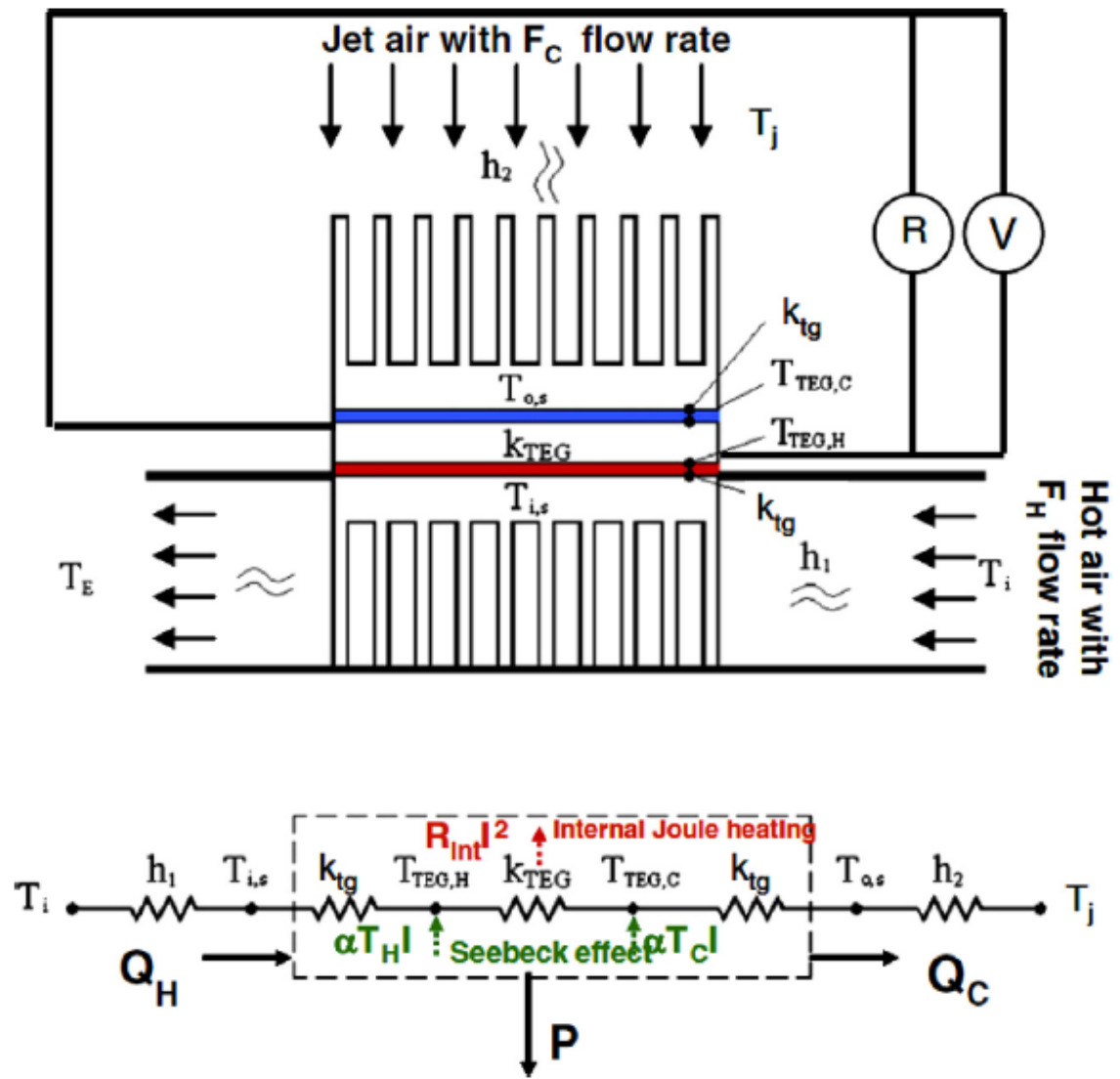

Fig. 3. Heat transfer mechanism and Seebeck effect for the thermoelectric module.

The derivation of heat conduction equation is based on the internal energy generation of the TE module [29]:

$$
\frac{\partial^{2} T}{\partial x^{2}}+\frac{\dot{q}}{k_{T E G}}=0
$$


Where $\mathrm{x}$ is any thickness of the TEG material, $\dot{q}$ is heat energy generated per unit volume and $\mathrm{K}_{\mathrm{TEG}}$ is the thermal conductivity of the TEG.

Assuming the low and high temperature sides are taken to be same, the boundary conditions are expressed as $\mathrm{T}(0)=\mathrm{T}_{\mathrm{i}, \mathrm{s}}$ at $\mathrm{x}=0$ and $\mathrm{T}(\delta)=\mathrm{T}_{\mathrm{o}, \mathrm{s}}$ at $\mathrm{x}=\delta$.

The total generated power can be calculated as follows:

$$
P=Q_{H}-Q_{c}=\alpha I\left(T_{i, s}-T_{o, s}\right)-\delta A_{T E G} \dot{q}
$$

Putting the Seebeck effect into consideration, the thermal power $\mathrm{Q}_{\mathrm{H}}$ and $\mathrm{Q}_{\mathrm{C}}$ from the high and low temperature sides can respectively be computed as:

$$
\begin{aligned}
& Q_{H}=\frac{k_{T E G} A_{T E G}}{\delta}\left(T_{i, S}-T_{o, S}\right)+\alpha T_{i, s} I-\frac{1}{2} R_{i n t} I^{2} \\
& \mathrm{Q}_{\mathrm{C}}=\frac{\mathrm{k}_{\mathrm{TEG}} \mathrm{A}_{\mathrm{TEG}}}{\delta}\left(\mathrm{T}_{\mathrm{i}, \mathrm{s}}-\mathrm{T}_{\mathrm{O}, \mathrm{S}}\right)+\alpha \mathrm{T}_{\mathrm{o}, \mathrm{s}} \mathrm{I}-\frac{1}{2} \mathrm{R}_{\mathrm{int}} \mathrm{I}^{2}
\end{aligned}
$$

Where $\delta$ is the thickness of the TEG and I is the current. In this case, $\mathrm{A}_{\mathrm{TEG}}$ has two meanings; first as the area of the heat sink for the high-temperature side, and as the area of the TE module for the low temperature side_[29].

The maximum electric power generated from the TEG is expressed as [30]:

$$
P_{\text {max }}=\frac{k_{T E G} A_{T E G}}{\delta} * \frac{\left[(\gamma+\lambda+1)-\sqrt{(\gamma+\lambda+1)^{2}-4 \alpha^{*} \lambda\left(T_{i}-T_{j}\right)}\right]}{4 \alpha^{*}}
$$

Where, $\lambda$ is the biot number of the TEG, $\gamma$ is the heat transfer ratio of the heat absorber to the heat sink and $\alpha^{*}$ is the Seebeck parameter of the TEG.

In another form

$$
P_{\max }=\frac{E_{m}^{2}}{4 R_{m}}
$$

Where $E_{m}$ is the electromotive force (EMF) generated by Seebeck effect. $P_{\max }$ occurs when the RL equals to TEG module internal resistance $R_{\text {int }}$.

For the physical properties of TE materials, some previous studies assumed that they are temperature-independent, however, it has been demonstrated experimentally [28] that the physical properties of the TE materials are temperature dependent. This dependence can be very significant and strongly affect the TEG performance [31]. The physical properties of $\mathrm{Bi} 2 \mathrm{Te} 3$ are calculated as:

$$
\alpha=-6.034 * 10^{-5}+6.270 * 10^{-7} T-1.571 * 10^{-9} T^{2}+1.260 * 10^{-12} T^{3}\left(V K^{-1}\right)
$$




$$
\begin{gathered}
\delta=-7.188 * 10^{-7}+6.926 * 10^{-9} T-3.573 * 10^{-12} T^{2}(\Omega m) \\
k=2.244+6.067 * 10^{-5} T-2.308 * 10^{-6} T^{2}+4.439 * 10^{-9} T^{3}\left(W m^{-1} K^{-1}\right)
\end{gathered}
$$

The heat transfer coefficient is also expressed as:

$$
h=\frac{Q_{\max }}{A_{B}\left(T_{i}-T_{o}\right)}
$$

Where $A_{B}$ is the heat sink base area.

\subsection{Important parameters of TE module}

The parameters that affect the performance of TE devices can be physical or nonphysical. The most important optimization parameters for TEG include TE element leg length, leg area ratio between n- and p-type legs, fill fraction, load resistance and module spacing. The effect of various leg geometries on thermo-mechanical and power generation performance of thermoelectric devices are investigated by modelling leg geometries and analysed using finiteelement method [32]. Thermal stresses in the legs, power outputs, temperature distributions and conversion efficiencies are evaluated and the results show that significant differences in sizes and distributions of the thermal stresses in the legs occur due to varying leg geometries. The different output parameters for TEG device are identified as power generation, thermal efficiency, current, thermal and electric fields, etc [33].

It is also noted that the influences of the effective Seebeck coefficient and carrier density variations on the performance of $\mathrm{TE}$ system are generally neglected, resulting in an overestimation of the power generator performance under strong-ionization temperature region [34]. Therefore, researchers suggested and proved the use of finite element tool to solve such complexity, whereby the characteristics of TEG and their relationship to its performance can be well analysed. Additionally, the behaviour of power generation from TEG exposed to a transient heat source on the hot side and natural convection on the cold side are studied [35]. It is stressed that modelling TEGs under these conditions is complicated compared to TE coolers because of the non-linearities and the unknown electric currents in a closed-loop circuit. Therefore a transient TE model which comprises Seebeck, Thomson, Peltier, and Joule effects using finite-difference techniques is suggested and the incorporation of Thomson effect plays a significant role in precisely predicting the generated power. Fateh et al. used a finite difference model to investigate the interdependencies among these optimization parameters for TE elements included with an exhaust gas heat exchanger [36]. Different researchers look at the optimum parameters differently depending on the method used in the parameter analysis. 
The influence of geometric features on TEG device characteristics is done using multiobjective evolutionary algorithms [37]. The parameters assessing geometric features include pin length size and shape factor while operating parameters include external load and temperature ratio parameter. The influences of the thermal conductivity ratio, the external load parameter, the conductance ratio and the figure of Merit on the output power, the efficiency, and the entropy generation rate are predicted for various device parameters [38]. A technical solution for recycling blast furnace slag flashing water heat based on TEG is also presented [39]. The effects of key parameters like the TE element length, slag washing water temperature, the packing factor of the TE module and heat exchanger flow passage length on the performance of the TEG device are examined.

While studying the optimum design of TE devices, dimensionless groups are used to properly define and represent important parameters of the TE device [40]. According to this study, the optimum design comprises the optimum parameters such as efficiency, current, power, geometry or number of thermocouples, and thermal resistances of heat sinks. The geometry effects on thermoelectric properties of silicon nanowires based on electronic band structures are also investigated where it is found that thermoelectric properties significantly depend on nanowire geometry such as different sizes, shapes, and orientations [41]. As nanowire size decreases, TE properties of nanowires can be enhanced and as a result, triangular nanowires with side length of $1 \mathrm{~nm}$ have the best results of ZT and it can be improved to 1.5 for n-type and 0.85 for p-type nanowire. The study on TE Properties of Ge Nanowires (Ge NWs) which is based on electronic band structures also reveals that thermoelectric properties vary significantly depending on the band structure of the Ge NWs of different sizes, crosssectional shapes, and orientations [42]. Moreover, the thermodynamics and thermal stress analysis of TEG is also done to assess the influence of pin geometry on device performance [43]. With finite element method, it is established that thermal efficiency increases for certain geometric configuration of TEG device and the maximum thermal stress in the pin decreases slightly representing improved life expectancy of TEG.

The power density (power generated per unit surface area) of TEG strongly depends on the TEG module spacing. The optimisation of the TEG module spacing and its spreader thickness, for TEG modules attached to a rectangular chimney plate for venting hot flue gases is also done [44]. Therefore, finding the optimal module spacing for the TEG system used in waste heat recovery is crucial to ensure optimum power generation from the system. The predicted numerical data obtained using finite difference method and a simplified conjugate-gradient method has demonstrated a good power vs. current curve. It is important to note that heat 
transfer in the TEG is one of the performance measures that need to be investigated before using TEG. Some methods like the longitudinal vortex generators have been used to improve heat transfer performance as well as power output and thermal conversion efficiency [45].

\section{Different materials used for TEG/TEC}

The material used in the construction of a TEG or TEC plays an important role in controlling the performance of these devices. There are many features that describe the performance of these materials to make them suitable for use in TEG device manufacture. In this section, various TEG/TEC materials will be discussed and the selection criteria of these materials for use in thermoelectric power generation as well as for cooling are clarified.

\section{1 Selection criteria of TEG/TEC material}

To achieve the best performance from the TE module, there are some properties of the material that characterise a good TE module. Many researchers have carried a number of works to determine the effect of these properties on the performance of TE devices. For example three different methods for predicting the Seebeck coefficient of TEC module are used to determine the properties and performance of a TEC [46]. One method is based on experimental measurements while other two are formulated based on mathematical models. Basically, all the methods are able to provide useful tools for designing and constructing a TE generation system. Some of the thermal and electrical properties of TE materials that make the selection criteria for the TEG/TEC material are described below.

\section{Thermal conductivity of the material}

The electronic thermal conductivity of TE material is determined by holes and electrons transporting heat $\left(\mathrm{k}_{\mathrm{e}}\right)$ as well as phonons travelling through the lattice $\left(\mathrm{k}_{1}\right)$. Majorly, ke is related to electrical conductivity by Wiedemann-Franz law [47];

$$
\begin{aligned}
& \mathrm{k}=\mathrm{k}_{\mathrm{e}}+\mathrm{k}_{1} \\
& \mathrm{k}_{\mathrm{e}}=\mathrm{L} \sigma \mathrm{T}=\mathrm{ne} \mu
\end{aligned}
$$

Where $\mathrm{L}$ is defined as the Lorenz factor equivalent to $2.4 \times 10-8 \mathrm{~J} 2 \mathrm{~K}-2 \mathrm{C}-2$, for free electrons.

In order to get high thermoelectric efficiency, the figure of merit should be large. Table 1 gives the available materials for TE applications categorized according to temperature range along with ZT of the material. As high ZT requires low thermal conductivity but high electrical 
conductivity, the Wiedemann-Franz law reveals an in-built materials conflict for attaining high thermoelectric efficiency. For materials with very high electrical conductivity (metals) or very low $\mathrm{k}_{\mathrm{l}}$, the Seebeck coefficient alone primarily determines ZT, as can be seen in equation (12), where $(\mathrm{kl} / \mathrm{ke})<<1[47]$ :

$$
Z T=\frac{\alpha^{2} / L}{1+\frac{k_{1}}{k_{e}}}
$$

Another parameter of relative importance is the Power factor which only focuses on the material performance of electrons when thermal conductivity at the two end reservoirs can be ruled out.

$$
\text { Power factor }=\sigma S^{2}
$$

The difficulty of maximizing ZT and power factor lies in the fact that the above parameters are generally interdependent. Therefore, it is a challenge to develop advanced thermoelectric materials with an optimization of these conflicting properties to increase ZT and power factor. Current thermoelectric devices are considered to be

- $\quad$ inefficient when ZT is about 1 ;

- $\quad$ able to recover waste heat when $\mathrm{ZT}=2$;

- $\quad$ able to match a refrigerator when $\mathrm{ZT}=4 / 5$ [28].

For a long time, the best ZT has been 1 for Bismuth Telluride (BiTe), which translates to efficiencies of about 5 to 7 percent for most applications but falls off rapidly with hot side temperatures of over $230^{\circ} \mathrm{C}$ [48].

Table. 1. The characteristic of available thermoelectric generator materials [49].

\begin{tabular}{|l|l|l|l|}
\hline Temperature $\left({ }^{\circ} \mathrm{C}\right)$ & Type & TEG Material & ZT (Maximum) \\
\hline$<150$ & $\mathrm{p}$ & $\mathrm{Bi}_{2} \mathrm{Te}_{3}$ & 0.8 \\
\hline & $\mathrm{n}$ & $\mathrm{Bi}_{2} \mathrm{Te}_{3}$ & 0.8 \\
\hline $150-500$ & $\mathrm{p}$ & $\mathrm{Zn}_{4} \mathrm{Sb}_{3}$ & - \\
\hline & $\mathrm{p}, \mathrm{n}$ & $\mathrm{PbTe}$ & $0.7-0.8$ \\
\hline & $\mathrm{p}$ & $\mathrm{TeAgGeSb}$ (TAGS) & 1.2 \\
\hline $500-700$ & $\mathrm{p}$ & $\mathrm{CeFe}_{4} \mathrm{Sb}_{12}$ & 1.1 \\
\hline & $\mathrm{n}$ & $\mathrm{CoSb} 3$ & 0.8 \\
\hline $700-900$ & $\mathrm{p}, \mathrm{n}$ & $\mathrm{SiGe}$ & $0.6-1.0$ \\
\hline
\end{tabular}




\begin{tabular}{|l|l|l|l|}
\hline & p & LaTe & 0.4 \\
\hline
\end{tabular}

\subsection{Recent advances on TEG material}

For materials with $\mathrm{ZT}>1$, it is discovered that most of them have a common feature of having lattice thermal conductivities that are lower than other materials that have low ZT [47]. With reduced lattice thermal conductivity, the TE efficiency and ZT improve in addition to allowing re-optimization of the carrier concentration, leading to more ZT improvement. Alternatively, to achieve practical TE materials with ZT of more than 2, enhancement of the Seebeck coefficient (S ) without reducing the electrical conductivity $(\sigma)$ is also possible by using two-dimensional electron gas (2DEG) that enables realization of practical TE materials without the use of toxic heavy elements [50]. Table 2 gives the most commonly used alloys for TE application due advancement in material research. For instance alloying Bi2Te3 with $\mathrm{Sb} 2 \mathrm{Te} 3$ and $\mathrm{Bi} 2 \mathrm{Se} 3$ allows fine tuning of the carrier concentration with a decrease in lattice thermal conductivity. The most commonly studied alloys are the p-type compositions which are near $(\mathrm{Sb} 0.8 \mathrm{Bi} 0.2) 2 \mathrm{Te}_{3}$ whereas n-type compositions are close to $\mathrm{Bi} 2(\mathrm{Te} 0.8 \mathrm{Se} 0.2) 3$. In investigating TE material for waste heat recovery with advanced heat exchangers, Crane and Jackson [51] analysed heat exchanger integrated with Bi2Te3 thermoelectric modules. They proved that power losses from an air fan and a fluid pump result in an optimal configuration at intermediate cooling air and hot fluid flow. However, heat exchangers with Bi2Te3 thermoelectrics can achieve net power densities over $40 \mathrm{~W} / \mathrm{l}$. A two-dimensional numerical model of a TEG system using nanostructured thermoelectric semiconductor materials with BiSbTe and $\mathrm{Bi}_{2} \mathrm{Te}_{3}$ is developed [33]. A TEG with p-type nanostructured material of BiSbTe and n-type Bi2Te3 with 0.1 vol.\% Silicon Carbide ( $\mathrm{SiC}$ ) nanoparticles is considered for evaluation of performance. The results indicate that amount of current generated increases as the temperature difference increases the output power.

For mid-temperature power generation (500-900 K), materials based on group-IV tellurides are typically used, such as PbTe, GeTe or SnTe. Alloys, particularly with AgSbTe2, have led to several reports of ZT > 1 for both n-type and p-type materials. The p-type alloy (GeTe) 0.85 (AgSbTe2)0.15, commonly referred to as TAGS, having maximum $\mathrm{ZT}>1.2$, has been successfully used in durable TEGs. 
For high temperature TEGs (>900 K), silicon-germanium alloys have been used for both nand p-type legs. The ZT of these materials is somehow low, mainly for the p-type material because of the relatively high lattice thermal conductivity of the diamond structure.

Table 2. The most commonly used alloys for TE application.

\begin{tabular}{|c|c|c|c|}
\hline Material Name & $\begin{array}{l}\text { Molecular } \\
\text { Formula }\end{array}$ & Description & Application \\
\hline $\begin{array}{l}\text { Antimony (III) } \\
\text { Telluride powder }\end{array}$ & $\mathrm{Sb} 2 \mathrm{Te} 3$ & $\begin{array}{l}99.9 \% \text { trace metals } \\
\text { basis and } 325 \text { mesh }\end{array}$ & \\
\hline Antimony (III) selenide & $\mathrm{Sb} 2 \mathrm{Se} 3$ & $\begin{array}{l}99.9 \% \text { trace metals } \\
\text { basis }\end{array}$ & \\
\hline Bismuth (III) selenide & $\mathrm{Bi} 2 \mathrm{Se} 3$ & - & \\
\hline $\begin{array}{l}\text { Bismuth (III) selenide } \\
\text { granular (melted) }\end{array}$ & Bi2Se3 & $\begin{array}{l}99.9 \% \text { trace metals } \\
\text { basis }\end{array}$ & \\
\hline $\begin{array}{l}\text { Bismuth (III) Telluride } \\
\text { powder }\end{array}$ & Bi2Te3 & $\begin{array}{l}99.9 \% \text { trace metals } \\
\text { basis and } 325 \text { mesh } \\
\text { - Bi2Te } 3 \text { alloys have } \\
\text { the highest ZT for n- } \\
\text { and p-type TE } \\
\text { systems }\end{array}$ & $\begin{array}{l}\text {-Near room } \\
\text { temperature } \\
\text { (Refrigeration } \\
\text { - waste heat } \\
\text { recovery up to } \\
200{ }^{\circ} \mathrm{C}\end{array}$ \\
\hline Silver (I) terruride & Ag2Te & - & \\
\hline Lead (II) telluride & $\mathrm{PbTe}$ & $\begin{array}{l}99.9 \% \text { trace metals } \\
\text { basis }\end{array}$ & \\
\hline Lead (II) selenide & $\mathrm{PbSe}$ & - & \\
\hline Bismuth Antimonide & $\mathrm{BiSb}$ & $\begin{array}{l}\text { crystalline TE } \\
\text { material with a cage- } \\
\text { like crystal structure } \\
\text { known as a } \\
\text { skudderite [52]. }\end{array}$ & $\begin{array}{l}\text { Potential for new } \\
\text { semiconductor } \\
\text { chips, } \\
\text { thermoelectric } \\
\text { devices }\end{array}$ \\
\hline
\end{tabular}


The compound zinc antimony $\mathrm{Zn}_{4} \mathrm{Sb}_{3}$ has also been reported as one of the most efficient TE materials known with high efficiency obtained through its extraordinarily low thermal conductivity and with the electronic structure of a heavily doped semiconductor [53]. Research discovered Zn4Sb3 as a TE material with high ZT between 450 and $670 \mathrm{~K}(\mathrm{ZT}=1.3$ at $670 \mathrm{~K})$, mainly because of its low thermal conductivity [54]. Park et al. stress that the integration of $\mathrm{CeO}_{2}$ and $\mathrm{Dy}_{2} \mathrm{O}_{3}$ to $\mathrm{ZnO}$ leads to a notable increase in the electrical conductivity. The power factor is approximately 56 times larger than that of $\mathrm{ZnO}\left(0.08 \mathrm{E}-4 \mathrm{Wm}^{-1} \mathrm{~K}^{-2}\right.$ at $\left.800{ }^{\circ} \mathrm{C}\right)$. The addition of a slightly smaller quantity of $\mathrm{Dy}_{2} \mathrm{O}_{3}$ is very effective for improving the thermoelectric properties of $\mathrm{ZnO}$ [55].

For cooling below room temperature, alloys of BiSb have been used in the n-type legs, coupled with p-type legs of $(\mathrm{Bi}, \mathrm{Sb}) 2(\mathrm{Te}, \mathrm{Se}) 3$. It has been noted that the poor mechanical properties of $\mathrm{BiSb}$ allow for improved low-temperature materials. Using micro electromechanical systems (MEMS), several different metals and thermoelectric materials are fabricated in a three-dimensional structure to form a TEG [56]. It consists of $126 \mathrm{n}$-type and ptype (Bi,Sb)2Te3 TE elements. The device showed good performance in terms of thermal control when operated as a cooler (TEC), and portable power when operated as a TEG. Fig. 4 shows a TE device made with BiSb.

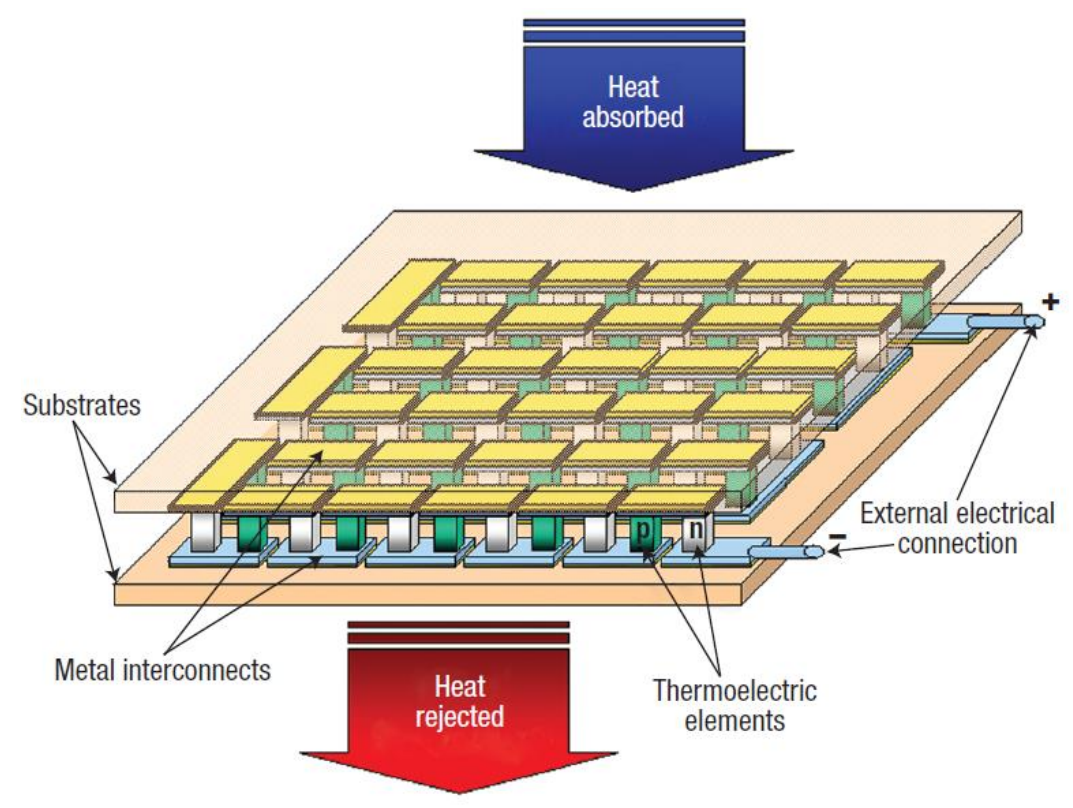

Fig. 4. A TE device made with BiSb [56].

Oriented thermoelectric p-Sb2Te3 and n-Bi2Te3 thin films having special nanostructures have also been synthesized by a simple vacuum thermal evaporation technique and the $n$ - and 
p-type elements set in parallel and series circuits to form a prototype [57]. The conductivity and Seebeck coefficient which act as electric transport properties and the thermal transportation of the oriented films have been analysed to have optimized properties. The results verified that introducing nanostructures into films is an effective choice to obtain more efficient micro TE device because the cooling and electric output power obtained is more than that of the common films.

\section{Application of thermoelectric devices}

Thermoelectric device applications are concerned with environmentally-friendly refrigeration and power generation in industrial utilities, transportation tools, military devices, space applications and medical services [58]. TEGs have also found application in biomass gasifiers to further improve the recovery of heat [59].TE devices are either used for cooling purposes or for power generation from either low heat recovery applications or as stand-alone heat to electric energy conversion systems such as the battery charger powered by TEG modules [60]. However, methods of delivering maximum power to the battery for a range of temperature gradients across the thermoelectric module have to be used [61].

\subsection{Application of TEG for heat recovery from the vehicle}

Thermoelectric technology presents solution for energy reuse in vehicles driven by internal combustion engine especially in the exhaust pipe and the radiator. TEGs are placed at different points of the vehicle to generate energy from the waste heat. If the waste energy from the vehicle is appropriately utilized, the consumption of diesel fuel is reduced because it eliminates need for the generator used for battery charging and other low energy needs in the vehicle [62]. Most of waste heat energy from the vehicle is recovered from the exhaust pipe than in the radiator, and the most suggest positon is after the catalyst where the high temperature is found. It is therefore noted that if the TE technology advances, in a near future it will be possible to decrease the fuel consumption to $10 \%$.

Various parameters for the TEG in the vehicle are predicted, where the maximum possible exhaust power that can be extracted is defined as [63];

$$
W_{e, \max }=\dot{m}_{e}\left(C_{p_{e, i}} T_{e, i}-C_{p_{e_{f, i}}} T_{f, i}\right)
$$

Where $W_{e, \max }^{\cdot}$ is the total possible exhaust power that can be extracted, $C_{p_{e, i}}$ is the specific heat of the exhaust evaluated at $T_{e, i}, T_{e, i}$ is the exhaust inlet temperature into the TEG, $C_{p_{e_{f, i}}}$ is the 
specific heat of the exhaust evaluated at $T_{f, i}$, and $T_{f, i}$ is the coolant inlet temperature into the TEG.

The actual exhaust energy extracted is defined by;

$$
\dot{W}_{e}=\dot{m}_{e}\left(C_{p_{e, i}} T_{e, i}-C_{p_{e, o}} T_{e, o}\right)
$$

Where $\dot{W}_{e}$ is the exhaust energy extracted, $C_{p_{e, o}}$ is the specific heat of the exhaust evaluated at $T_{e, o}$ and $T_{e, o}$ is the exhaust outlet temperature from the TEG.

Several researches have been conducted regarding the generation of useful electric power from waste heat using TEG. The case study is carried out on two vehicle models [63]; HZQW and HZ20M with power generated from TEG at vehicle speeds of $117.2 \mathrm{~km} / \mathrm{h}$ reported to be $453 \mathrm{~W}$ and $140 \mathrm{~W}$ respectively. The efficiency of the TEG which is the ratio of power generated by the TEG to exhaust energy extracted is found to be $8.53 \%$ and $2.25 \%$ for the HZQW and HZ20M vehicle models respectively. The increase in efficiency for the HZQW model is attributed to HZQW's ability to reject less heat and therefore use lower coolant flow rate. Based on this study, a lower parasitic loss and hence higher TEG power is registered although relatively low fuel gains are observed mainly because of the high efficiency of TEG. If attempts are made to further reduce the parasitic loss from the TEG, the output power of TEG device can equally be increased.

The performance features of the TEG were analysed through a prototype vehicle, where an energy harvesting system was constructed to extract electrical energy from the automotive exhaust pipe using TEG [64]. The characteristics of the system include cold-side temperature, hot-side temperature, power output, open circuit voltage and maximum power. The maximum powers obtained are $183.24 \mathrm{~W}, 600 \mathrm{~W}$ and $944 \mathrm{~W}$ and the corresponding efficiencies reported as $0.9 \%, 1.28 \%$ and $1.85 \%$ for the TEG system test, road test and revolving drum test respectively. Because it is not easy to put in place an independent cooling system, a revolving drum test table with the fan system is used to keep the prototype vehicle stationary while at the same time regulating the fan speed. It is noted that the fabricated TEG device is able to recover a significant amount of energy from waste heat. However, the main challenge is in improving the exhaust pipe to decrease the effect of thermal contact followed by increased hot side temperature, thereby increasing the generated power from TEG.

A mathematical model of a TEG device embedded on vehicles' exhaust pipe is analysed with Fourier's law and the Seebeck effect [65]. It is indicated that the TEG power output and efficiency increase significantly by adjusting the convection heat transfer coefficient of the 
high-temperature-side instead of low-temperature-side. Additionally, the maximum TEG power and efficiency appear when internal resistance is lower than external resistance. However, with the increment of ZT, the maximum value moves toward the direction of an increasing ratio of external resistance to internal resistance. However, with the raising ratio of external resistance to internal resistance due to increase in ZT, the maximum TEG power equally increases. In particular, a new idea is presented to improve TEG performance using the reformed experimental design. Moreover, with the usage of phase change materials made possible to strengthen heat transfer property of the hot temperature side of TEG, the power output and efficiency of TEG can be improved by applying suitable phase change materials.

An energy-harvesting is also constructed by using test benches to analyse the performance of the TEG module [15]. The analysis of the maximum power output and the results from the experiments demonstrate enhanced TEG efficiency with $183.24 \mathrm{~W}$ maximum power output at engine revolution of $3200 \mathrm{r} / \mathrm{min}$. The cold-side temperature, cold-side flow rate and applied pressure are found to have a significant effect on the maximum power output. It is also observed that Bi2Te3-based thermoelectric modules have the potential to extract low-grade temperature waste heat energy from automotive exhaust pipes.

In a separate move, the effectiveness of TE device in cooling and pre-heating as well as waste heat recovery is examined on the Li-family battery system for electric vehicle. [66]. The TE device is found to be able to contribute meaningfully to sound operation of the battery, enhanced reliability and the overall performance of EV is improved.

In a unique application, the study is conducted where TEG devices are used to recover heat energy from a table lamp[67]. The cold side of the TEG is subjected to cooling by a natural convection heat sink and the power generation rate is predicted based on the hot side and cold side thermal conductance of the open-circuit system. A relatively larger maximum power generation rate is observed with a slightly smaller optimal electric load. This is ascribed to residual electric resistances in the circuit rather than the internal resistance of the external load and TEG device. It is indicated from this study that there is an undesirable role played by the insulating layer which reduces the TEG efficiency. However, it is concluded that that TE conversion is capable of recovering waste heat, due to the fact that the TE device performance can be improved for example by appropriate selection of TE modules and proper handling of thermal contacts. 


\subsection{Cooling applications of thermoelectric devices}

Thermoelectric coolers are commonly known as Peltier coolers. These are well suited for such applications where conventional air-cooling system is not adequate to remove the heat fluxes at an appropriately high rate. The general design criteria for these TECs include high reliability, flexibility in packaging and integration and low weight [49]. Additionally, the application of a Peltier cell for electric generation is assessed based on its output power and efficiency where it is demonstrated that Peltier cell is promising for recovering waste heat [68]. The cooling applications using TE devices are mainly found in three categories including; thermoelectric air conditioners (TEACs), refrigerators and air conditioners as well as for cooling electronic devices.

1. Cooling electronic devices: In electronic cooling application, a thermoelectric cooler (TEC) is used to transport heat from a surface that has a temperature higher than the ambient temperature. The purpose of a TEC is to maintain the junction temperature of an electronic device below a certain temperature by removing heat from the device [69].

2. Refrigerators: In refrigeration application, Peltier cooling appliances provide rapid cooling. For example a solar Peltier refrigerator is capable of reducing the temperature from $27{ }^{\circ} \mathrm{C}$ to $5^{\circ} \mathrm{C}$ in about $44 \mathrm{~min}$. A TE refrigeration system has the merits of being light, rugged, reliable and noiseless. TE refrigeration devices are at low cost in mass production if charge carriers in the thermoelectric material are used rather than refrigerant as the heat dissipation carrier.

3. Thermoelectric air conditioners (TEACs): These are environmentally friendly, simple and reliable; they offer convenient installation and switching between the cooling and heating modes can be easily achieved by reversing the input current. However, these systems are still very expensive at present. TEACs are quite operation and are portable, but with somehow lower COP that limits their application for domestic cooling [49]. However, as air conditioners, TEACs have a large promising market for small enclosures, such as submarine cabins and cars, where reliability and safety are indispensable and the power consumption is relatively low.

\subsection{Hybrid systems}

In the hybrid TE systems, part of the recovered or harvested heat is used for electric generation while other part is used for other purposes like water heating. The performance 
analysis has been done for a thermoelectric cogeneration system (TCS) which generates electricity and preheats water for home use [70]. The main source of heat for the thermoelectric cogeneration is boiler exhaust waste heat. Water is used for cooling the cold side of the TEG and is circulated through a compact heat exchanger for both electricity generation and domestic water heating. The system also uses solar energy from a solar collector mounted on the roof of a building to supply heat on the hot side which is added to the heat from the exhaust pipe of the boiler. Fig. 5 illustrates the TCS system. It has been noted that the overall efficiency is increased but with some challenges met during heat transfer to and from the TEG. Although TE technology has been mainly applied for heat recovery, here it can be observed that the technology is now applicable to harvesting energy from solar systems. Such applications are more likely to result into more rigorous research into TE technology advocate for higher efficiency of TE devices.

Similarly, an integrated TEG-cooling system is numerically studied by use of finite element method in which it is discovered that when the lengths of TEG and TEC vary, the highest reductions in system performance are $12.45 \%$ and $18.67 \%$, respectively [71]. It is reported that the system performance for different TEC lengths are significantly different from the performance of TEG for different TEG lengths. However, the results provide useful insights into the design of integrated TEG-TEC systems. 


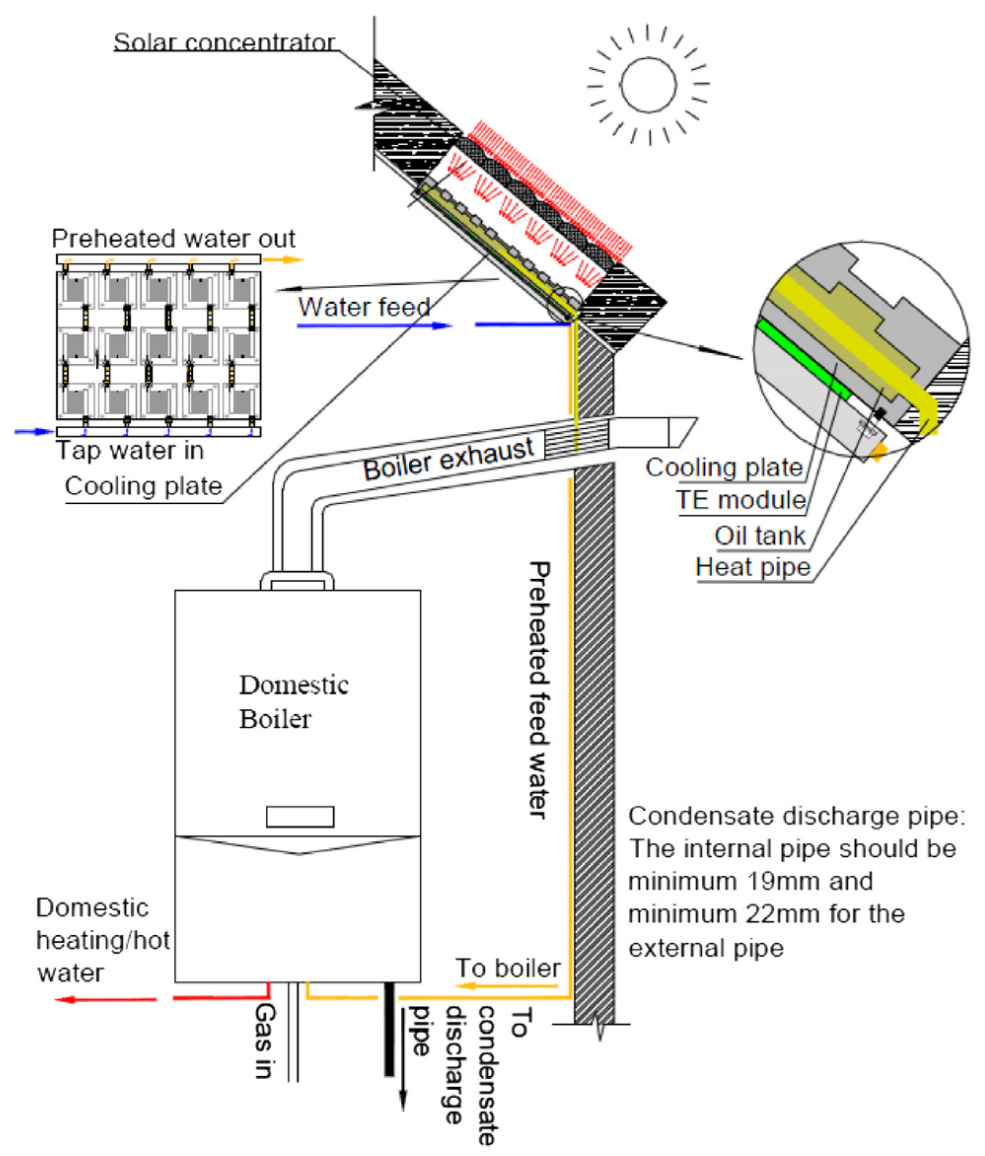

Fig. 5. The domestic thermoelectric cogeneration system [70]

Bekir et al. [72] investigated a system that comprises of a TEG and the refrigerator where the effect of the location of the TEG in the refrigerator cycle on the coefficient of performance (COP) of the system is analysed. By introducing the dimensionless parameters such as temperature ratio, heat transfer ratio, capacitance ratio to mention but a few, the influences of the operating conditions on the COP are studied. It is discovered that the placement of the TEG between the condenser and evaporator reduces the COP while TEG's location between condenser and its ambient increases the COP. This finding verifies why hybrid TE systems are useful because in an area where one device say TEG cannot perform better, another device say TEC can demonstrate an optimum performance. Therefore, if both devices are applied in the system, the overall harvested energy and hence system efficiency is likely to increase with hybrid systems. On a serious note however, the operating parameters affect the overall performance of the whole system with notable improvement in system performance within some range of the parameters.

Furthermore, an evaluation is done for a combined cooling, heating and power (CCHP) system, with the use of TEG and condensing heat exchanger to recover the exhaust gas waste heat from a $16 \mathrm{~kW}$ internal combustion engine (ICE) [73]. The results reveal that the primary 
energy efficiency of the system can go up to $94.4 \%$ with a cost saving ratio and primary energy saving ratio of 0.417 and 0.304 , respectively. CCHP for long has been used with relatively good performance since the rejected heat is utilised for heating. However, with the application of TEG on CCHP, higher systems performance is expected since even the mild waste heat is utilised for power generation.

From this section, we can observe that with the introduction of TE technology into heat transfer systems, the overall system performance increases because a significant amount waste heat it recovered. As well, it can be noted that although solar energy has been utilised by using solar cells, solar PV as well as solar collectors, with the hybridization of the energy systems, the use of TEGs in the system improves the energy extraction and therefore increases the energy supply however little it maybe.

\subsection{Application of thermoelectric devices for electric power generation}

Although TE technology is used for other heat energy conversion purposes, the emphasis in this section is solely highlighting the generation of electric power from heat using TEG. This is because for most of the TEG application, the harvested or recovered heat is mainly converted into electrical energy for various areas of application. Recent developments of TEGs have mainly put emphasis on standalone power-generation technology for biomedical, aerospace, military and remote power applications. Below is the list of some of TEG applications.

- condition monitoring in industrial environments

- $\quad$ smart metering

- environmental monitoring in remote locations

- $\quad$ structural monitoring

- the transport sector in vehicles, aircraft, and spacecraft (in hostile environments such as in space). Customized military and aerospace applications dominate the market.

\subsubsection{Categories of thermoelectric applications for electric power generation}

TE applications for electricity generation are divided into two main categories; low and high power generation applications.

1. Low power generation: TEGs are being developed as autonomous power sources to compete with batteries which are the most dominant source of energy in applications like body-mounted devices in the range of $5 \mu \mathrm{W}$ to $1 \mathrm{~W}$ and with 5 years life time. For 
example Citizen and Seiko are now manufacturing wristwatch with that of Seiko having efficiency of about $0.1 \%$, open circuit voltage of $300 \mathrm{mV}$ at $1.5 \mathrm{~K}$ temperature gradient [49].

2. High power generation: some manufacturers including Volvo, Volkswagen, BMW and Ford are developing TEG systems with generated power of about $1 \mathrm{~kW}$. A TEG having a ZT of 1.25 and about $10 \%$ efficiency could be employed to recover 35-40\% of the power from the exhaust manifold at an average temperature of $250^{\circ} \mathrm{C}$ where a considerable amount of power can be generated to contribute to up $16 \%$ increase in efficiency[25].

\subsubsection{Power generation with TEG using non-waste heat}

Although TEG devices have found applications majorly in the waste heat recovery, they have also been used to generate electric power from other alternative sources of energy. For example TEGs are used to generate electricity from biomass, geothermal energy and solar energy to form stand-alone energy harvesting systems. Some of the progressive works on this development are reported here.

With the geothermal as a source of heat, electric power is generated using TEG modules [74]. The tools for the evaluating TEG devices are developed in which the modelling is done on two levels. In the large scale level, a number of TEG modules are integrated in a heat transfer unit and a cross-flow heat exchanger is used. For the lower size level, the modules are modelled in 3D where the non-linearities and irreversibilities are simulated with the finite elements method (FEM). The results show that selection of the geometric parameters should be a compromise between highest power output and best efficiency as these quantities demonstrate opposing tendencies. Based on this study, it can be observed that geothermal energy can also be used as a heat source with low temperature and low energy density to generate electrical power using TEG which can be used in niche applications. This saves the use of wasteful technology like turbines with moving parts on already low temperature heat source.

Another application of TEG is the generation of electricity using solar concentrator. Kossyvakis et al. note that the implementation of TEG in solar energy conversion systems, as an alternative method for exploiting the solar potential, has attracted increasing attention [75]. They performed an analytical study on thermoelectric-based solar conversion unit using ANSYS software. They predicted electrical output from the system under various operating conditions, achieving maximum power output of $33.7 \mathrm{~W}$. Similarly, a solar parabolic concentrator coupled to a thermoelectric module is used to generate electricity by using a BiTe- 
based TE module installed on the receiver plate [76]. At maximum heat flux, TE module has the ability to produce output power of $1.32 \mathrm{~W}$ at $0.42 \mathrm{~m}^{3} / \mathrm{min}$ air flow rate which corresponds to a conversion efficiency of $2.89 \%$. Therefore, a higher flow rate is suggested subject to the level of efficiency of the heat sink used in order to achieve higher power from TEG.

In a unique application, thermo-photovoltaic (TPV) cells are used to provide heat input to the TE to generate electricity. TPV cells are capable of converting infrared radiation into electricity. The TPV and TEG are cascaded, with TPV acting as a heat stream to supply the TEG which later converts heat into electricity [77]. Through analysing the electrical characteristics of the TPV cells and the TEG under various operating conditions, the results indicate that the cascading power generation is practicable and has the potential for some applications.

A stand-alone biomass power plant that uses TEG to generate electrical energy from biomass is designed and tested [78]. The test facility is intended to give a great deal of information about the integration of TEG device with biomass power plant and to show the feasibility of having a stand-alone biomass power plant where electrical energy generated is consumed directly by the load. Another study reports the estimation of power generated using TEG by recovering waste heat from biomass fired thermal oil heater [79]. The TEGs are placed between flue gas duct and fresh air duct of an industrial thermal oil heater, and the results indicate that the estimated annual electrical power generation from this system is about 181,209 kWh.

Miranda et al. carried out a feasibility study on the use of TEC in air conditioner for electric vehicles [80]. The TECs were used as load, high power lithium-ion batteries as an energy storage device and dye sensitized solar cells (DSSCs) as energy source to form a solid state air conditioner model. The dynamic performance simulation demonstrates that a solid state air conditioning system is feasible in providing green energy from DSSCs through the use TECs unlike traditional vapour compression air conditioning systems that consume substantial amount of energy that could reduce the driving performance of electric vehicle.

\section{Thermoelectric modelling methods}

Thermoelectric effect is the direct conversion of temperature difference into electric voltage and vice versa [81]. The term "thermoelectric effect" embraces three separate effects: the Seebeck, Peltier, and Thomson. The Peltier-Seebeck and Thomson effects 
are thermodynamically reversible, whereas Joule heating is not. Joule heating occurs when an electric current flows through a resistance or a conductor and it induces temperature gradient in microfluidic device [82]. If it occurs in graphene or nanowire/nanotube element under high current density, Joule heating affects mainly the electronic transport properties and henceforth is an important aspect of device design [83].

With application of current through a thermoelectric element, thermal energy is generated or absorbed at the junction due to Peltier effect. The exchange of Peltier heat between the semiconductor and metal (both the n- and p-type) is demonstrated in Fig. 6(a). The Seebeck coefficient is proportional to the temperature and this effect is different at different places along the TE material [17]. The thermoelectric element is a combination of a series of many small Peltier junctions [as shown in dotted lines in Fig. 6(a)], each of which separately produces or absorbs heat. This is the Thomson power developed per unit volume. In Thomson effect, the heat is evolved or absorbed when the current is passed through a TE element with a temperature gradient. Therefore, this effect is equally proportional to the temperature gradient and the electric current.

The Thomson coefficient $\tau$ is expressed as

$$
\tau=\mathrm{T} \frac{\mathrm{d} \alpha}{\mathrm{dT}}
$$

Based on equation (16), Thomson coefficient cannot be applied in situations where Seebeck coefficient is constant and calculated with the average temperature. 


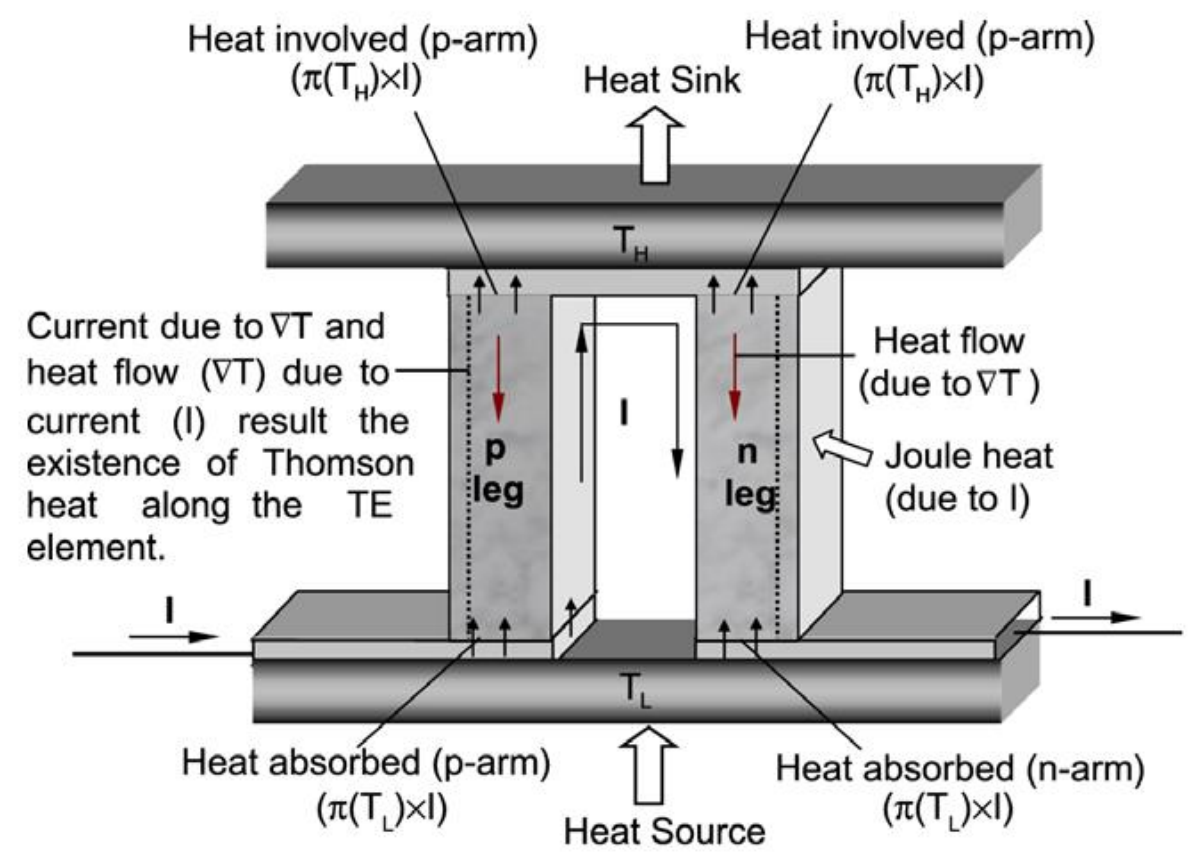

(a)

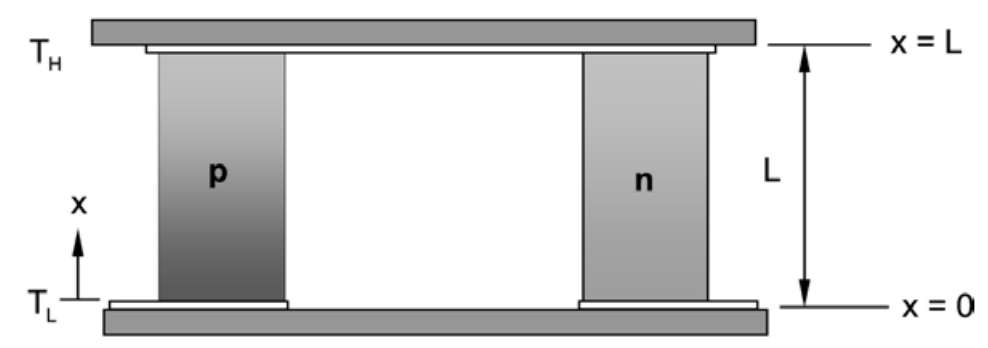

(b)

Fig. 6. The schematic view of a thermoelectric cooler [84]

Because of those thermoelectric effects subjected to the thermoelectric material and hence thermoelectric device, it is necessary to carefully analyse the performance of the TE device when subjected to different temperatures. This can be done by proper experimental setups or mathematical models. With the advancement in computer technology, several thermoelectric mathematical models have been incorporated into design software to analyse the performance of different prototypes before actual implementation. With TE device analysis, there are basically two major categories of thermoelectric models: the simplified and the complex models. 


\subsection{The simplified thermoelectric models}

The simplified TE models are derived based on the global balance of thermoelectric effects and heat transfer (macro approach) i.e. some of the TE effects are kept constant while others are neglected. For example in one instance the Seebeck effect is kept constant, rendering the Thomson effect zero or negligible [85]. The simplified models include the standard simplified and improved simplified models.

\subsubsection{Standard simplified models}

Assuming the distribution of Joule effect between the hot and cold side to be symmetrical, the total energy balance is setup to formulate this model. It is mainly due to this popularly used assumption that the TE element is described in the TEH and TEC modelling. The heat flux convention in the TE leg used in the setup of the simplified model is shown in Fig. 7.

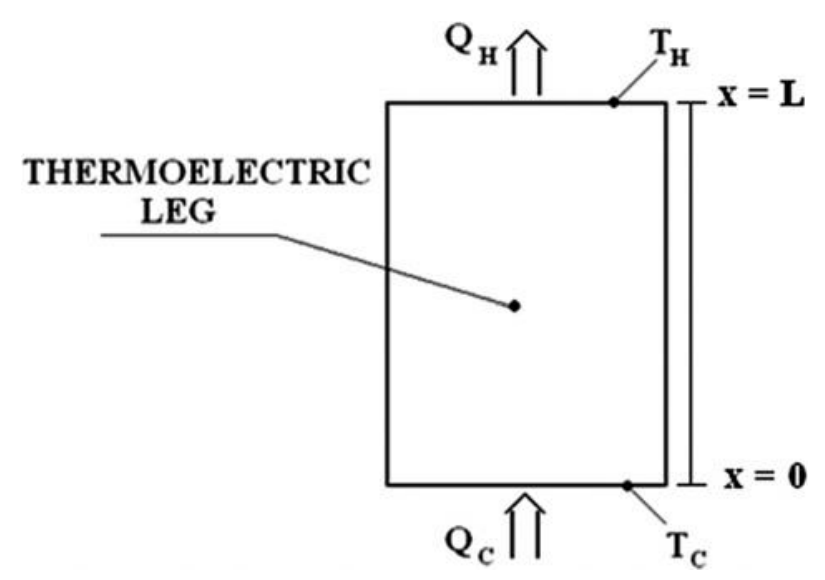

Fig. 7. Heat flux convention in a thermoelectric leg.

The electrical conductivity $\sigma$, thermal conductivity k, and the Seebeck coefficient $\alpha$ of TE element is held constant and is calculated from the average temperature $\bar{T}$ of the cold and hot side temperatures $\mathrm{T}_{\mathrm{C}}$ and $\mathrm{T}_{\mathrm{H}}$ respectively.

$$
\bar{T}=\frac{T_{H}+T_{C}}{2}
$$

This assumption is reliably applied in steady state as long as the Joule effect is kept to minimum value.

The variation of temperature in this case is a posteriori known, i.e. the variations have to be justified through experiment observation. The global energy balance therefore results into several equations for the heat fluxes for the TE element in the cold and hot side. The heat flux equations are given as;

For cooling (TEC) and heating (TEH) devices: 


$$
\begin{aligned}
& Q_{H}=\bar{\alpha} I T_{H}-\bar{K} \Delta T+\frac{1}{2} \bar{R} I^{2} \\
& Q_{C}=\bar{\alpha} I T_{c}-\bar{K} \Delta T-\frac{1}{2} \bar{R} I^{2}
\end{aligned}
$$

For TEG:

$$
\begin{aligned}
& Q_{H}=\bar{\alpha} I T_{H}+\bar{K} \Delta T-\frac{1}{2} \bar{R} I^{2} \\
& Q_{c}=\bar{\alpha} I T_{H}+\bar{K} \Delta T+\frac{1}{2} \bar{R} I^{2}
\end{aligned}
$$

Where

$$
\begin{array}{ll}
\bar{R}=\frac{L}{\bar{\sigma} A} & : \text { Electrical resistance } \\
\bar{K}=\frac{\bar{k} A}{L} & : \text { Thermal conductance }
\end{array}
$$

The calculation of electrical power is based on the cold and hot heat fluxes as;

$$
P=Q_{H}-Q_{C}
$$

This gives:

$$
\begin{aligned}
& P=\bar{\alpha} I \Delta T+\bar{R} I^{2}, \text { for TEC } / \mathrm{TEH} \\
& P=\bar{\alpha} I \Delta T-\bar{R} I^{2}, \text { for TEG }
\end{aligned}
$$

In TEC and TEH modes, The respective coefficients of performance (COPs) for TEC and TEH are;

$$
C O P_{C}=\frac{Q_{C}}{P} \text { and } C O P_{H}=\frac{Q_{H}}{P}
$$

The electrical efficiency in TEG mode is given by;

$$
\eta=\frac{P}{Q_{H}}
$$

It can be observed from the equation that since the Seebeck coefficient is kept constant, the Thomson effect is reduced to a zero value.

\subsubsection{Improved simplified thermoelectric model}

In this improved version of thermoelectric model, the Thomson effect is considered and is never zero and it is uniform distribution is ensured on the two sides of the semiconductor device. The model is found to have notable improvement in terms of accuracy in prediction of various performance parameters in the TEC mode [4]. 
For the Seebeck effect, each side's temperature is used to evaluate $\alpha_{H}$ and $\alpha_{C}$ at $T_{H}$ and $T_{C}$ and the heat fluxes are computed as;

TEC/TEH:

$$
\begin{aligned}
& \mathrm{Q}_{\mathrm{H}}=\alpha_{\mathrm{H}} \cdot \mathrm{I} \cdot \mathrm{T}_{\mathrm{H}}-\mathrm{K} \cdot \Delta \mathrm{T}+\frac{1}{2} \cdot \mathrm{R} \cdot \mathrm{I}^{2}-\frac{1}{2} \cdot \tau \cdot \mathrm{I} \cdot \Delta \mathrm{T} \\
& \mathrm{Q}_{\mathrm{C}}=\alpha_{\mathrm{C}} \cdot \mathrm{I} \cdot \mathrm{T}_{\mathrm{C}}-\mathrm{K} \cdot \Delta \mathrm{T}+\frac{1}{2} \cdot \mathrm{R} \cdot \mathrm{I}^{2}+\frac{1}{2} \cdot \tau \cdot \mathrm{I} \cdot \Delta \mathrm{T}
\end{aligned}
$$

The electrical power in Eq. (24) becomes;

$$
P=\left(\alpha_{H} T_{H}-\alpha_{c} T_{c}\right) I+\bar{R} I^{2}-\bar{\tau} I \Delta T
$$

It can be clearly observed in equations (29) and (30) that the Joule effect is compensated by the Thomson effect (if $\tau>0$ and I $>0$ ). Therefore, the consideration of Thomson effect in this case plays an important role in cooling mode to increase the thermal flux. However, it plays a negative role in the heating mode since it reduces the heat flux.

If the temperature difference DT is low in the THE/TEC mode, the $\alpha_{C}$ and $\alpha_{H}$ are then substituted with $\alpha$, resulting into:

$$
P=(\bar{\alpha}-\bar{\tau}) I \Delta T+\bar{R} I^{2}
$$

TEG:

$$
\begin{aligned}
& \mathrm{Q}_{\mathrm{H}}=\alpha_{\mathrm{H}} \cdot \mathrm{I} \cdot \mathrm{T}_{\mathrm{H}}+\mathrm{K} \cdot \Delta \mathrm{T}-\frac{1}{2} \cdot \mathrm{R} \cdot \mathrm{I}^{2}-\frac{1}{2} \cdot \tau \cdot \mathrm{I} \cdot \Delta \mathrm{T} \\
& \mathrm{Q}_{\mathrm{C}}=\alpha_{\mathrm{C}} \cdot \mathrm{I} \cdot \mathrm{T}_{\mathrm{C}}+\mathrm{K} \cdot \Delta \mathrm{T}+\frac{1}{2} \cdot \mathrm{R} \cdot \mathrm{I}^{2}+\frac{1}{2} \cdot \tau \cdot \mathrm{I} \cdot \Delta \mathrm{T}
\end{aligned}
$$

The electrical power is thus:

$$
P=\left(\alpha_{H} T_{H}-\alpha_{c} T_{c}\right) I-\bar{R} I^{2}-\bar{\tau} I \Delta T
$$

Therefore, the Thomson effect plays a negative role if $\mathrm{I}>0$ and $\tau>0$ since the efficiency of TE device is reduced due to decrease in device power out If DT is low while $\alpha_{H} \cong \alpha_{c}$, being substituted with $\alpha$ estimated at $T$, the power output is given as:

$$
P \approx(\bar{\alpha}-\bar{\tau}) I \Delta T-\bar{R} I^{2}
$$




\subsection{Complex TE models}

Contrary to the simplified models, the complex models are those models in which the thermoelectric element behaviour is described more precisely with the use of local energy balance equations. This is because all TE effects are generated due to the bond between heat and charge transport as shown in Fig. 1. These transports are quantified based on the entropy, energy and mass equations which form complex thermodynamic frameworks [84].

The energy balance is expressed as;

$$
\rho C_{p} \cdot \frac{\partial T}{\partial t}=\nabla \cdot(\lambda \nabla T)+\frac{(J)^{2}}{\sigma}-\tau J \nabla T
$$

Where $\tau$ is the Thomson coefficient,

This equation is applied in a situation where heat and electric current flow parallel to each other from $\mathrm{n}$ - to $\mathrm{p}$-leg or vice versa in the presence of an electric field.

Lord Kelvin proposed the quasi-thermodynamic technique [6] for TE effect to validate that $-\tau=\frac{\pi}{\mathrm{T}}-\frac{\mathrm{d} \pi}{\mathrm{dT}}$ and $\tau=\alpha \mathrm{T}$ where $\pi$ is representing Peltier heat.

With the conditions set in Fig. 1(b), for TE legs with length $\mathrm{L}(0<=\mathrm{x}<=\mathrm{L})$, Based on Fig. 1(b), for $\mathrm{p}$ - and n-legs of a TE element with length $\mathrm{x}$ ( $\mathrm{x}$ from 0 to $\mathrm{L}$ ) in transient regime, the one-dimensional equation is given in Eq. (38)

$$
\rho . C_{p} \cdot \frac{\partial T(x, t)}{\partial t}=k \cdot \frac{\partial}{\partial x}\left(\frac{\partial T(x, t)}{\partial t}\right)+\frac{1}{\sigma} \cdot\left(\frac{I}{A}\right)^{2}-\tau \cdot \frac{I}{A} \cdot \frac{\partial T(x, t)}{\partial t}
$$

At both leg extremities; $\mathrm{x}=0$ and $\mathrm{x}=\mathrm{L}$, the Seebeck effect has to be defined;

$$
\begin{gathered}
Q\left|(x=o, t)=\alpha I T_{c}-k A \cdot \frac{\partial T}{\partial x}\right|_{(x=0, t)} \\
Q\left|(x=L, t)=\alpha \mathrm{IT}_{\mathrm{c}}-\mathrm{kA} \cdot \frac{\partial \mathrm{T}}{\partial \mathrm{x}}\right|_{(\mathrm{x}=\mathrm{L}, \mathrm{t})}
\end{gathered}
$$

Defining Fourier heat $Q_{F}=\frac{\lambda A D T}{L}$, Joule heat $Q_{J}=\frac{\rho I^{2} L}{A}$, Thomson heat $Q_{T}=I \tau D T$ and $\frac{Q_{T}}{Q_{F}}=$ $\frac{I \tau \mathrm{L}}{\lambda \mathrm{A}}$, where $\mathrm{I}=\mathrm{JA}$ :

$$
-\lambda A \frac{d T}{d x}=\frac{\lambda \rho I}{\tau}+\frac{\left(-Q_{F}+\frac{\lambda \rho I}{\tau}\right) \frac{Q_{T}}{Q_{F}}}{\left(\exp \left(\frac{Q_{T}}{Q_{F}}\left(1-\frac{x}{L}\right)\right)-\exp \left(-\frac{Q_{T} x}{Q_{F} L}\right)\right)}
$$

Consequently, at cold junction $(\mathrm{x}=0)]$ 


$$
-\left.\lambda \mathrm{A} \frac{\partial \mathrm{T}}{\partial \mathrm{x}}\right|_{(\mathrm{x}=0)}=\left[-\mathrm{Q}_{\mathrm{F}}-\frac{1}{2} \mathrm{Q}_{\mathrm{T}}-\frac{1}{2} \mathrm{Q}_{\mathrm{J}}\right]+\frac{1}{6}\left[\frac{1}{2} \frac{\mathrm{Q}_{\mathrm{T}}{ }^{2}}{\mathrm{Q}_{\mathrm{F}}}+\frac{1}{2} \frac{\mathrm{Q}_{\mathrm{J}} \mathrm{Q}_{\mathrm{T}}}{\mathrm{Q}_{\mathrm{F}}}\right]-\frac{1}{360}\left[\frac{1}{2} \frac{\mathrm{Q}_{\mathrm{T}}{ }^{4}}{\mathrm{Q}_{\mathrm{F}}{ }^{3}}+\frac{1}{2} \frac{\mathrm{Q}_{\mathrm{J}} \mathrm{Q}_{\mathrm{T}}{ }^{3}}{\mathrm{Q}_{\mathrm{F}}{ }^{3}}\right]+\cdots
$$

Removing all higher order terms:

$$
-\left.\lambda \mathrm{A} \frac{\partial \mathrm{T}}{\partial \mathrm{x}}\right|_{(\mathrm{x}=0)}=\left[-\mathrm{Q}_{\mathrm{F}}-\frac{1}{2} \mathrm{Q}_{\mathrm{T}}-\frac{1}{2} \mathrm{Q}_{\mathrm{J}}\right]+\frac{1}{6}\left[\frac{1}{2} \frac{\mathrm{Q}_{\mathrm{T}}^{2}}{\mathrm{Q}_{\mathrm{F}}}+\frac{1}{2} \frac{\mathrm{Q}_{\mathrm{J}} \mathrm{Q}_{\mathrm{T}}}{\mathrm{Q}_{\mathrm{F}}}\right] .
$$

Similarly at hot junction $(\mathrm{x}=\mathrm{L})$ :

$$
-\left.\lambda \mathrm{A} \frac{\partial \mathrm{T}}{\partial \mathrm{x}}\right|_{(\mathrm{x}=\mathrm{L})}=\left[-\mathrm{Q}_{\mathrm{F}}+\frac{1}{2} \mathrm{Q}_{\mathrm{T}}+\frac{1}{2} \mathrm{Q}_{\mathrm{J}}\right]+\frac{1}{6}\left[\frac{1}{2} \frac{\mathrm{Q}_{\mathrm{T}}{ }^{2}}{\mathrm{Q}_{\mathrm{F}}}+\frac{1}{2} \frac{\mathrm{Q}_{\mathrm{J}} \mathrm{Q}_{\mathrm{T}}}{\mathrm{Q}_{\mathrm{F}}}\right] \text {. }
$$

The higher order terms of equations (41) and (42) shows the relationship between the Thomson, Joule and Fourier effects. The transportation of energy in the TE arm is described as;

$\mathrm{Q}(\mathrm{x})=\alpha \mathrm{IT}(\mathrm{x})-\lambda \mathrm{A} \frac{\mathrm{dT}}{\mathrm{dx}}$, which becomes:

$$
\mathrm{Q}(\mathrm{x})=\alpha \mathrm{IT}(\mathrm{x})-\frac{\lambda \rho \mathrm{I}}{\tau}+\frac{\left(-\mathrm{Q}_{\mathrm{F}}+\frac{\lambda \rho \mathrm{I}}{\tau}\right) \frac{\mathrm{Q}_{\mathrm{T}}}{\mathrm{Q}_{\mathrm{F}}}}{\left(\exp \left(\frac{\mathrm{Q}_{\mathrm{T}}}{\mathrm{Q}_{\mathrm{F}}}\left(1-\frac{\mathrm{x}}{\mathrm{L}}\right)\right)-\exp \left(-\frac{\mathrm{Q}_{\mathrm{T}} \mathrm{x}}{\mathrm{Q}_{\mathrm{F}} \mathrm{L}}\right)\right)}
$$

The entropy flux of the TE arm is therefore obtained by the ratio of $Q(x)$ to $T(x)$, i.e.,

$$
\mathrm{J}_{\mathrm{S}}(\mathrm{x})=\alpha \mathrm{I}-\frac{\lambda \rho \mathrm{I}}{\tau \mathrm{T}(\mathrm{x})}+\frac{\left(-\mathrm{Q}_{\mathrm{F}}+\frac{\lambda \rho \mathrm{I}}{\tau}\right) \frac{\mathrm{Q}_{\mathrm{T}}}{\mathrm{Q}_{\mathrm{F}}}}{\left(\exp \left(\frac{\mathrm{Q}_{\mathrm{T}}}{\mathrm{Q}_{\mathrm{F}}}\left(1-\frac{\mathrm{x}}{\mathrm{L}}\right)\right)-\exp \left(-\frac{\mathrm{Q}_{\mathrm{T}} \mathrm{x}}{\mathrm{Q}_{\mathrm{F}} \mathrm{L}}\right)\right)} \frac{1}{\mathrm{~T}(\mathrm{x})}
$$

Equation (44) is a representation of the flow of entropy along the TE arm and signifies the actions of Thomson, Peltier, Fourier and Joule effects. The contribution of Joule results into the extraction of entropy which is generated by the flow of heat current. Similarly, Fourier heat also results into the energy flow which happens because of the movement of heat to the cold from the hot junction. On the other hand, the Thomson effect symbolizes the flow of entropy within the TE element. Therefore, the Thomson heat can as well be termed as 'the specific heat of electricity' [6].

Improved models have been applied in a number of research works in different TE applications. Three dimensional transient modelling of TE coolers is done in which the model involves the analysis of the Thomson, Joule Fourier and Peltier TE effects [86]. The results reveal that this model is able to predict the negative effect of the some of these TE effects. It is indicated that when at a specific large current value, the transferred from hot to cold junction due to Fourier effect is observed to exceed the heat absorbed at the cold junction due to Peltier effect. This results into a high rise of temperature at both junctions, rendering the TEC to fail 
to reach the steady state. Through the use of exergy analysis, another improved standard model has been used to study the TEC [87]. The irreversible and exoreversible TE models are applied with the consideration of Peltier, Thomson, Fourier and Joule effect at the junctions. The results demonstrate that the Thomson effect leads to the increase of the cooling power and efficiency of the TEC system for example the cooling power and energy efficiency increased to $16.36 \mathrm{~W}$ from $14.87 \mathrm{~W}$ and to 0.4998 from 0.4079 respectively for a temperature difference of $40 \mathrm{~K}$ after the considering the Thomson effect in the exoreversible condition. It can be observed that the improved models are able to capture the effect of the other TE effect such as Thomson effect which are not catered for in the ordinary simplified model.

\subsubsection{Analytical model}

In this model type, an assumption is the leg section and TE coefficients are constant along the length of the TE leg during the steady state condition and the Thomson effect is included. The analytical solution can be obtained in the following equations;

In the cooling mode:

$$
\begin{aligned}
& Q(x)=\bar{\alpha} I T(x)-\frac{\bar{k} \mathrm{I}}{\bar{\tau} \bar{\sigma}}+\frac{\left(-\mathrm{Q}_{\mathrm{F}}+\frac{\bar{k} \mathrm{I}}{\bar{\tau} \bar{\sigma}}\right) \frac{\mathrm{Q}_{\mathrm{T}}}{\mathrm{Q}_{\mathrm{F}}}}{\left(\exp \left(\frac{\mathrm{Q}_{\mathrm{T}}}{\mathrm{Q}_{\mathrm{F}}}\left(1-\frac{\mathrm{x}}{\mathrm{L}}\right)\right)-\exp \left(-\frac{\mathrm{Q}_{\mathrm{T}} \mathrm{x}}{\mathrm{Q}_{\mathrm{F}} \mathrm{L}}\right)\right)} \\
& T(x)=T_{c}+\left(T_{c}-T_{c}-\frac{c}{b} L\right) \cdot \frac{\exp (-b \cdot x)-1}{\exp (-b \cdot L)-1}+\frac{c}{b} x
\end{aligned}
$$

Where $Q_{F}=\bar{k} A \frac{\Delta T}{L}$ which is conduction flux or Fourier, $Q_{F}=\bar{\tau} I \Delta T$ (Thomson), $b=\frac{\bar{\tau} \mathrm{I}}{\overline{\mathrm{k}} A}$ and $=$ $\frac{\mathrm{I}}{\overline{\mathrm{k}} \bar{\sigma} A}$.

\subsubsection{Electrical analogy model}

This mode is also derived from the energy balance equation and assists in simplifying the modelling of complex problems for example the TE coefficients, non-constant leg section of TE element and the transient regime o [88] [89].. As illustrated in Fig. 8, the leg is divided into discrete sections to cater for all the TE effects keeping in mind their temperature dependence. 


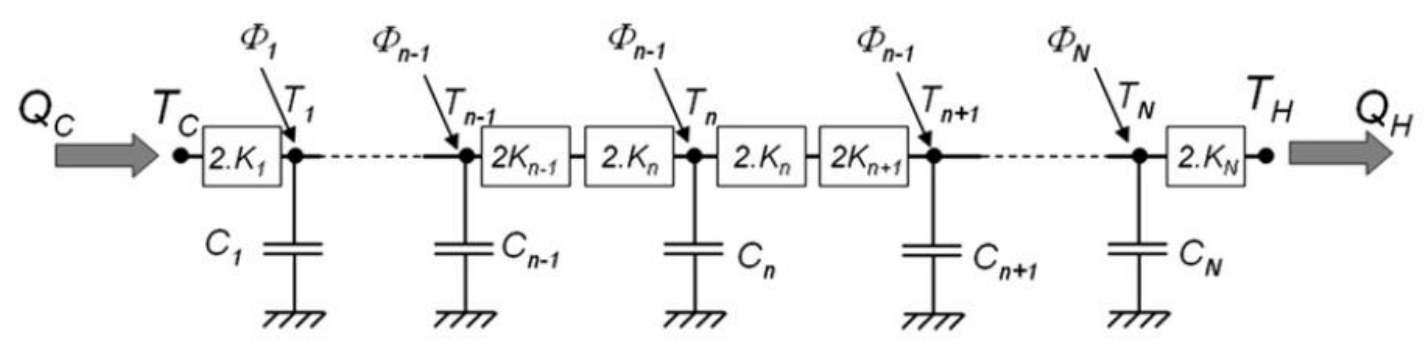

Fig. 8. Analogical scheme of the thermoelectric phenomena with the thermal capacitances.

The balance equation after the discretization process in steady state for any node $\mathrm{n}$ (for a number of $\mathrm{N}$ nodes) is given as:

$$
\frac{T_{n-1}-T_{n}}{\frac{1}{2}\left(\frac{1}{K_{n-1}}+\frac{1}{K_{n}}\right)}+\frac{T_{n+1}-T_{n}}{\frac{1}{2}\left(\frac{1}{K_{n+1}}+\frac{1}{K_{n}}\right)}+\Phi_{n}=0
$$

In order to respect the local energy balance, Heat flux $\Phi_{n}$ in equation (48) is added to fully constitute the energy balance:

$$
\Phi_{n}=R_{n} I^{2}-\tau_{n} I \frac{T_{n+1}-T_{n-1}}{2}
$$

The boundary conditions are the same as those in Eq. (39).

In each element, the electrical resistance $\mathrm{Rn}$ and the thermal conductance $\mathrm{Kn}$ are determined on the basis of each leg section and its local temperature. The advantages of the electrical analogy based models are simple and accurate. The fact that unspecified number of time steps is used in the model and the resolution of the systems is direct makes it possible to limit the numerical problems meaningfully.

\subsubsection{Numerical TE models}

This model is implemented in software based on energy balance where the numerical expressions of the TE effects are integrated. The steady state analyses in the thermal and electric fields are achieved using ANSYS software with the Newton-Raphson method. The advantage is that it is appropriate for transient regime and for 3D geometries.

A reasonable number of research works have been carried out using numerical TE model. In the aspect of thermal management, the study on improvement of thermal environment by using TEC and numerical optimization of Thermal Performance is conducted [90]. Analysis shows that the maximum COP and minimum power consumed by TECs can be obtained at different optimum numbers of $p$-n couples, which is independent of electrical current across by 
TECs. Numerical simulations are also performed on temperature gradient and thermal stress of a TEG device [91]. It is found that under high heat flux imposing upon the hot end, the thermal stress is so strong that it has a decisive effect on the life expectation of the device. Similarly, a numerical transient simulation tool based on TRNSYS is used to assess and optimize TEG in real applications [92]. This tool takes into account the whole energy system, and the designed TEG component is able to cope with both electrical and thermal dynamics. A mathematical model for simulating the electrical and thermal behaviours of a longitudinal TE energy harvester was additionally developed [93]. A new TRNSYS component has been developed in order to implement the theoretical analysis and can be used as a design tool. In another work, a FORTRAN computation program is used for the numerical calculation in which an a mathematical model of multi-element thermoelectric components connected in series is developed [94]. The model considers internal and external irreversibilities as well as the temperature gradients along the flow direction. A 3-D numerical simulation and experimental analysis on turbulent flow of venting flue gas using TEG modules is also done [95]. The numerical results for the power versus current are found to be in good agreement with the experimental data within an error of $9 \%$.

\section{Different structures of TEG unit/Module}

In this section, we look at the TEG structure itself and how different modifications have been made in order to improve the performance. The modifications are done by altering different TEG components, for example by stacking materials of different properties to form a segmented TEG device. First, the basic structure of TEG is highlighted followed a detailed discussion of the progress on structural improvements.

\subsection{The basic structure of TEG module}

A TEG unit is primarily composed of an n-type and a p-type semiconductor. A number of TEG units are normally stacked to form a TEG module so as to produce the required power as illustrated in Fig. 9. 


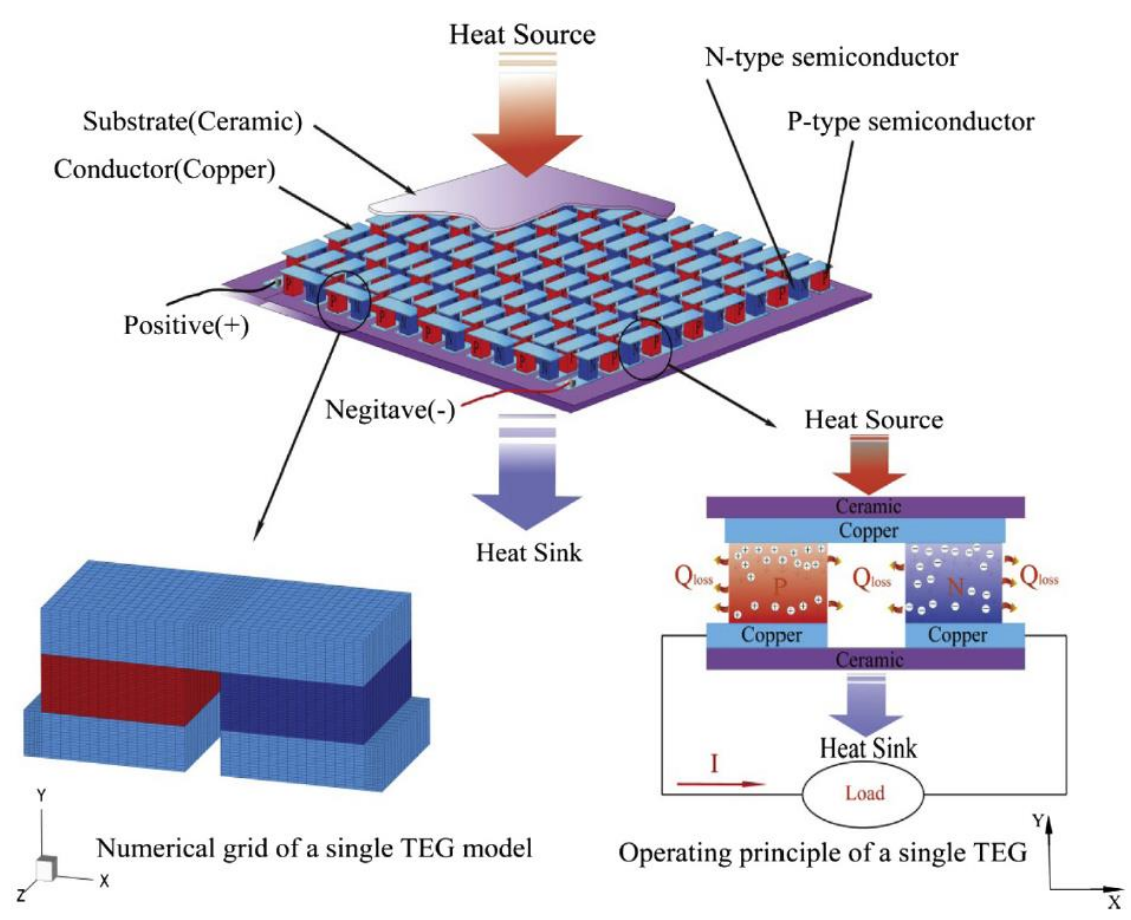

Fig. 9. Illustration of the TEG setting for Power generation [27].

\subsection{The modified structures of TEG module}

With increased interest in TEG systems for different applications, research has been intensified, leading to the introduction of several advanced models into the TEG scenery. This has been done through various modifications of the basic TEG module by several ways such as hybridizing of the materials used to form TEG, geometrical modifications, etc. This has led to more improvements in the power output and efficiency.

\subsubsection{Progress on TEG module structural improvement}

Various TEG modules made up of different materials, design methodologies and thermal conditions have been reported in literatures. First to mention, a TEG is designed through numerical modelling and gradient-based optimization with advanced multi-parameter. The TEG is made up of three segments each with a different material where a high power density material is used in the heat exchanger to enable thermal isolation in the direction of heat flow as shown in Figs. 10 and 11 [96]. 


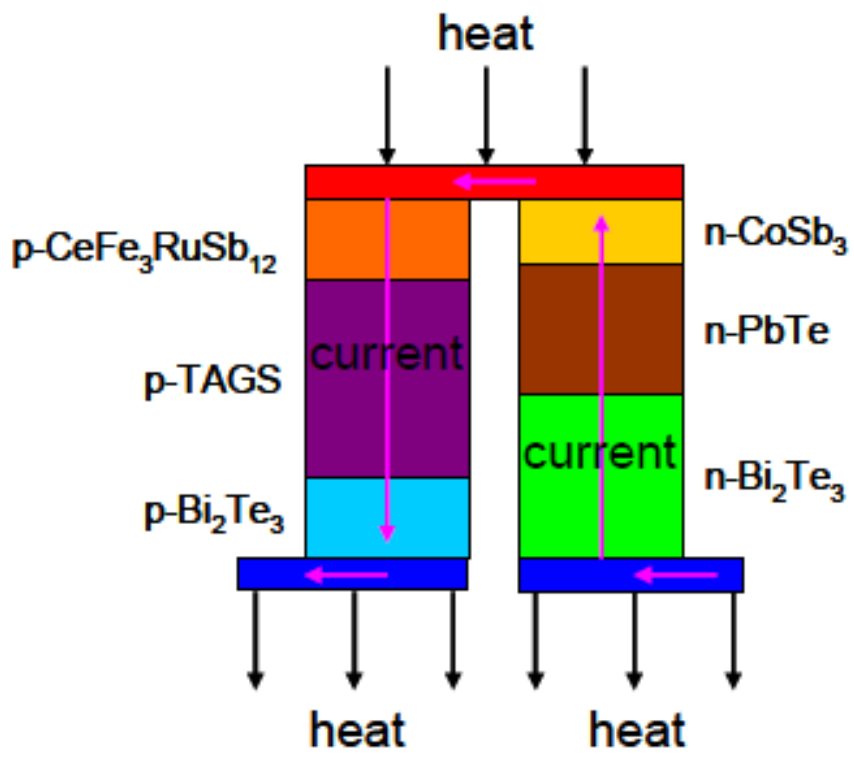

Fig. 10. Traditional TE couple configuration with segmented elements.

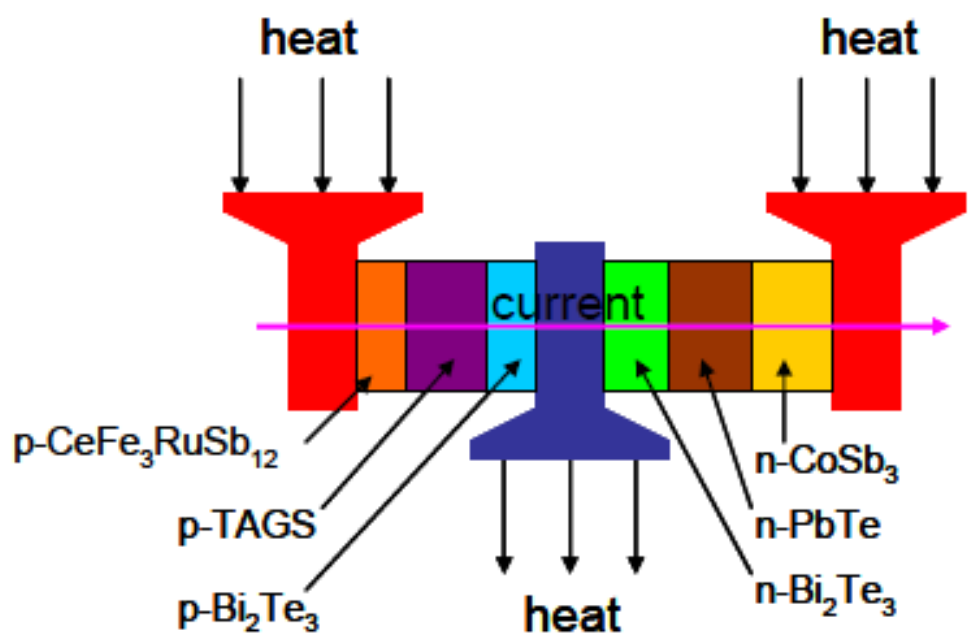

Fig. 11. Alternative TE couple configuration with segmented elements of different total element thickness.

Likewise a model is presented to determine the theoretical limit of electrical power generation that provides optimal electrical loading conditions for a given exhaust stream and system configuration [97]. According to this study, ZT is not a sufficient parameter to describe system performance; basing on the predicted results, it was established that there is an optimum number of thermoelectric leg pairs that maximize the power extracted for any system, and that adding more leg pairs beyond this optimum can reduce system performance.

In another study, an integrated TE device (iTED) is designed and tested, which consists of plates of $\mathrm{p}$ - and n-type semiconductor bonded on a highly electrical and thermal conducting 
inter-connector material with a hole through which a flow channel is drilled [98]. The iTED comprised of several elements connected thermally in parallel and electrically in series, where the top and bottom surfaces of the device are exposed to cold temperature whereas the flow channel walls contained a hot fluid. Fig. 12 shows the dimensions of a single stage TE device. The performance of the device was numerically investigated through simulations. For a single module iTED with fixed TE material sizes $d$ and inlet temperatures $T_{\text {in }}$ values, the power output and efficiency were increased five- and twofold, respectively at pressure drops for the hot fluid flow rate of 500 litre/min as compared to a flow rate of 100 litre/min. It was discovered that there exists an optimum $d$ where a maximum power output is achieved. The device with number of modules $\mathrm{N}=5$ indicated more than a twofold rise in power output and approximately a $33 \%$ reduction in both efficiency and electric current compared to $\mathrm{N}=1$ values.

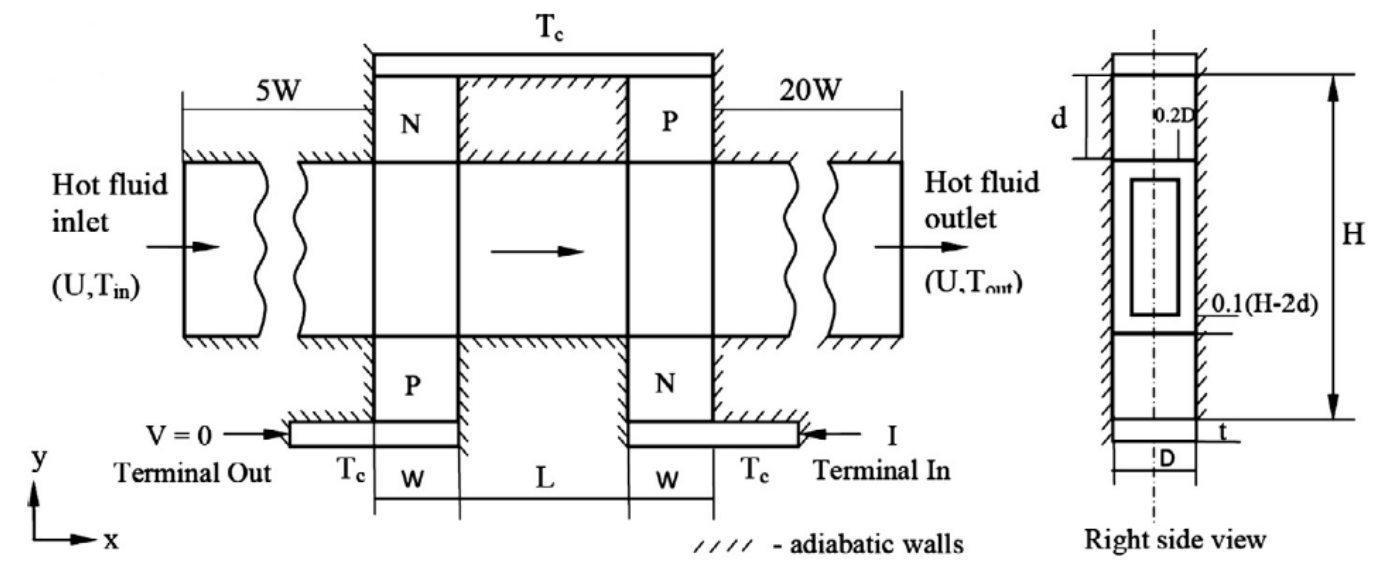

Fig. 12. Schematic of single-stage integrated thermoelectric device [98].

In a different development, TE module architecture is designed with Bismuth Telluride cells. The segmented TE power generators are designed and manufactured which are characterized by a counter-current arrangement of the hot and cold gaseous streams as well as a catalytic combustion chamber that ignites an air/fuel mixture [99]. The designed TEG is able to accommodate a flexible electrical load and exhibits enhanced conversion efficiency due to improved thermal management.

Because of the fluctuations of the heat sources in industry, TEG system may experience these fluctuations, leading to poor power output and low efficiency. Therefore these fluctuations can be catered for to ensure a stable power output from the TEG system. A novel TEG system with thermal switch is designed to address problem of instability of TEG power output [100]. Fig. 13 shows the physical model of the new TEG system with a thermal switch. 
Results indicate that the thermal switch can efficiently decrease the temperature fluctuation and improve the output power and efficiency of the TEG system.

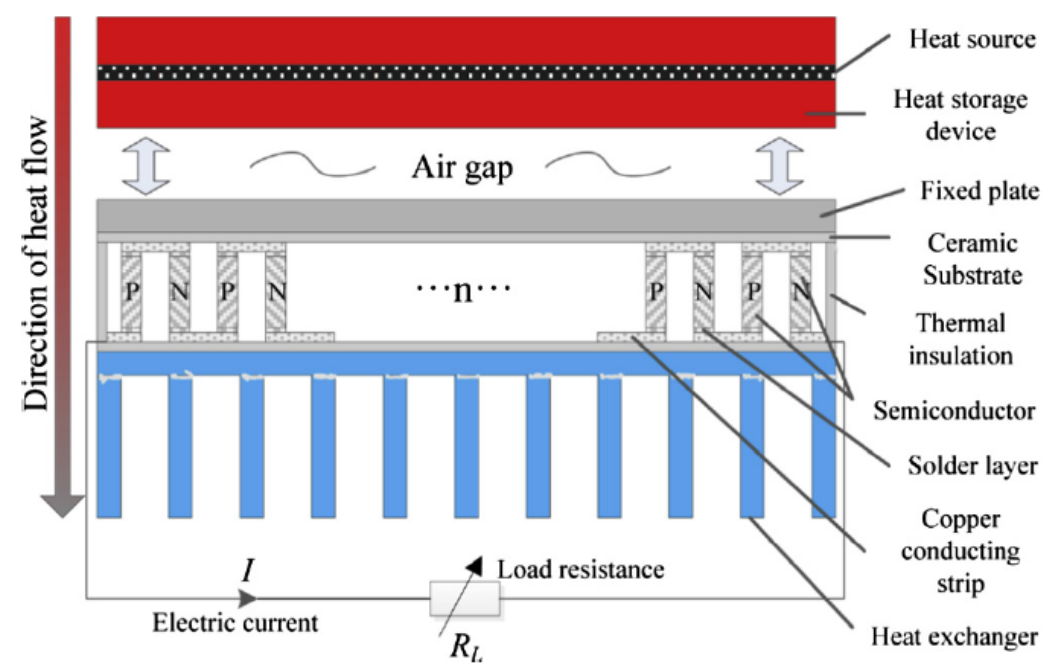

Fig. 13. The physical model of the new TEG system with thermal switch [100].

The concept of thermoelectric self-cooling is introduced whereby a TE device can be cooled and the temperature can be controlled without consuming electricity [101]. The TE is designed with an internal heat source and a usual cooling system is attached to the device to analyse its thermal performance. According to the results from the study, thermal resistance between the heat source and the environment is reduced by 25 to $30 \%$ when the self-cooling concept is implemented. Robel et al. have studied the relationship between coolant flow rate and heat flux at heat source device to study the viability of self-cooling concept [102]. They found out that at an optimum flow rate of cooling fluid, the required temperature of the heat source is possible to be kept while at the same time providing power.

Thermoelectric power enhancement which are brought about by flow impeding panel "inserts" in a thermoelectric generator's flow channels under the fixed thermal input conditions is investigated [103]. This work is based on the advancements in TEG inner pipe flow optimisation mainly to improve the conversion efficiency. The research tried to ensure TEG system's ability to maintain an asymmetric thermal field across its component modules since this mechanism somehow determines the efficiency of the TEG device.

In another study, the columnar $\mathrm{Cu}$ film is found to be similar to parallel microchannel which can create some sort of channels for the easy transports of electrons and phonons in the TE device [104]. The p-Bi0.5Sb1.5Te3, $\mathrm{n}-\mathrm{Bi} 2 \mathrm{Se} 0.3 \mathrm{Te} 2.7$ and $\mathrm{Cu}$ films are fabricated by a magnetron sputtering method but the films are integrated into low-dimension cross-plane 
devices using mask-assisted deposition technology. The micro-device with densely columnar $\mathrm{Cu}$ film electrode shows very superior to those devices with ordinary structure electrode. For instance a typical device with 98 pairs of $\mathrm{p} / \mathrm{n}$ couples, the output voltage and maximum power are up to $120.5 \mathrm{mV}$ and $145.2 \mathrm{~mW}$, respectively, for a temperature difference of $4 \mathrm{~K}$. Figs. 14a and $b$ show the scanning electron microscopy (SEM) images of the bilayer structure for $\mathrm{Bi} 0.5 \mathrm{Sb} 1.5 \mathrm{Te} 3 / \mathrm{Cu}$ and $\mathrm{Bi} 2 \mathrm{Te} 2.7 \mathrm{Se} 0.3 / \mathrm{Cu}$ films couples with columnar electrode whereas Figs. $14 \mathrm{c}$ and $\mathrm{d}$ show the corresponding ordinary $\mathrm{Cu}$ film electrodes.
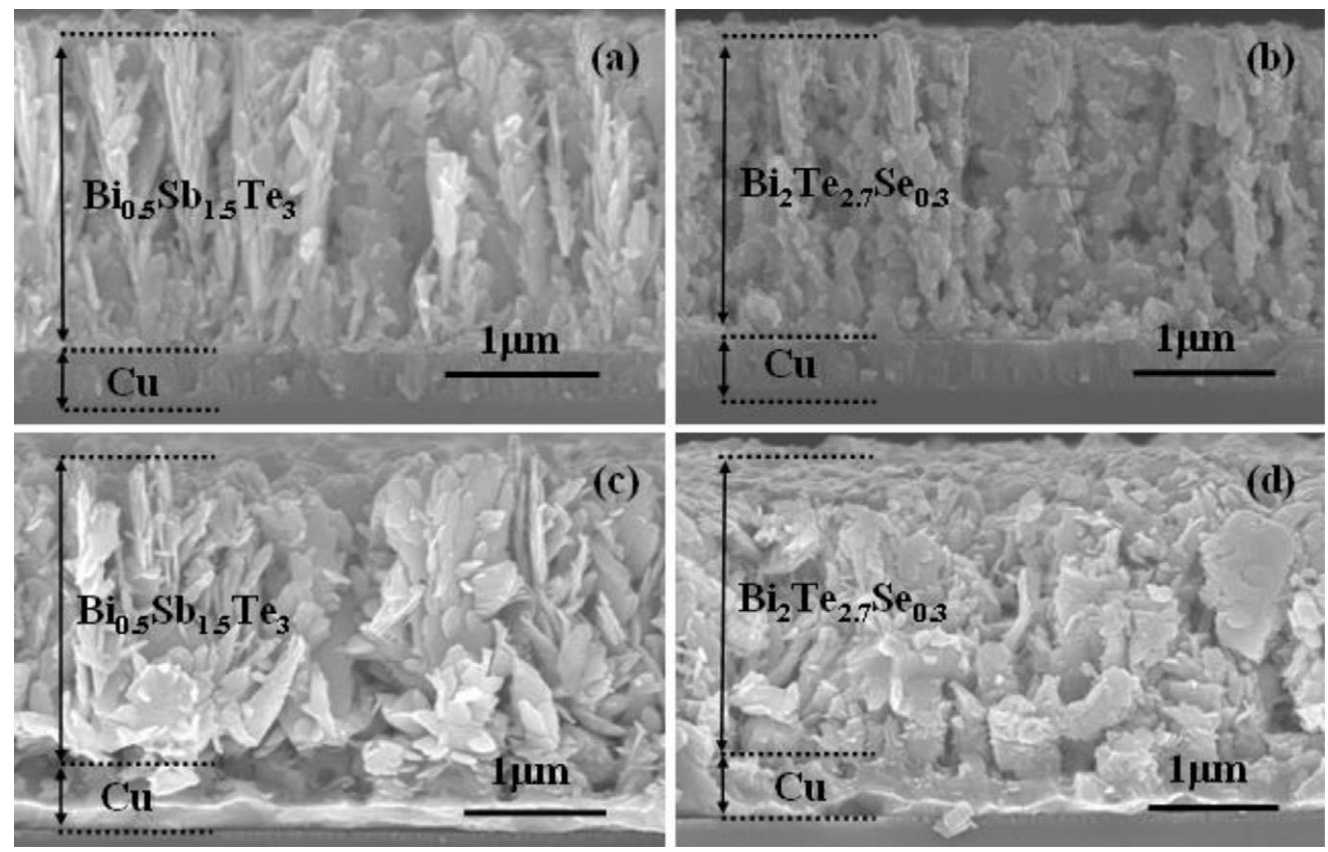

Fig. 14. SEM images of the couples in devices with $(\mathrm{a}, \mathrm{b})$ columnar and $(\mathrm{c}, \mathrm{d})$ ordinary $\mathrm{Cu}$ film electrodes.

The integrated thermoelectric device (TEDs) which refers to TE elements made of semiconductor plates laminated with a highly thermally and electrically conducting interconnector are well investigated using fluid-thermo-electric coupled field numerical methods [105] . These are mainly made up of bulk crystalline n-type and p-type (Bismuth-TellurideSelenium) semiconducting materials with copper as a conducting material. At higher inlet fluid temperatures the increment in load resistance showed a significant change in the heat input value. The flow rate has been noted to cause a prominent effect on TED performance. It is recommended that the optimization of TED with flow channels can be done using fluid-thermoelectrical coupling field simulation. Alternatively, a composite thermoelectric device (CTED) that comprises of TE elements made of TE semiconductor materials bonded to highly electrically and thermally conductive material in a segmented fashion is investigated [106]. 
Compared to conventional TED with equivalent geometry, the CTED shows the ability of extracting more energy in heat recovery system.

\subsection{Progress of TEG system improvement}

Various studies have been carried out on the performance optimization of TEG as well as improvement of heat recovery efficiency. The optimizations of the configuration and layout of TEGs heated by exhaust gas are carried out [30]. Fig. 15 shows the layout of TEG module in a generator. As there is always a temperature difference between the rear and front ends of the generator, TEGs with different performance capabilities are installed in different positions where they would perform better. In the rear side where there is low temperature, HZ-14 modules are installed because they have lower operating range and therefore cannot produce good results if they are installed at the front side where the temperature is too high. Conversely, HZ-20 modules with higher operating range are installed at the front side where the temperature is high.

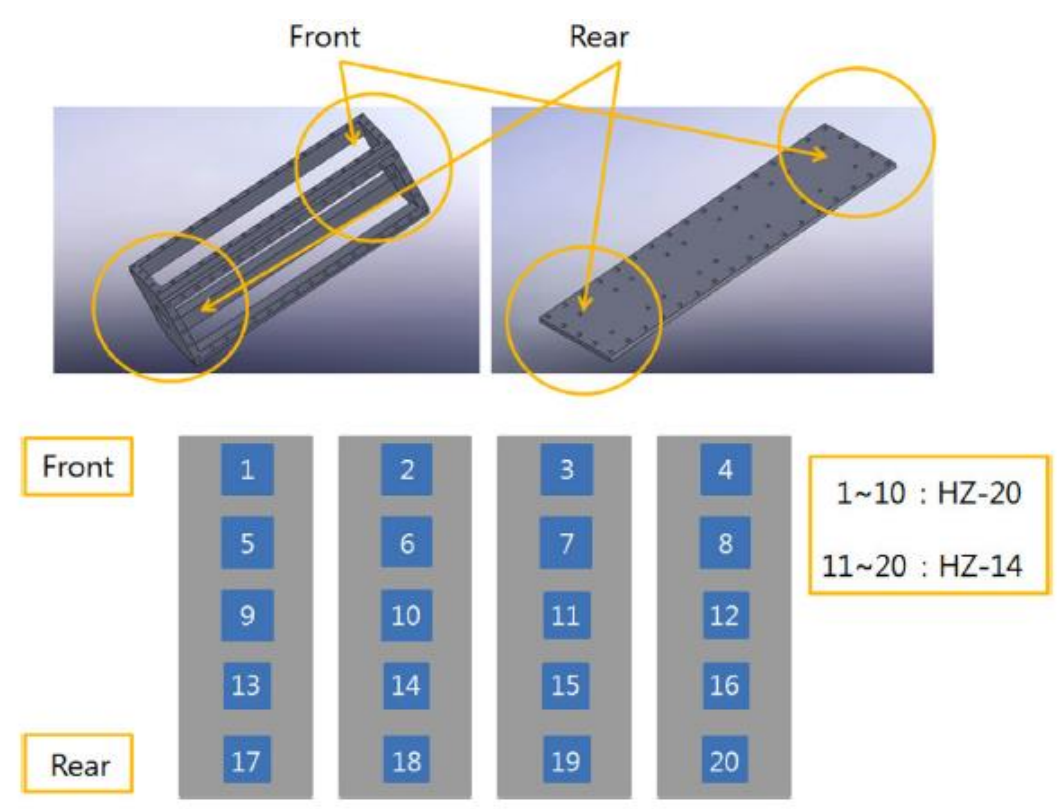

Fig. 15. Schematic diagram of each module installation on thermoelectric generator.

In addition, TEG power output increases with temperature difference between the hot and cold sides. However, the excessive increase of $\mathrm{T}_{\mathrm{H}}$ results into decreased TEG performance especially when $T_{h}$ is near the durable temperature of the TEG. It can be observed from Fig. 16 that the power output at relatively higher temperatures is less than that at lower temperature. Therefore, appropriate temperature must be maintained to achieve the maximum power output. 


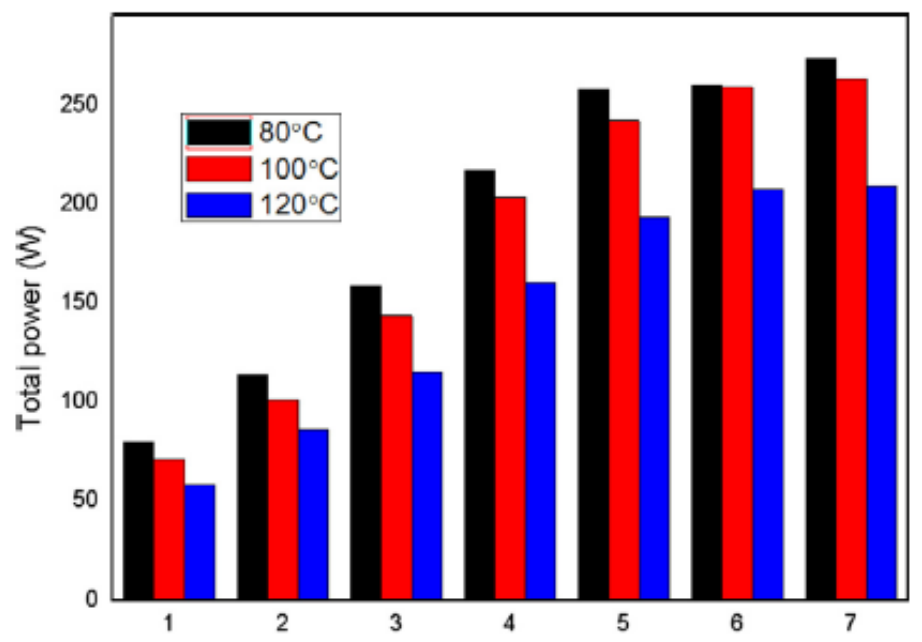

Fig. 16. Comparison of power output under the different temperatures.

Similarly, the performances of thermoelectric modules at various flow patterns, heating temperatures, flow rates of water and numbers of modules in series are studied [107]. It is found that the effects of flow pattern of heat sink and water flow rate on the performance are insignificant, but the heat source or heating temperature plays an important role. Consequently, a lower water flow rate is suggested to minimize power consumption, while a higher hot-side temperature leading to a larger temperature difference is suggested to improve TEMs performance.

The effect of temperature uniformity of the heat spreader on the TEG performance is studied [108]. The power output of the TEG with uniform temperature distribution is compared with that with non-uniform temperature distribution. Fig. 17 illustrates the experimental setup of the system as well as the system arrangement. By carrying out finite element based simulation and experiment work, the evaluations of power output, electric current, open circuit voltage and the system efficiency are done. The results demonstrate that the uniform temperature distribution over the heat spreader gives better results than the non-uniform temperature distribution. 


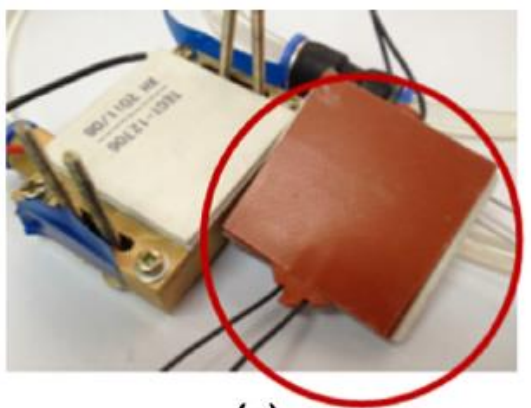

(a)

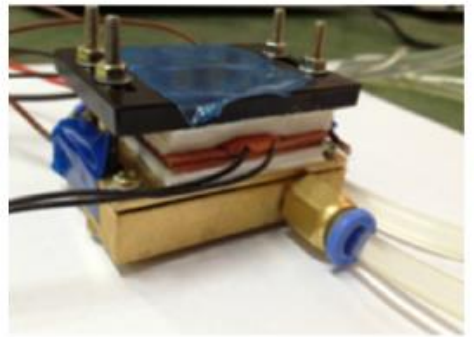

(c)

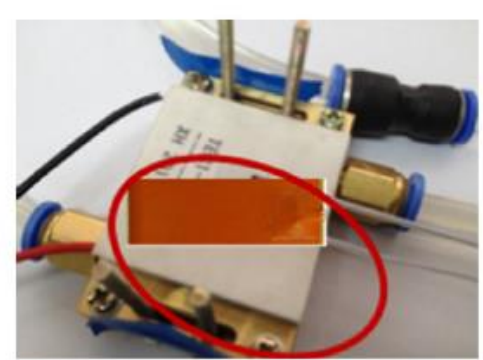

(b)

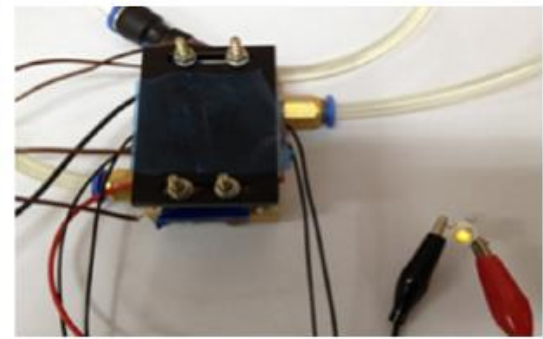

(d)

Fig. 17. Experimental components and setup (a) the heater covered all top surface of the module, (b) the heater covered some parts of the module, (c) and (d) experiment set up in case (a) and case (b), respectively.

Though most of the researchers concentrate on static placement of the TEG to improve the system performance, a novel rotating TE device is studied analytically while operating in periodic steady state in order to improve the energy conversion performance [109]. The rotating TEC device consists of the single TE conductor and operates in both the switching periodical mode (P-mode) in which the hot and cold ends of the TE conductor are periodically suddenly reversed, and the continuous sinusoidal mode (S-mode) in which the temperature of TE conductor edges varies continuously according to a sine wave. The two periodical modes are shown in Fig. 18. In addition to ZT, it is found that the cooling temperature and efficiency also depend on an additional dimensionless parameter comprising of the rotation period, the size and the thermal diffusivity of the TE conductor. The S-mode demonstrates deeper cooling at certain times than the P-mode. 

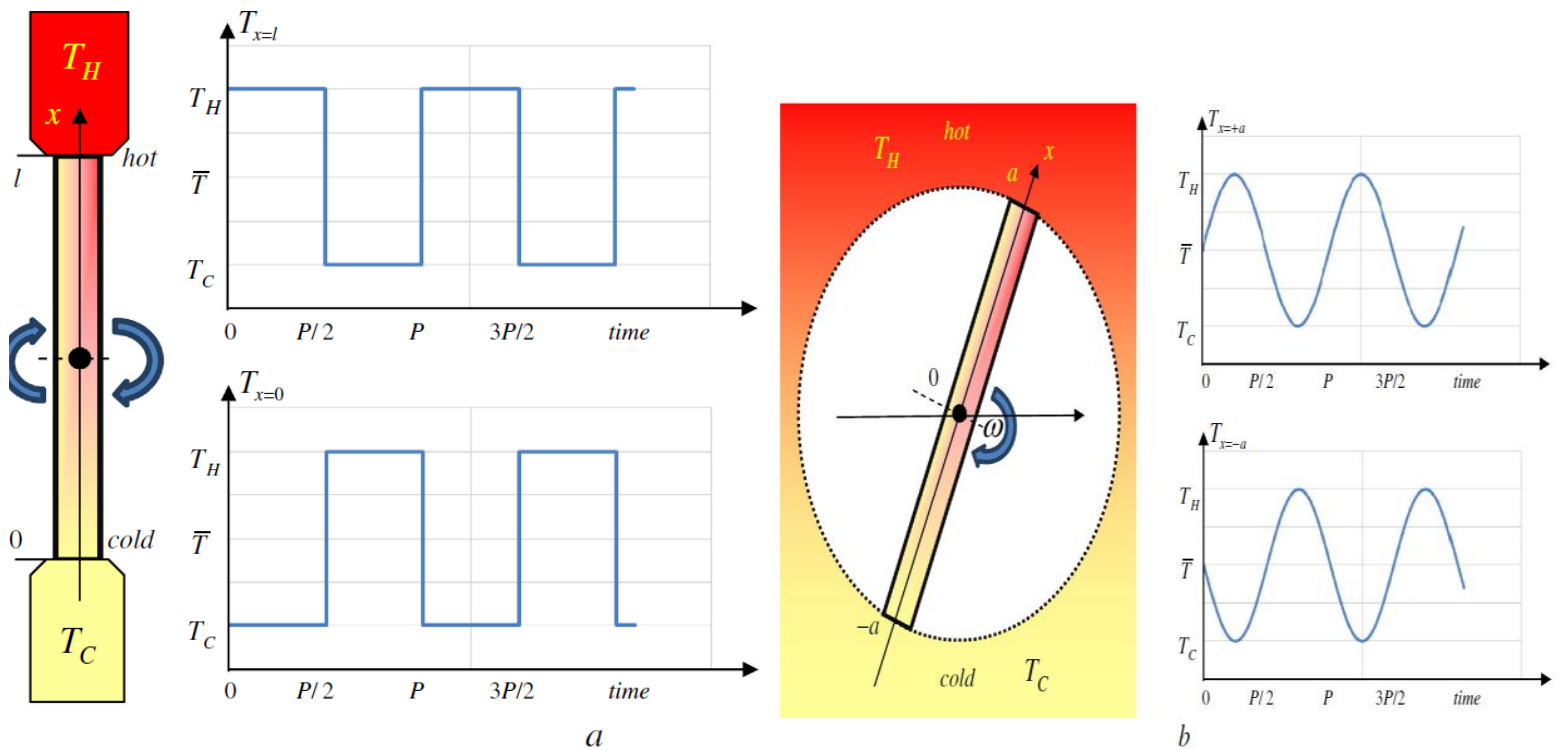

Fig. 18. Schematic sketch of proposed TE devices operating in (a) the switching periodical mode (P-mode) and (b) the continuous sinusoidal mode (S-mode) [109].

A new TEG system based on liquid metal, used for harvesting waste heat is also designed and tested through a prototype which is a combination of commercially available thermoelectric (TE) modules with the electromagnetic pump [110]. The maximum open-circuit voltage of $34.7 \mathrm{~V}$ is attainable when the temperature of the waste heat source is $195.9{ }^{\circ} \mathrm{C}$ and the temperature gap between liquid metal heating plate and cooling-water plate is about 100 ${ }^{\circ} \mathrm{C}$, and the efficiency of the TEG system is $2 \%$.

A two-stage TEG prototype for recovering waste heat from the vehicle exhaust gas is also investigated [111]. The two-stage TEG is found to generate a maximum output power of around $250 \mathrm{~W}$ at $473 \mathrm{~K}$ hot side temperature whereas the thermal efficiency achieved is $5.35 \%$, increased by $32 \%$ compared to $4.04 \%$ of single stage TEG in the same operating condition.

Amaral et al. introduced mechanical methods to increase the thermal tension, driving the electromotive force responsible for thermoelectric power production [112]. In this method, the flow impeding geometries are inserted into the flow channels of a liquid-to-liquid TEG which results into enhanced heat transfer near its embedded TE modules. In the end, the thermal dipole across the modules is increased which consequently improves the overall power output. Fig.19 shows the generator assembly of embedded TE modules using this method. 


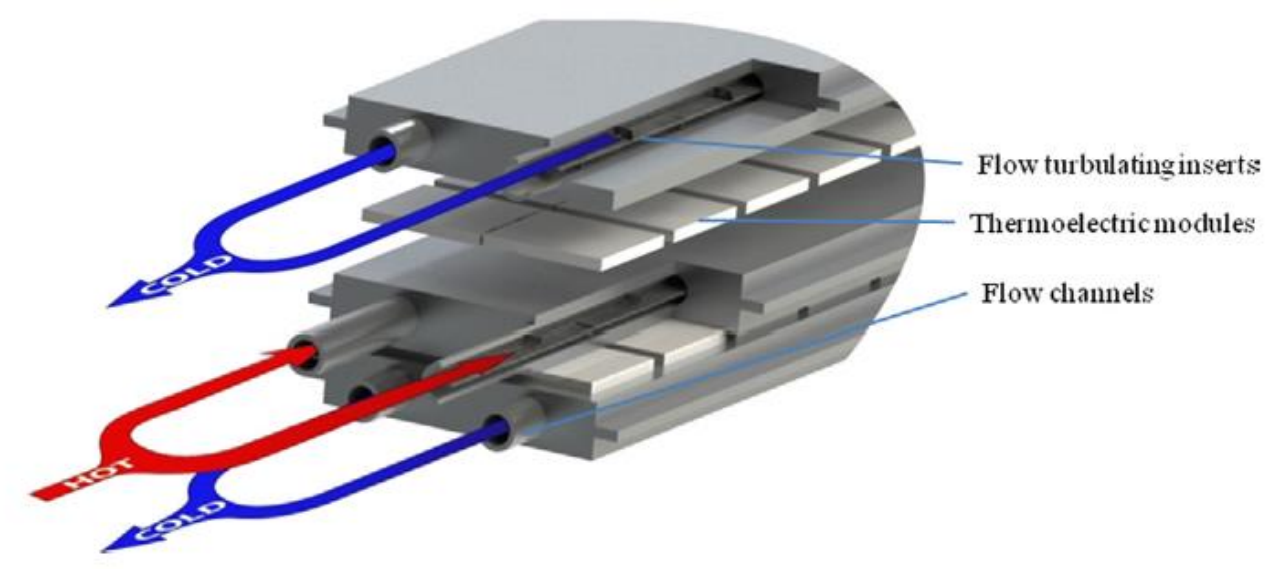

Fig. 19. Generator assembly of embedded thermoelectric modules and a hot-cold contour flow water circuit.

Table.3. Comparison of different TEGs systems with respect to performance improvement

\begin{tabular}{|c|c|c|c|c|c|c|c|}
\hline TEG & $\begin{array}{l}\text { Heat } \\
\text { transport } \\
\text { medium }\end{array}$ & $\begin{array}{l}\text { Voltage } \\
\text { (V) }\end{array}$ & $\begin{array}{l}\text { Hot side } \\
\text { Tempera } \\
\text { ture }\left({ }^{0} \mathrm{C}\right)\end{array}$ & $\begin{array}{l}\text { Cold } \\
\text { side } \\
\text { tempe } \\
\text { rature } \\
\left({ }^{0} \mathrm{C}\right)\end{array}$ & $\begin{array}{l}\text { Temperat } \\
\text { ure } \\
\text { differenc } \\
\text { e }\left({ }^{0} \mathrm{C}\right)\end{array}$ & $\begin{array}{l}\text { Maximu } \\
\mathrm{m} \text { power } \\
\text { output } \\
\text { (W) }\end{array}$ & $\begin{array}{l}\text { TEG } \\
\text { efficienc } \\
\text { y }(\%)\end{array}$ \\
\hline $\begin{array}{l}\text { Liquid } \\
\text { metal } \\
\text { based[110] }\end{array}$ & $\begin{array}{l}\text { Liquid } \\
\text { metal }\end{array}$ & 34.7 & 195.9 & & 100 & & 2 \\
\hline $\begin{array}{l}\text { GM200- } \\
71-14-16 \\
\text { type [113] }\end{array}$ & & 2.74 & 200 & 30 & 170 & & 5 \\
\hline $\begin{array}{l}\text { Two-stage } \\
\text { TEG [111] }\end{array}$ & $\begin{array}{l}\text { Vehicle } \\
\text { exhaust } \\
\text { gas }\end{array}$ & $\begin{array}{l}292 \text { up } \\
\text { from } 200 \\
\text { for single } \\
\text { stage TEG }\end{array}$ & 199.85 & 29.94 & 170.25 & 248.49 & $\begin{array}{l}5.35 \text { up } \\
\text { from } \\
4.04 \text { for } \\
\text { single } \\
\text { stage }\end{array}$ \\
\hline $\begin{array}{l}\text { HZQW and } \\
\text { HZ20M } \\
{[63]}\end{array}$ & $\begin{array}{l}\text { Exhaust } \\
\text { gas }\end{array}$ & & 562.8 & 76.61 & & $\begin{array}{l}453 \text { and } \\
140\end{array}$ & $\begin{array}{l}8.53 \text { and } \\
2.25\end{array}$ \\
\hline Four-TEGs & & 201.7 & 312 & 69 & & 944 & 1.85 \\
\hline
\end{tabular}




\begin{tabular}{|l|l|l|l|l|l|l|l|}
\hline $\begin{array}{l}\text { system } \\
{[64]}\end{array}$ & & & & & & & \\
\hline
\end{tabular}

\section{Methods of efficiency improvement of TEG system}

The efficiency of TE device can be improved through various methods including proper matching of internal resistance of the TE device with external load, adjusting the boundary temperature and the number of TEG units, use of dc to dc converters etc. The performance and efficiency of TE conversion system can also be improved by minimizing the heat losses to the ambient medium. A three-dimensional numerical model of TEs with consideration of coupling of temperature field and electric potential field is developed [114]. The model is used to determine the performance of TECs with the temperature-dependent thermal conductivity, Seebeck coefficient, and electric conductivity of semiconductor materials. The results indicate that the variable properties and the heat losses to the ambient gas have significant effects on the cooling capacity and the COP of the TEC.

\subsection{Impedance matching}

The usefulness of matching the TEG power output with the electrical load is demonstrated in the simulation and experimental work [115]. It is indicated that the internal resistance of the TEG module and the electrical resistance of the load have to be known to ensure load matching. For proper impedance matching, the optimal electrical load should be equal to the internal resistance of the TEG module in order to ensure that maximum power is transferred to the load. The normalized thermopower $\mathrm{P}^{*}=\mathrm{P} / \mathrm{P}_{\max }$ is defined as [115];

$$
P^{*}=\frac{4 R_{L}^{*}}{\left(1+R_{L}^{*}\right)^{2}}
$$

Where $R_{L}^{*}=R_{L} / R_{i}$ stands for the normalized electrical load, $\mathrm{R}_{\mathrm{L}}$ and $\mathrm{R}_{\mathrm{i}}$ are the load and TEG module resistance respectively

A normalized power output curve is used to determine the optimal electrical load for peak power output under several working conditions. The curve is shown in Fig. 20. 


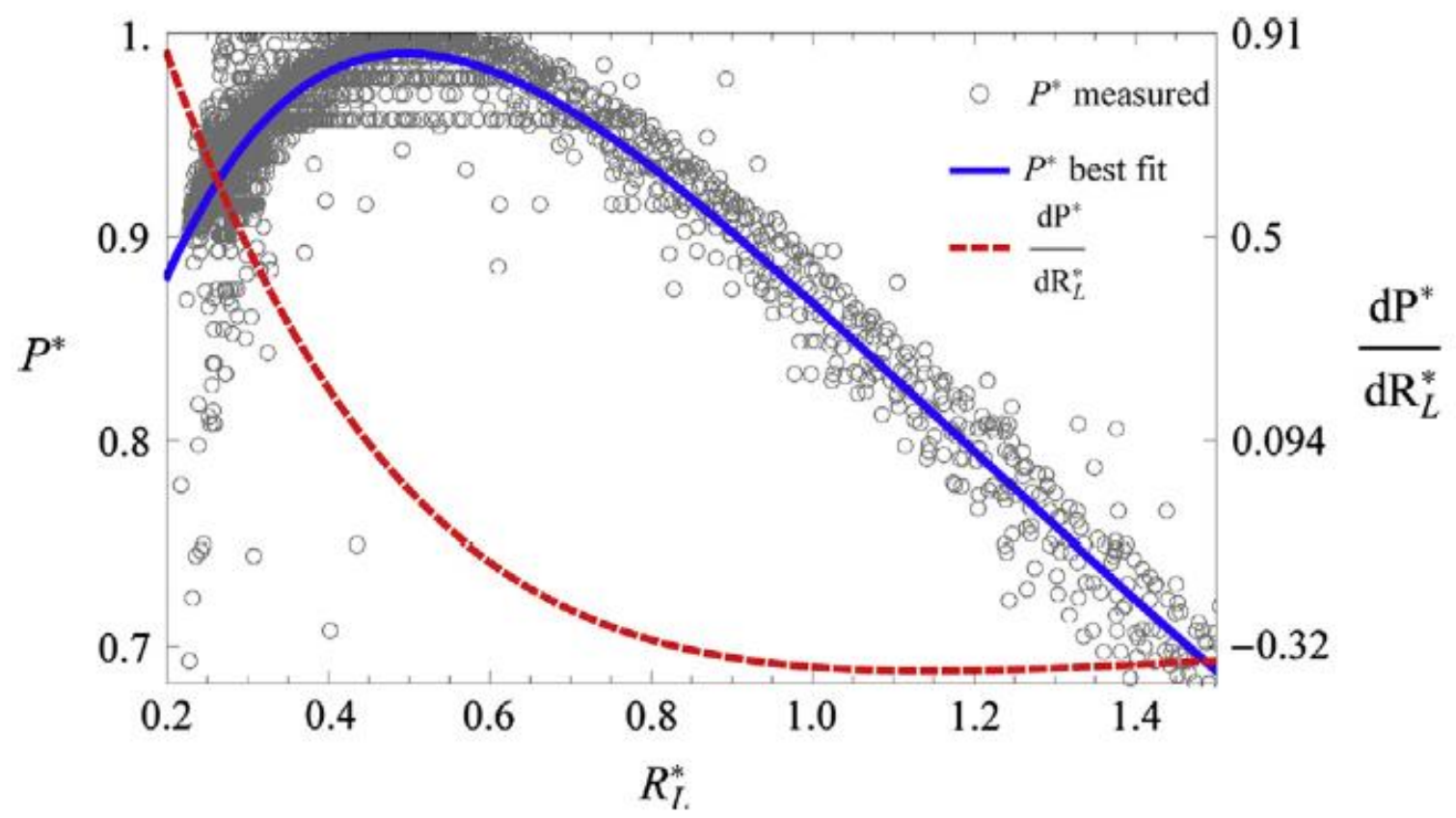

Fig. 20. Normalized thermopower from all thermal conditions tested and its rate of change relative to the electrical load.

The relatively large values of $d P / d R_{L}^{*}$ are obtained prior to $\mathrm{P}=1$ as shown in Fig. 20. This means that thermopower output is sensitive to small changes in load resistance in this region. After attaining a value of zero (0) near the maximum point, the $d P / d R_{L}^{*}$ tends to a constant value. This implies that the thermoelectric power output is less sensitive to changes in electrical load when they are greater than optimal value. This method has some limitations which calls for the use of another method to improve the performance of TEG. By connecting the load directly to the output terminal of TEG, it is difficult get a stable output voltage without proper voltage regulation mechanism. It is also unlikely that the maximum power output can be extracted from the system as it is difficult to balance the internal resistance of TEG and the load resistance to ensure impedance matching.

\subsection{Adjusting the boundary temperature and the number of TEG units}

Several ways are suggested to improve TEG power output. One of them is to raise the hotside temperature and/or lowering the cold-side temperature [66]. The aim of this is to widen the temperature difference on which the output from TEG depends. An independent cooling system can be used to lower the temperature of the cold side as much as possible. However, for every type of TEG, there is limitation to the lowest and the highest junction 
Another method involves adjusting the number of TEG modules. Increasing the number of TEG units results into increase in TEG power output and vice versa. Similarly there are limitations associated with this method. First, space where TEGs can be mounted in the heat pipe may be unavailable. Moreover, adding more TEG modules increases the cost of the systems.

Because of the limitations associated with the above discussed methods, other alternative methods that involve proper use of the generated power from TEG can be applied improve the performance of TEG.

In order to further utilise the recovered heat, a method [116] is introduced to recover heat not only for heating purposes but also for power generation using TEG. A combination of heat pipes and TEGs that employ Bi2Te3 material is presented in Fig. 21 based on this method. The results indicate that the proposed method is able to recover $1.345 \mathrm{~kW}$ of waste heat and generate $10.39 \mathrm{~W}$ of electrical power with 8 TEGs.

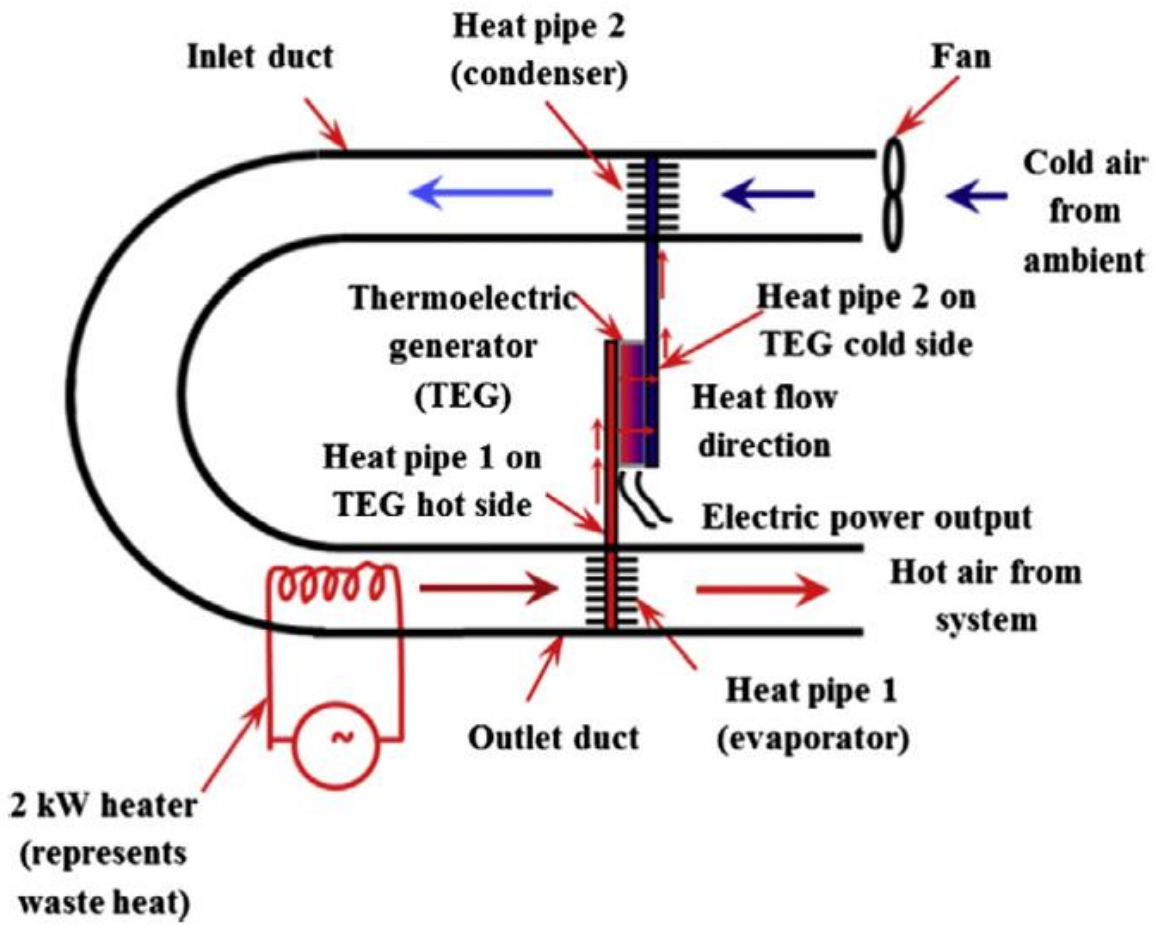

Fig. 21. Concept of the HPTEG system.

\subsection{TEG power conditioning using DC-DC converters}

To mitigate the problems associated with the above discussed methods, dc-dc converters are used. The dc-dc converters are capable of giving regulated dc voltage, step up or down the dc voltage and the maximum power can easily be extracted from TEG if the maximum power 
tracking (MPPT) algorithm is used in conjunction with the converter. The dc-dc converter is an electronic circuit capable of converting from one source of dc voltage to another dc voltage. They are important in situations where a higher voltage is needed from a lower voltage level (boosting) or a low voltage is needed from a higher voltage (bucking). They are also applied to regulate the voltage from unregulated sources such as TEG devices, solar cells etc. therefore, several configurations of dc-dc converters are available to suit different applications. Many of the readily available converters are designed to work under a (nearly) constant voltage source and therefore their performance may not be as expected when connected to a variable current source like a TEG or PV system [117]. Therefore, the choice of a right converter affects the optimum performance of the whole system and therefore a proper criterion has to be followed to choose the best converter.

To give a big picture on the available converter architectures, Table 4 presents the summary of the qualities and the implications of applying these converters in TEG environment.

Table 4. Summary of the qualities and the implications converters

\begin{tabular}{|c|c|c|c|c|}
\hline Converter & Features & Application & Advantage & Limitation \\
\hline Boost & $\begin{array}{l}\text { - Converts from a low } \\
\text { voltage to higher } \\
\text { voltage } \\
\text { - PWM controlled } \\
\text { - Load current smaller } \\
\text { than the input current } \\
\text { - Most commonly used } \\
\text { - middle and low level in } \\
\text { the conversion network }\end{array}$ & \begin{tabular}{l} 
- Suitable for TEG \\
with unstable \\
internal resistance \\
\multicolumn{2}{c}{ and output voltage }
\end{tabular} & $\begin{array}{l}\text { - Precise and } \\
\text { flexible } \\
\text { conversion } \\
\text { factor }\end{array}$ & $\begin{array}{l}\text { - Requires a large } \\
\text { Inductance to get } \\
\text { high efficiency }\end{array}$ \\
\hline Buck & $\begin{array}{l}\text { - converts from a higher } \\
\text { voltage to a lower } \\
\text { voltage } \\
\text { - PWM controlled }\end{array}$ & & & $\bullet$ \\
\hline Push-pull & $\begin{array}{l}\text { - High level conversion } \\
\text { of high power }\end{array}$ & $\begin{array}{ll}\text { - High } & \text { Power } \\
\text { Application } & \text { (range } \\
\text { of kWs) } & \end{array}$ & $\begin{array}{l}\text { - Less likely to } \\
\text { cause saturation }\end{array}$ & $\begin{array}{l}\text { - More complex } \\
\text { - MOSFETs must } \\
\text { be able to handle }\end{array}$ \\
\hline
\end{tabular}




\begin{tabular}{|c|c|c|c|c|}
\hline & $\begin{array}{l}\text { - step-up and step-down } \\
\text { tasks } \\
\text { - Multiple outputs due to } \\
\text { transformer isolation }\end{array}$ & $\begin{array}{ll}\text { - Fairly } & \text { good } \\
\text { efficiency } & \end{array}$ & $\begin{array}{l}\text { than in the fly- } \\
\text { back converter, } \\
\text { - Hence smaller } \\
\text { size }\end{array}$ & $\begin{array}{l}\text { twice the input } \\
\text { voltage, } \\
\text { - Hence used for } \\
\text { low voltage } \\
\text { application }\end{array}$ \\
\hline Cu'k & $\begin{array}{l}\text { - Middle level conversion } \\
\text { - continuous output } \\
\text { current } \\
\text { - can boost or buck the } \\
\text { voltage } \\
\text { - }\end{array}$ & $\begin{array}{l}\text { - suitable for } \\
\text { sensitive } \\
\text { environments }\end{array}$ & $\begin{array}{l}\text { - Stable input and } \\
\text { output terminal } \\
\text { currents } \\
\text { - Easy to canceled } \\
\text { ripples (by } \\
\text { adjusting } \\
\text { inductors)1, } \\
\text { - Emit less RF } \\
\text { noise }\end{array}$ & $\bullet$ \\
\hline Buck-boost & $\begin{array}{l}\text { - Increase and decrease } \\
\text { the output voltage } \\
\text { - load voltage is inverted }\end{array}$ & & & $\bullet$ \\
\hline Fly-back & $\begin{array}{l}\text { - Increase or decrease the } \\
\text { output voltage } \\
\text { - Transformer is used } \\
\text { - Multiple output can be } \\
\text { obtained } \\
\text { - Output energy is stored } \\
\text { as magnetic energy and } \\
\text { released to the load } \\
\text { later. }\end{array}$ & $\begin{array}{cr}\text { - Where } & \text { multiple } \\
\text { outputs } & \text { are } \\
\text { required } & \end{array}$ & & • \\
\hline
\end{tabular}

${ }^{1}$ Output ripple means the current amplitude difference and should be as small as possible.

\subsubsection{Use of $d c$-dc converter with maximum power point tracking}


In an ordinary dc-dc converter, the switch is triggered by the use pulse width modulated (PWM) signal. The duty cycle is normally adjusted to tune the required output voltage from the converter. However, with the change in the input to the converter, it is difficult to keep in touch with the change in the changes to provide the maximum power from the input. With the use of MPPT algorithm, the maximum power can easily be tracking as the MPPT tracker is technically configured to respond to the changes in the input. The use of MPPT algorithm along with the dc-dc converter makes it possible to extract maximum power from TEG. The description of wow the MPPT works can be accessed in [118]. The MPPT techniques may be grouped into two based on the parameter being monitored to achieve the tracking purpose: the first based voltage feedback and the second based on regulating the generated power. The method based on voltage feedback works in such a way that a predetermined reference voltage is compared with the voltage of TEG module in a feedback loop [119]. The second method is based on regulating the generated power by sensing the TEG module voltage and current to track the MPP. Perturb and observe (P\&O) and incremental conductance (IC) are the examples of this method. The MPPT functionality is normally integrated into the dc-dc converter to achieve higher power-extracting efficiency. Therefore the non-isolated dc-dc buck, boost, buck-boost, $\mathrm{Cu}^{\prime} \mathrm{k}$ and SEPIC converters have been assessed to find a one that best suits an application with MPPT [120].

A boost converter cascaded with a buck converter in a continuous MPPT mode is developed for conditioning the power generated from a TEG [121]. Fig. 22 shows the proposed system and Fig. 23 shows the hardware setup of the TEG power conditioning system. The system is able to maximize the power while at the same time charging the battery. The MPPT employed in a boost converter makes use of $\mathrm{P} \& \mathrm{O}$ technique to ensure that maximum power is continuously extracted from the TEG. 


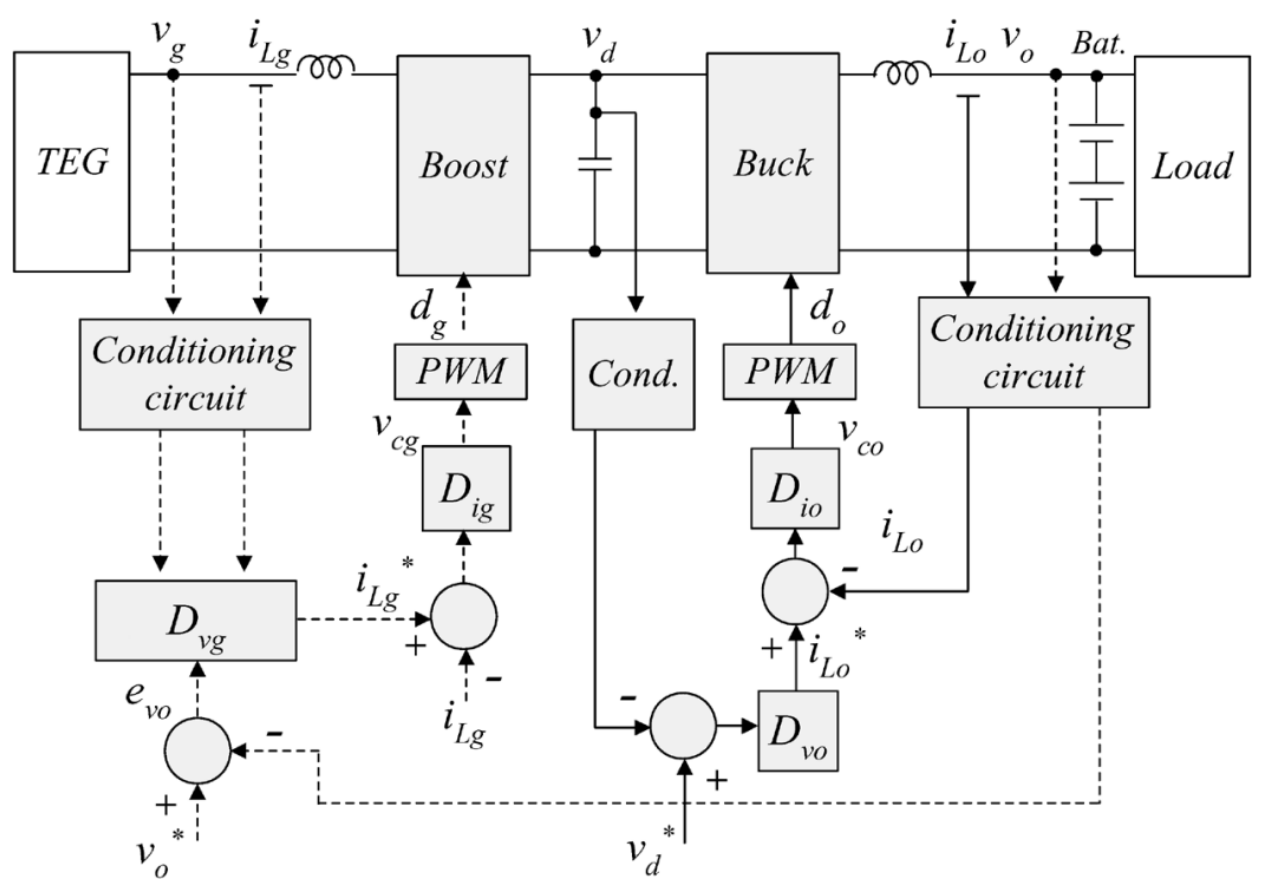

Fig. 22. TEG power conditioning system MPPT controller [121].

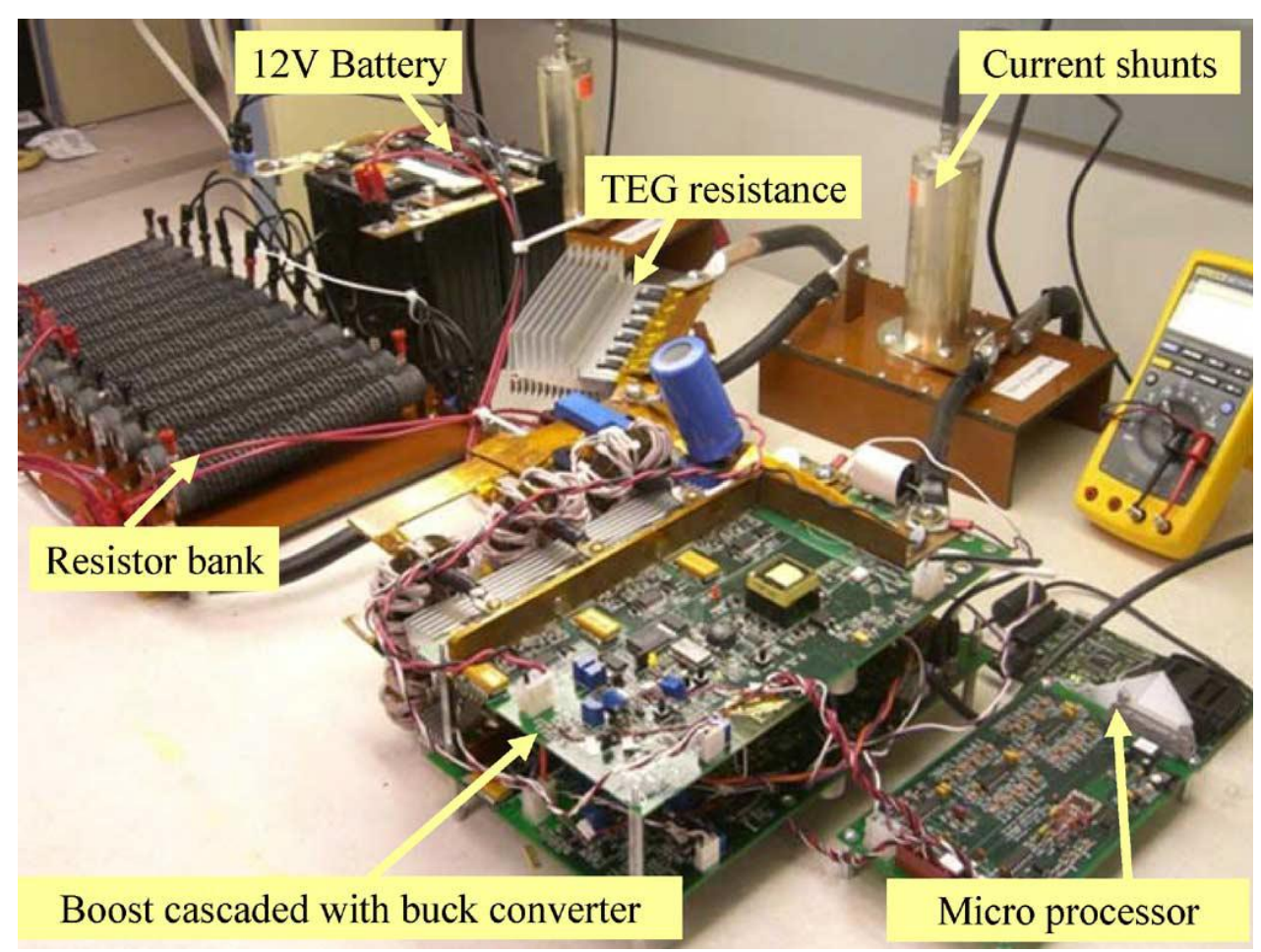

Fig. 23. Hardware setup of the TEG power conditioning system.

The theoretical maximum power MPP is calculated to be $264.3 \mathrm{~W}$ at $35.5 \mathrm{~A}$. When the load is reduced, the output voltage $\mathrm{V}_{\mathrm{o}}$ reaches its level. The input current is reduced gradually, and the operating mode is changed to the power matching (PM) mode. The results reveal the 
stability of the proposed MPPT controller and output voltage regulation under load steps, source impedance variation and different dc link voltage commands.

Alternatively, an MPPT for TEG to support a vehicle power supply is reported [122]. This digital cascade controller for a boost-buck converter is used to charge a vehicle battery and supply the load. The tracking of the MPP is realized with a gradient algorithm and an input current control.

\subsubsection{Application of TEG output power regulation with $d c-d c C^{\prime} u k$ converter}

Since its discovery, the C'uk converter has received much attention in power electronics research and industry. The main features that make it work well with TEG system is that the ripple amplitude can easily be reduce to a zero value by properly winding both the input and output inductor coils on the same core. This prevents the pulsating input from interfering with the voltage output of the converter, hence ensuring proper power conditioning of TEG power output. A basic C'uk converter is shown in Fig. 24. The functioning of a Cuk is clearly reported in [123].

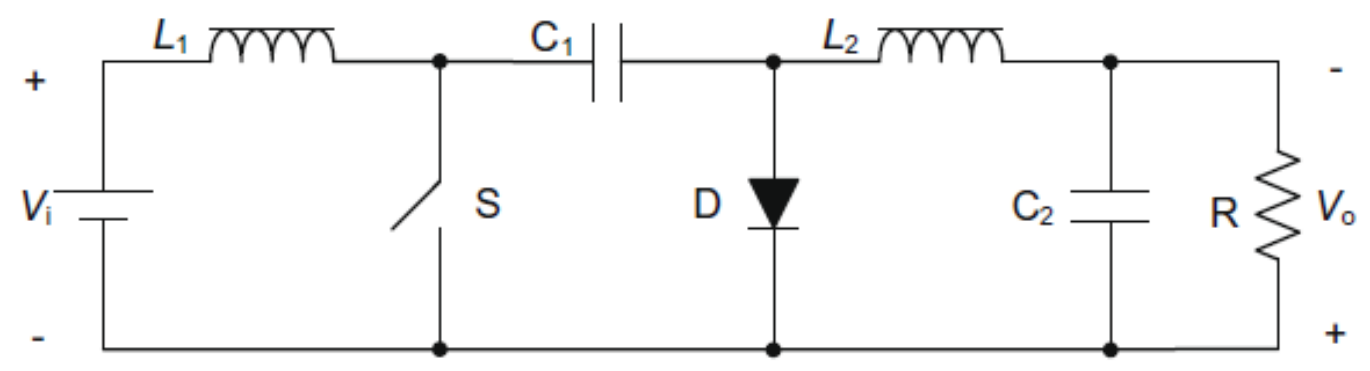

Fig. 24. Basic $\mathrm{C}^{\prime}$ uk converter.

With TEG system, a dc-dc C'uk converter with MPPT is utilised to charge a battery. The TEG system connected through the power conditioning systems to the battery is illustrated in Fig. 24. From the results, the output power is reported to be maximised with the converter giving power output increase of up $14.5 \%$ compared to the TEG system without the use of a converter. Besides, a more stable output voltage is achieved with the use of this converter configuration. 


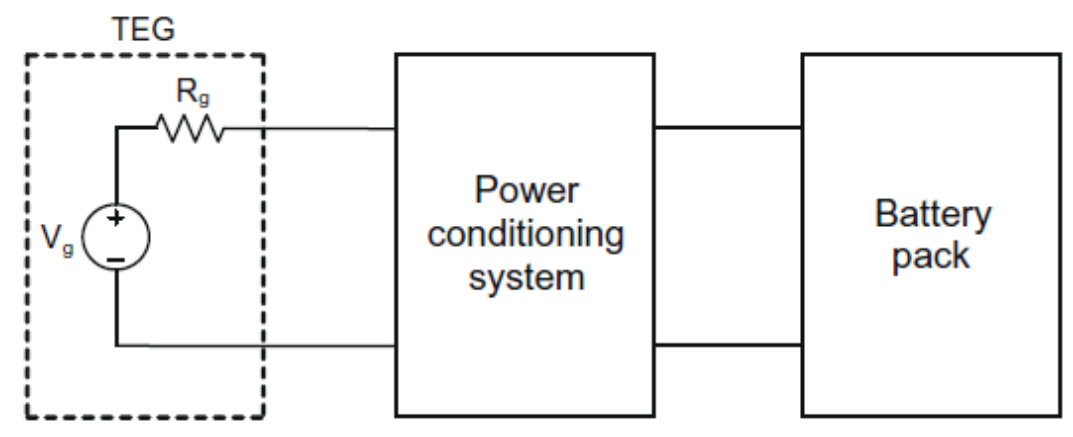

Fig. 25. TEG power system [123].

\subsubsection{MPPT control with cuk dc-dc converter}

MPPT control has been widely implemented in PV power systems, and its effectiveness in ensuring maximum extraction of power has been reported in various researchers. In addition to the classical P\&O and IC MPPT methods, There are several MPPT algorithms including constant-voltage and parasitic-capacitance techniques to mention but a few.

As the TEG power system' voltage-current (V-I) characteristics is similar to that of a PV power system, P\&O MPPT techniques used in PV power system can still be used for TEG system. So, this MPPT technique is proposed for use in the waste heat energy recovery system as shown in Fig. 26.

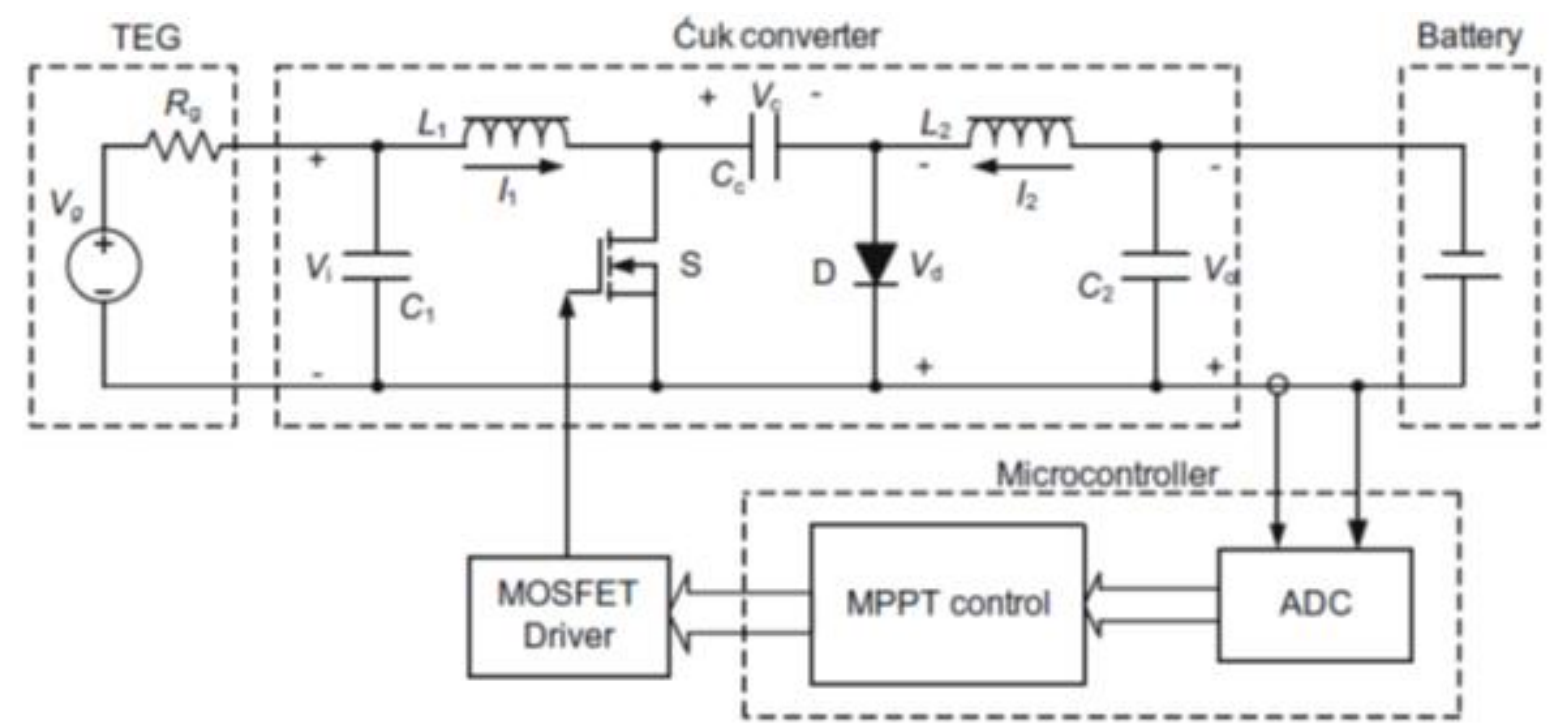

Fig. 26. Power conditioning system based on Cuk converter with MPPT. 
The MPPT is implemented digitally with a microcontroller which is configured to detect and capture the feedback signals and a direct PWM signal is used to drive the power MOSFET. The MPPT is observed with good TEG performance improvements because the power output is recorded to be increased to $22.6 \%$ with MPPT up from $14.5 \%$ without MPPT.

\subsubsection{Use of distributed multi-section multilevel dc-dc conversion networks}

Li et al proposed a network of dc-dc converters to be used in the regulation of power generated from TEG devices [124]. Fig. 27 shows the architecture of dc-dc converters that were suggested.

(a)

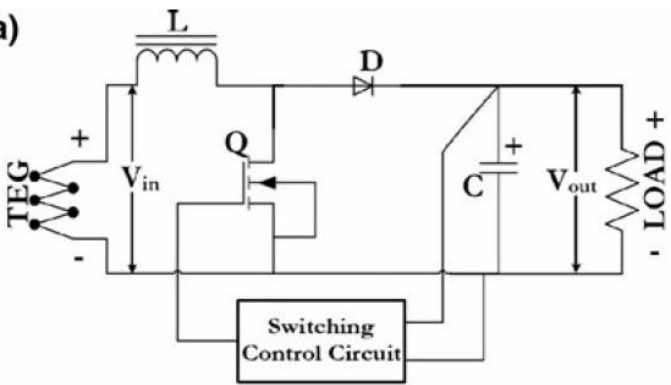

(c)

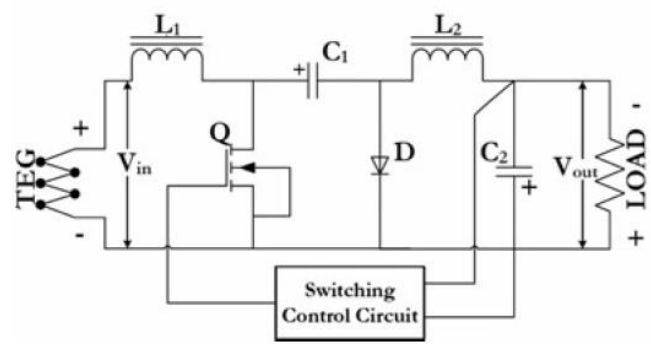

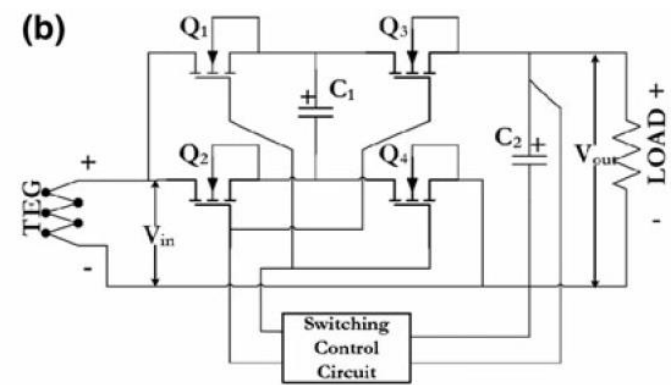

(d)

Fig. 27. DC-DC converter architectures suitable for application in the conversion network:

(a) boost converter, (b) charge pump, (c) C' uk converter, and (d) push-pull converter [124].

The thermoelectric-generator-based dc-dc conversion network is a distributed multi-section multi-stage network which is aimed to solve the problems facing the traditional single-stage system for TEG application in EVs [125]. The parameters of the network can be adjusted based on needs of the intended application. Such parameters include the number of conversion levels, conversion locations, the number of TEG modules at each location and so on. The proposed network topology is shown in Fig. 28. 


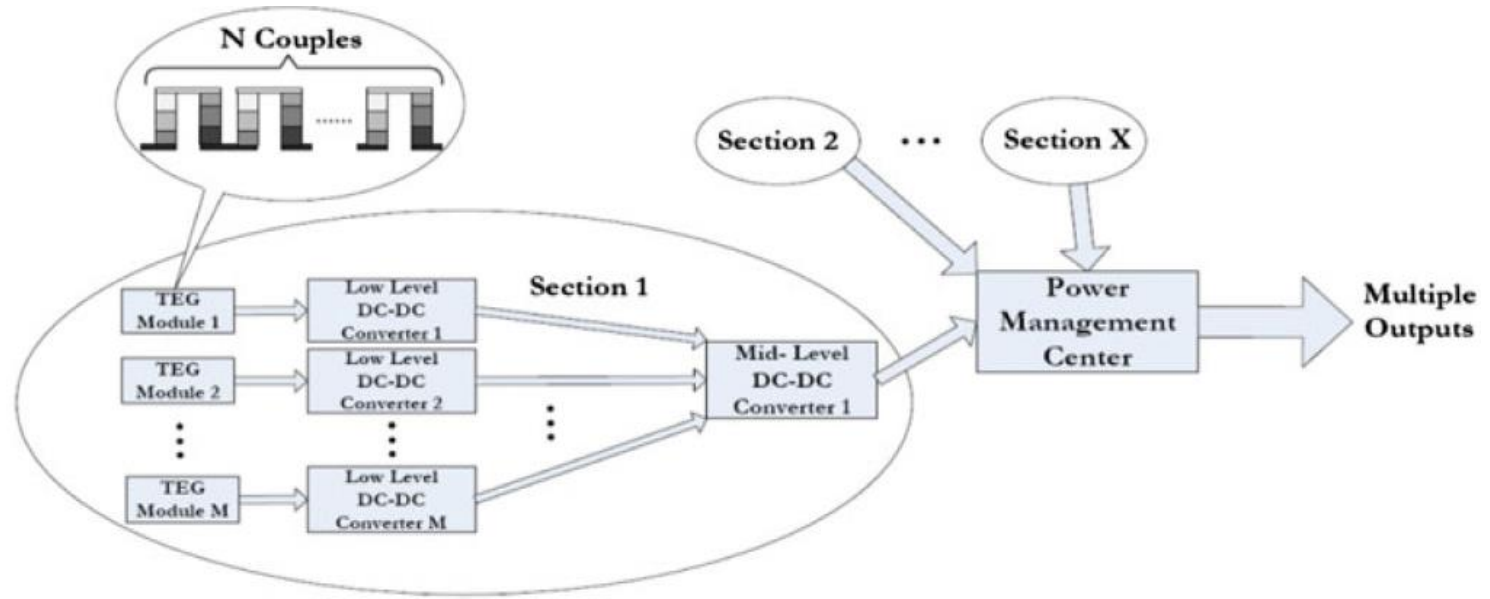

Fig. 28. General topology of the proposed TEG-based DC-DC conversion network [124].

A relatively small voltage with a large current is obtainable from TEGs. However, many applications require high and more stable voltage supplies than the output level of TEGs. For an initial boost, the output of each TEG module is forwarded to a low-level dc-dc converter. The outputs of all low-level dc-dc converters in the same conversion location are then forwarded to a mid-level dc-dc converter for further voltage boost. There is a power management center with multiple outputs, which mainly consists of a high-level dc-dc converter and it is responsible for the collection of the intermediate output voltage from midlevel converters. It is from this center that all the electronic systems (loads) on the vehicle are supplied with a stabilised power output. The advantages with this networked converter topology is that a high amount of heat is recovered due to multiple distribution of various TEGs within the system. It is also easy to designate a suitable TEG for a given location to ensure maximum efficiency and the system is less prone to faults, increasing its reliability. Interesting to note, the network topology increases the conversion efficiency up to about $400 \%$ as well as the matching efficiency of $99 \%$ with $200^{\circ} \mathrm{C} \sim 300^{\circ} \mathrm{C}$ temperature range at hot side.

\subsection{Power conditioning using temperature sensor based MPPT}

Another MPPT technique applied on TEG system is a temperature sensor based method with a tracking error of $1.15 \%$. Significant amount of time is required for TEG systems to reach the steady state by the conventional MPPT methods. Unlike in conventional MPPT methods where complex microcontrollers are employed, in this case, the MPP tracking is based on the use of temperature sensors with inexpensive, stable and simple circuitry without measuring the instantaneous power implying that there is no TEG disconnection. The open circuit voltage characteristic of the TEG is used with respect to temperature gradient to produce a proper 
reference voltage signal which is maintained by the power converter at a given level such that the maximum power can be harvested for a particular temperature. Fig. 29 shows the temperature sensor based MPPT circuitry [126].

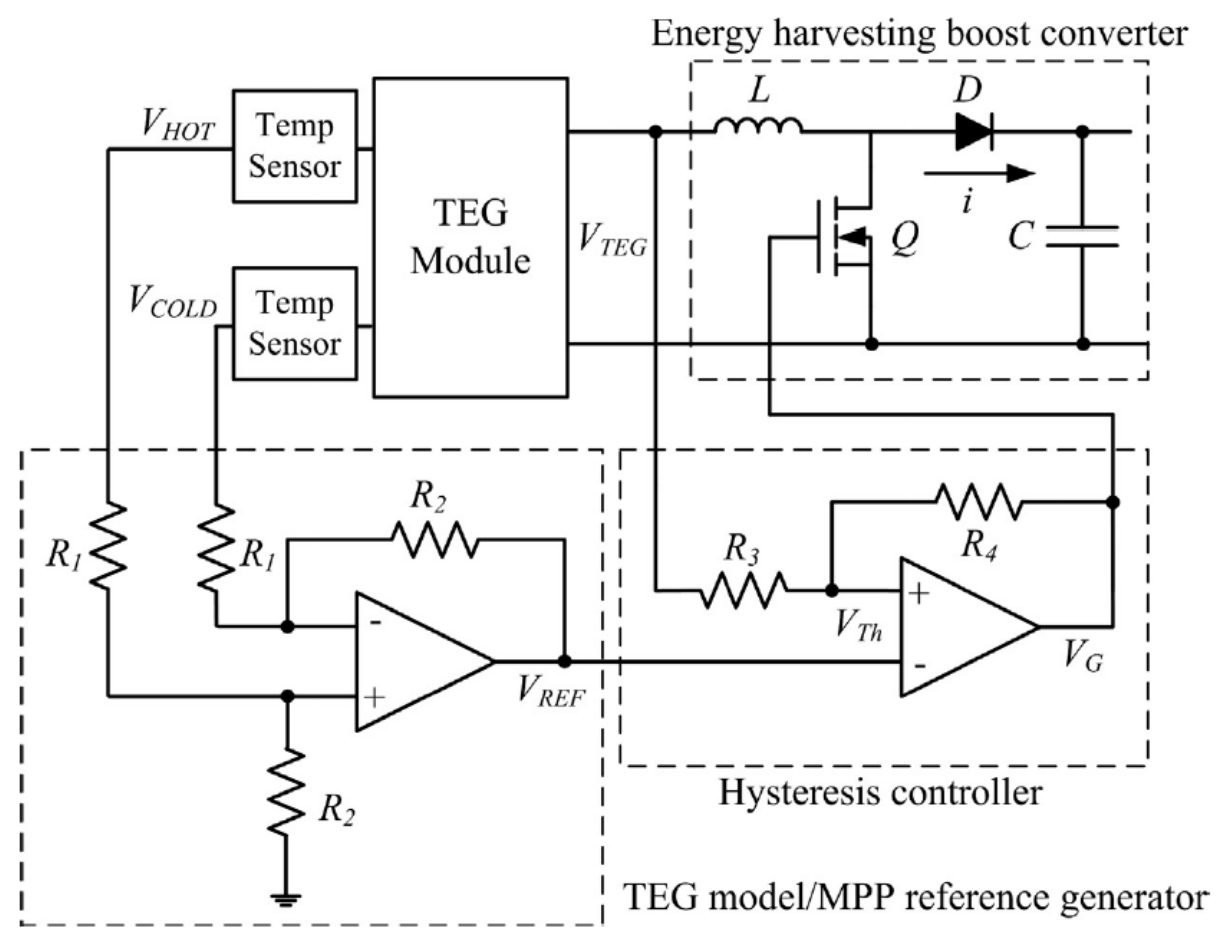

Fig. 29. The temperature sensor based MPPT circuitry.

TEG model feeds the hysteresis controller with an MPP voltage reference. Hysteresis controller controls boost converter and maintains energy harvesting at MPP [126]. It is argued that the dc-dc converter can be eliminated because of the power dissipation it causes. This may be accomplished by ensuring that the output voltage from the TEG is always above the voltage. The TEG modules need to be configured in such a manner that they can produce such a high voltage under normal working conditions. This means that many TEG modules must be connected in series and this may result in reliability problem. Furthermore many modules in series will cause a large internal resistance which will lead to a reduced power output. Therefore, this system is only an option and it is not applicable to large system with many TEGs.

\subsection{Other methods to improve the performance of thermoelectric devices}

In other efforts to improve the performance of TEG, the dollar/watt $(\$ / W)$ value is used to indicate the device's practical use. Kim et al. presented a method of lowering a $\$ / \mathrm{W}$ value while 
keeping a reasonable power output by modifying the TEG device architecture [127]. The \$/W means adjusting or reducing TE material consumption instead of increasing ZT to achieve higher efficiency. The power per unit volume (P/V) is defined as [127];

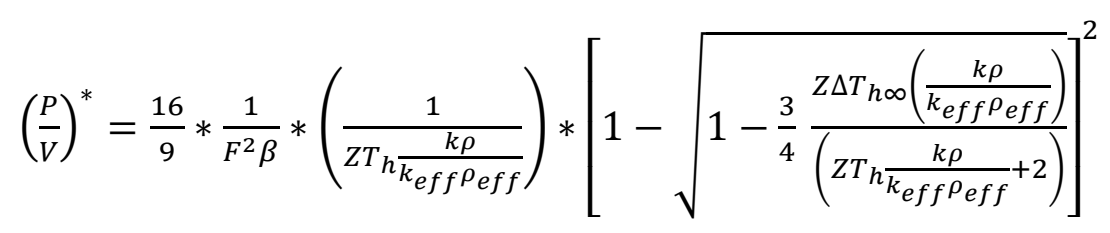

Where, $\mathrm{F}$ and $\beta$ are the fill factor and the TM ratio respectively. $\mathrm{T}_{\mathrm{h} \infty}$ is the temperature difference between the hot side $\mathrm{T}_{\mathrm{h}}$, and the surroundings $\mathrm{T}_{\infty} ; \rho_{\text {eff }}$ and $\mathrm{k}_{\text {eff }}$ are the effective electrical resistivity and thermal conductivity, respectively.

It is observed from this expression that the power per unit volume depends on $\mathrm{F}, \beta$ and ZT and increases as $\mathrm{F}$ and $\beta$ decrease. The power per volume of material however is proportional to the $\$ / \mathrm{W}$, achieved by introducing the volumetric material cost $\mathrm{C}\left[\$ / \mathrm{m}^{3}\right]$ as in the following equation:

$$
\left(\frac{\$}{\mathrm{~W}}\right) \sim\left(\frac{\mathrm{V}}{\mathrm{P}}\right)^{*} \mathrm{C}
$$

Only the cost of the TE material is considered, the results show that the $\$ / \mathrm{W}$ value can be reduced to about $10 \%$ while maintaining about $65-70 \%$ of the maximum possible power output with a constant ZT.

A heat exchanger is used to recover heat from vehicle exhaust gas. A study [128] is completed by combining exhaust heat exchanger with muffler in the forms of 1-inlet 2-outlet, 2-inlet 2-outlet and the baseline empty cavity. The results indicate that the pressure drops of 1inlet 2-outlet and 2-inlet 2-outlet are $165 \%$ and $318 \%$ more than that of empty cavity for inlet temperature of $100{ }^{\circ} \mathrm{C}$ and mass flow rate of $131 \mathrm{~kg} / \mathrm{h}$. However, the pressure drops are $319 \%$ and $523 \%$ more than that of empty cavity for inlet temperature of $400{ }^{\circ} \mathrm{C}$ and mass flow rate of $156 \mathrm{~kg} / \mathrm{h}$, respectively for 1 -inlet 2-outlet and 2-inlet 2-outlet.

Heat removal on the cold side of the generator, in order to achieve the required temperature difference, represents a serious challenge to the operation of TE devices. It is therefore suggested that enhancing heat dissipation on cold side is vital to improve power output. To address this challenge, a thermoelectric generation process coupled with methanol steam reforming for hydrogen production is proposed, a methanol steam reforming micro-reactor is heated with waste heat and coupled with TEG [129]. Results show that the cold spot effect exists in the catalyst bed under all conditions and that in the micro-reactor, the temperature difference between the reforming and heating channel outlets decreases rapidly with an 
increase in the conductivity coefficient of TE material. Similarly, a dynamic model for waste heat recovery using TEG is developed to assess the influences of heat reservoir and heat sink [130]. The dynamic response characteristics, such as maximum output power, system efficiency and cold and hot semiconductor surface temperatures, are studied. It is proven that enhancing heat dissipation on cold side is vital to improve power output whereas the fluctuation of hot reservoir results into rapid change of TEG output power, something undesirable.

\section{Description of the reviews on thermoelectric materials, parameters and applications}

In this section, different reviews of TE technology found in literature are discussed. This is aimed at helping the readers to find the necessary information that couldn't be found in this piece of work.

Fairbanks discussed the history and progress of thermoelectric applications in vehicles, from the discovery of Seebeck effect by Thomas Johann Seebeck in 1821 to the modern improvement of thermoelectric technology in the 21st century [48]. He described the progress in thermoelectric materials figure of merit, ZT, vehicular thermoelectric generators (TEGs) and vehicular thermoelectric HVAC systems. It is noted that TEGs should be considered not only as candidates for off-highway vehicles, buses, and locomotives but also as a near term opportunity for an auxiliary power unit for heavy-duty trucks.

Enescu et al. presented a review on thermoelectric cooling parameters and performance [131]. They described the characteristics and performance of cooling devices including ZT, COP, and characterisation of cooling capacity. Various features of different thermoelectric cooling materials are expressed such as the dependence on temperature of the thermoelectric materials, the effects of the electrical thermal resistance, contact resistance, current and thermos element length, from which the COP can be improved.

The progress and challenge in thermoelectric power generation, concerning the materials and device, are reviewed [17]. Here, the top down approach to phonon engineering like atomic construction of new materials is reviewed followed by the bottom-up approach to electron engineering, such as the formation of ordered nanostructures. Challenges that prevent widespread of TEG devices are discussed including reliable contact at the device level and thermal stability at the material level. Separately, the performance of the family of $\mathrm{Mg}-\mathrm{Mn}$ silicides materials is reviewed with consideration of thermoelectric parameters such as power factor, Seebeck coefficient, thermal and electrical conductivities [132]. The $\mathrm{Mg}-\mathrm{Mn}$ silicides family of materials are seen as alternative thermoelectric materials to bismuth telluride, for 
mid-temperature range. Although bismuth telluride TE materials have dominated the TEG market, the problems associated with them such as high production costs, depletion of raw resources and toxicity have given way for increased search into alternative TE materials. $\mathrm{Mg}-$ Mn silicides are characterised by relatively high thermoelectric performance, abundance of raw resources, environmental compatibility and lowered production costs.

Elsewhere, technologies to recover exhaust heat from internal combustion engine are reviewed [133]. In this review, the latest developments and technologies on waste heat recovery of exhaust gas from internal combustion engine (ICE) are discussed including the organic Rankine cycle TEG, turbocharger technology and six-stroke cycle ICE.

Hamid et al. reviewed the principle parameters that affect the performance of thermoelectric renewable energy [49]. They provided the basic knowledge of thermoelectric materials and an overview of parameters that affect ZT and the prospects for the optimization of thermoelectric materials and their applications.

Thermoelectrics research with emphasis on recent developments and potentials for sustainable and renewable energy applications is reviewed [26]. The material development, thermoelectric applications in different areas and difficulties in terms of the commercialisations of advanced materials are discussed. The review highlights the potential environmental and economic benefits by TE applications and concludes that due to the present conversion efficiency, TE devices are technically and economically practical for micro/small applications although more benefits can be expected from medium/large scale thermoelectric applications with ZT of more than two. The recent advances in the field of complex thermoelectric materials, the strategies used to improve the thermopower and ways of reducing the thermal conductivity are highlighted [47].

Bell [28] reviewed the cooling, heating, power generation as well as waste heat recovery using thermoelectric systems. He found that TE materials can be competitive with fluid-based systems in smaller-scale applications such as automobile seats, night-vision systems, and electrical-enclosure cooling. The principles and methods for improving the intrinsic energyconversion efficiency in addition to ways of implementing advancements in system architecture are illustrated. The progress of TE power generation for small to medium scale systems is presented through a literature survey [134]. The power generation potentials are reviewed with prospects of grid connections as well the development in the field of TE materials. 
A review is also done on the development and application of TE generators and coolers [135], the basic concepts TE, some material research, applications, structural optimisation and further researches are discussed.

\section{Critical observations and recommendation for further research on TE technology}

In this section some observation are highlighted from the present work with regard to the current status of various aspects of TE technology including improvements and challenges. Consequently, the areas for future research on the subject area are suggested accordingly.

On the TE materials, a tremendous improvement on ZT has been registered in recent years with ZT of more than 7 reported. This justified by the increased application of TE devices for heating and cooling which requires high ZT. Although several research works have been carried to raise ZT in order to improve TE efficiency, a challenge of developing advanced TE materials with an optimization of conflicting properties for example increasing both ZT and power factor at the same time remains. This due to the fact that both ZT and power factor are necessary to be large for higher performance of TEG. Hence additional research is also necessary in this regard.

Furthermore, the miniaturization of TE devices has been made possible with increased TE material research. This has resulted into the manufacture of micro TE devices which are used for different applications such as cooling of microprocessors, watches, micro medical equipment etc.

TE technology has seen increasing applications in recent years due to increase in research. Although TEG devices were primarily being used for waste heat recovery, based on the discussion above it can be observed that they are now applied for harvesting of biomass, geothermal, solar and others. However, the main challenge is due to the low efficiency of TE devices, making them less competitive for use. Therefore more research is necessary to improve the efficiency of these devices in order to further boost and diversify their application.

Several modelling techniques are being used to analyse TE effects in order to come with more efficient TE devices. It can be noted from our discussion that numerical methods are the most popular methods used in the design and analysis of TE effects. On the other hand, although the simplified methods are easy to implement, they are criticised for less representing some of the TE effects like Thomson heat. This makes the designed TE devices to perform less 
than predicted and therefore affect the overall efficiency of TE based products. With the increase in computer technology, more research is necessary to further implement the TE models in computer programs thereby improving the accuracy of predictions for TE device performance.

TE device leg geometries such as leg length, shape and area are stated to be one the physical parameters (geometric features) that affect the performance of the TEG. In this work we have presented several works in which it is generally concluded that the varying leg geometries significantly affect the TEG power output and result into different sizes and distribution of thermal stresses in the leg. Additionally, the geometric features have some effects on TE properties of some TE elements like silicon nanowires where it is reported that the decrease in size and change in the shape of the silicon nanowire results into significantly increase in ZT and hence improve the performance of the TE device. Therefore, more research is necessary to ascertain the geometrical requirement of the TE element based on the type of material used.

The Joule effect, carrier density and Seebeck coefficient (that determines the Thomson effect) are some of the non-physical performance parameters of the TEG. However, in some TE device analysis, these parameters are neglected resulting into overestimation of the output. To mitigate this problem, several complex TE models have been suggested by researchers such as Transient TE model, numerical models and electrical analogy model that put into consideration of these effects. Unfortunately, some of these models like electrical analogy model according to this study have not been widely utilised. Therefore, the application of these models can improve the performance prediction of TE devices.

In recent years, the Efficiency of TE devices has improved greatly due TE material and device geometrical improvements. However, TEG/TEC efficiency low, being a subject of further research for more improvement. In particular, to improving the performance of the overall TEG system, several power conditioning methods have been proposed and analysed. It can be observed that dc-dc converters are able to provide a more stable power output and improve the efficiency of TEG system. However, to facilitate better performance improvement, several MPPT methods can be applied to extract the maximum power from TEG system. Therefore, more research is necessary to test the performance several converter topologies with the available MPPT techniques on TEG system, especially those which are already tested on PV systems.

To further improve the performance of TEG/TEC, different structures of TE devices have been reported. TE performance improvements have been demonstrated mainly by; the segmentation of different TE materials to form TE modules, the design of an integrated TE 
device (iTED) with respective alternating thermal and electrical connections in parallel and series as well as the introduction of a thermal switch to decrease the temperature fluctuation. Therefore, more TEG/TEC structural improvements should be a subject of research to advance the improvement of the overall performance and efficiency.

\section{Conclusion}

With near exhaustion of fossil fuel resources coupled with desire to reduce global warming, it has become increasingly necessary to exploit alternative and renewable energy sources to diversify the energy supply. Thermoelectric (TE) devices are regarded as alternative and environmental friendly technology for harvesting and recovering heat which is directly converted into electrical energy. In this work, a comprehensive review of thermoelectric technology encompassing the materials, applications, modelling techniques and performance improvement has been carried out. It has been demonstrated that the increasing research into TE technology has led to an outstanding increase in the value of ZT, making the use TE devices in diversified application possible. The design of integrated TE devices and the increased TE material research and device geometrical adjustment have greatly contributed to TE device performance improvement. The use of advanced TE mathematical models which have facilitated appropriate segmentation TE modules using different materials, notwithstanding the use several power conditioning methods more especially dc-dc converters have also played a significant role in improving the overall performance of TEG in terms of Power output, stability of voltage and improved TEG systems efficiency. TE devices have registered growing usage in a number of applications such as in cooling, heating, power generation and hybrid applications. A notable use of TEG/TEC devices to recover heat energy from, geothermal, biomass, infra-red radiation have been observed in addition to the primary use of TE devices for was heat recovery. Nevertheless, the main challenge remains in designing and optimizing advanced TE materials with appropriate values of ZT and power factor, calling for more research work into TE technology.

\section{References}

[1] M. Morini, M. Pinelli, P. R. Spina, and M. Venturini, "Optimal allocation of thermal, electric and cooling loads among generation technologies in household 
applications," Appl. Energy, vol. 112, pp. 205-214, 2013.

[2] S. F. Tie and C. W. Tan, "A review of energy sources and energy management system in electric vehicles," Renew. Sustain. Energy Rev., vol. 20, pp. 82-102, 2013.

[3] S. Varnhagen, A. Same, J. Remillard, and J. W. Park, "A numerical investigation on the efficiency of range extending systems using Advanced Vehicle Simulator," J. Power Sources, vol. 196, no. 6, pp. 3360-3370, 2011.

[4] C. Haddad, C. Périlhon, A. Danlos, M.-X. François, and G. Descombes, "Some Efficient Solutions to Recover Low and Medium Waste Heat: Competitiveness of the Thermoacoustic Technology," Energy Procedia, vol. 50, pp. 1056-1069, 2014.

[5] a. Montecucco, J. R. Buckle, and a. R. Knox, "Solution to the 1-D unsteady heat conduction equation with internal Joule heat generation for thermoelectric devices," Appl. Therm. Eng., vol. 35, no. 1, pp. 177-184, 2012.

[6] K. Ebrahimi, G. F. Jones, and A. S. Fleischer, "A review of data center cooling technology, operating conditions and the corresponding low-grade waste heat recovery opportunities," Renew. Sustain. Energy Rev., vol. 31, pp. 622-638, 2014.

[7] J. Siviter, a. Montecucco, and a. R. Knox, "Rankine cycle efficiency gain using thermoelectric heat pumps," Appl. Energy, vol. 140, pp. 161-170, 2015.

[8] F. Akhtar and M. Husain, "Energy replenishment using renewable and traditional energy resources for sustainable wireless sensor networks : A review," Renew. Sustain. Energy Rev., vol. 45, pp. 769-784, 2015.

[9] T. Seetawan, K. Singsoog, and S. Srichai, "Thermoelectric Energy Conversion of pCa3Co4O9/n-CaMnO3 Module," in The 6th International Conference on Applied Energy - ICAE2014, 2014, vol. 00, pp. 2-5.

[10] J. Chen and C. Wu, "Analysis on the Performance of a Thermoelectric Generator," J. Energy Resour. Technol., vol. 122, no. 2, p. 61, Dec. 2000.

[11] R. J. Goldstein, W. E. Ibele, S. V Patankar, T. W. Simon, T. H. Kuehn, P. J. Strykowski, K. K. Tamma, J. V. R. Heberlein, J. H. Davidson, J. Bischof, F. a Kulacki, U. Kortshagen, S. Garrick, V. Srinivasan, K. Ghosh, and R. Mittal, "Heat transfer - A review of 2005 literature," Int. J. Heat Mass Transf., vol. 53, no. 2122, pp. 4397-4447, 2010.

[12] A. A. Bazmi and G. Zahedi, "Sustainable energy systems: Role of optimization modeling techniques in power generation and supply - A review," Renew. Sustain. Energy Rev., vol. 15, no. 8, pp. 3480-3500, 2011.

[13] M. a. Hannan, F. a. Azidin, and a. Mohamed, "Hybrid electric vehicles and their challenges: A review," Renew. Sustain. Energy Rev., vol. 29, pp. 135-150, 2014.

[14] A. Royale and M. Simic, "Research in Vehicles With Thermal Energy Recovery Systems," Procedia Comput. Sci., vol. 60, pp. 1443-1452, 2015.

[15] X. Liu, C. Li, Y. D. Deng, and C. Q. Su, "An energy-harvesting system using thermoelectric power generation for automotive application," Int. J. Electr. Power Energy Syst., vol. 67, pp. 510-516, 2015.

[16] M. Noori, S. Gardner, and O. Tatari, "Electric vehicle cost, emissions, and water footprint in the United States: Development of a regional optimization model," Energy, vol. 89, pp. 610-625, 2015.

[17] W. Liu, Q. Jie, H. S. Kim, and Z. Ren, "Current progress and future challenges in thermoelectric power generation: From materials to devices," Acta Mater., vol. 87, 
no. 155 , pp. 357-376, 2015.

[18] a. Zolriasatein, X. Yan, E. Bauer, P. Rogl, a. Shokuhfar, and S. Paschen, "Influence of PCA on thermoelectric properties and hardness of nanostructured Ba-Cu-Si clathrates,” Mater. Des., vol. 87, pp. 883-890, 2015.

[19] N. S. Bennett, N. M. Wight, S. R. Popuri, and J.-W. G. Bos, "Efficient thermoelectric performance in silicon nano-films by vacancy-engineering," Nano Energy, pp. 350-356, 2015.

[20] J. Alvarez-Quintana, "Impact of the Substrate on the Efficiency of Thin Film Thermoelectric Technology," Appl. Therm. Eng., vol. 84, pp. 206-210, 2015.

[21] a. Sellitto, "Frequency dependent figure-of-merit in cylindrical thermoelectric nanodevices," Phys. B Condens. Matter, vol. 456, pp. 57-65, 2014.

[22] B. Yang, P. Wang, and A. Bar-Cohen, "Mini-contact enhanced thermoelectric cooling of hot spots in high power devices," IEEE Trans. Components Packag. Technol., vol. 30, no. 3, pp. 432-438, 2007.

[23] M. Redmond, K. Manickaraj, O. Sullivan, S. Mukhopadhyay, and S. Kumar, "Hotspot cooling in stacked chips using thermoelectric coolers," IEEE Trans. Components, Packag. Manuf. Technol., vol. 3, no. 5, pp. 759-767, 2013.

[24] S. Leblanc, "Sustainable Materials and Technologies Thermoelectric generators : Linking material properties and systems engineering for waste heat recovery applications," Susmat, vol. 1-2, pp. 26-35, 2014.

[25] S. Yu, Q. Du, H. Diao, G. Shu, and K. Jiao, "Start-up modes of thermoelectric generator based on vehicle exhaust waste heat recovery," Appl. Energy, vol. 138, pp. 276-290, 2015.

[26] X. F. Zheng, C. X. Liu, Y. Y. Yan, and Q. Wang, "A review of thermoelectrics research - Recent developments and potentials for sustainable and renewable energy applications," Renew. Sustain. Energy Rev., vol. 32, pp. 486-503, 2014.

[27] Z. Niu, S. Yu, H. Diao, Q. Li, K. Jiao, Q. Du, H. Tian, and G. Shu, "Elucidating modeling aspects of thermoelectric generator," Int. J. Heat Mass Transf., vol. 85, pp. 12-32, 2015.

[28] L. E. Bell, "Cooling, heating, generating power, and recovering waste heat with thermoelectric systems.," Science, vol. 321, no. 5895, pp. 1457-1461, 2008.

[29] S. C. Tzeng, T. M. Jeng, and Y. L. Lin, "Parametric study of heat-transfer design on the thermoelectric generator system," Int. Commun. Heat Mass Transf., vol. 52, pp. 97-105, 2014.

[30] B. D. In, H. I. Kim, J. W. Son, and K. H. Lee, "The study of a thermoelectric generator with various thermal conditions of exhaust gas from a diesel engine," Int. J. Heat Mass Transf., vol. 86, pp. 667-680, 2015.

[31] S. Yu, Q. Du, H. Diao, G. Shu, and K. Jiao, "Effect of vehicle driving conditions on the performance of thermoelectric generator," Energy Convers. Manag., vol. 96, pp. 363-376, 2015.

[32] U. Erturun, K. Erermis, and K. Mossi, "Effect of various leg geometries on thermo-mechanical and power generation performance of thermoelectric devices," Appl. Therm. Eng., vol. 73, no. 1, pp. 126-139, 2014.

[33] R. Rabari, S. Mahmud, and A. Dutta, "Numerical simulation of nanostructured thermoelectric generator considering surface to surrounding convection," Int. Commun. Heat Mass Transf., vol. 56, pp. 146-151, 2014. 
[34] G. Wu and X. Yu, "A holistic 3D finite element simulation model for thermoelectric power generator element," Energy Convers. Manag., vol. 86, pp. 99-110, 2014.

[35] N. Q. Nguyen and K. V. Pochiraju, "Behavior of thermoelectric generators exposed to transient heat sources," Appl. Therm. Eng., vol. 51, no. 1-2, pp. 1-9, 2013.

[36] H. Fateh, C. a. Baker, M. J. Hall, and L. Shi, "High fidelity finite difference model for exploring multi-parameter thermoelectric generator design space," Appl. Energy, vol. 129, pp. 373-383, 2014.

[37] A. Ibrahim, S. Rahnamayan, M. Vargas Martin, and B. Yilbas, "Multi-objective thermal analysis of a thermoelectric device: Influence of geometric features on device characteristics," Energy, vol. 77, pp. 305-317, 2014.

[38] A. Z. Sahin and B. S. Yilbas, "Thermodynamic irreversibility and performance characteristics of thermoelectric power generator," Energy, vol. 55, pp. 899-904, 2013.

[39] F. Meng, L. Chen, F. Sun, and B. Yang, "Thermoelectric power generation driven by blast furnace slag flushing water,” Energy, vol. 66, pp. 965-972, 2014.

[40] H. Lee, "Optimal design of thermoelectric devices with dimensional analysis," Appl. Energy, vol. 106, pp. 79-88, 2013.

[41] G. Liang, W. Huang, C. S. Koong, J. S. Wang, and J. Lan, "Geometry effects on thermoelectric properties of silicon nanowires based on electronic band structures," J. Appl. Phys., vol. 107, no. 1, 2010.

[42] W. Huang, C. S. Koong, and G. Liang, "Theoretical Study on Thermoelectric Properties of Ge Nanowires Based on Electronic Band Structures," Semicond. Semimetals, vol. 31, no. 9, pp. 1026-1028, 2010.

[43] a. S. Al-Merbati, B. S. Yilbas, and a. Z. Sahin, "Thermodynamics and thermal stress analysis of thermoelectric power generator: Influence of pin geometry on device performance," Appl. Therm. Eng., vol. 50, no. 1, pp. 683-692, 2013.

[44] J. Y. Jang and Y. C. Tsai, "Optimization of thermoelectric generator module spacing and spreader thickness used in a waste heat recovery system," Appl. Therm. Eng., vol. 51, no. 1-2, pp. 677-689, 2013.

[45] T. Ma, J. Pandit, S. V. Ekkad, S. T. Huxtable, and Q. Wang, "Simulation of thermoelectric-hydraulic performance of a thermoelectric power generator with longitudinal vortex generators," Energy, vol. 84, pp. 695-703, 2015.

[46] W.-H. Chen, C.-Y. Liao, C.-C. Wang, and C.-I. Hung, "Evaluation of power generation from thermoelectric cooler at normal and low-temperature cooling conditions," Energy Sustain. Dev., vol. 25, pp. 8-16, 2015.

[47] G. J. Snyder and E. S. Toberer, "Complex thermoelectric materials.," Nat. Mater., vol. 7 , no. 2, pp. 105-114, 2008.

[48] J. Fairbanks, "Thermoelectric applications in vehicles status 2008," US Dep. Energy, 2008.

[49] M. Hamid Elsheikh, D. A. Shnawah, M. F. M. Sabri, S. B. M. Said, M. Haji Hassan, M. B. Ali Bashir, and M. Mohamad, "A review on thermoelectric renewable energy: Principle parameters that affect their performance," Renew. Sustain. Energy Rev., vol. 30, pp. 337-355, 2014.

[50] H. Ohta, S. Kim, Y. Mune, T. Mizoguchi, K. Nomura, S. Ohta, T. Nomura, Y. Nakanishi, Y. Ikuhara, M. Hirano, H. Hosono, and K. Koumoto, "Giant 
thermoelectric Seebeck coefficient of a two-dimensional electron gas in SrTiO3.," Nat. Mater., vol. 6, no. 2, pp. 129-134, 2007.

[51] D. T. Crane and G. S. Jackson, "Optimization of cross flow heat exchangers for thermoelectric waste heat recovery," Energy Convers. Manag., vol. 45, no. 9-10, pp. 1565-1582, 2004.

[52] American Elements, "Bismuth Antimonide (BiSb)." [Online]. Available: http://www.americanelements.com/bisb.html. [Accessed: 19-Jun-2015].

[53] G. J. Snyder, M. Christensen, E. Nishibori, T. Caillat, and B. B. Iversen, "Disordered zinc in Zn4Sb3 with phonon-glass and electron-crystal thermoelectric properties.," Nat. Mater., vol. 3, no. 7, pp. 458-463, 2004.

[54] Y. Mozharivskyj, a O. Pecharsky, S. Bud'ko, and G. J. Miller, "Promising thermoelectric material: Zn4Sb3 or Zn6-delta Sb5. Its composition, structure, stability, and polymorphs. Structure and stability of Zn1-delta Sb," Chem. Mater., vol. 16, no. 8, pp. 1580-1589, 2004.

[55] K. Park, H. K. Hwang, J. W. Seo, and W. S. Seo, "Enhanced high-temperature thermoelectric properties of $\mathrm{Ce}^{-}$and $\mathrm{Dy}^{-}$doped $\mathrm{ZnO}$ for power generation," Energy, vol. 54, pp. 139-145, 2013.

[56] G. J. Snyder, J. R. Lim, C.-K. Huang, and J.-P. Fleurial, "Thermoelectric microdevice fabricated by a MEMS-like electrochemical process.," Nat. Mater., vol. 2, no. 8, pp. 528-531, 2003.

[57] M. Tan, Y. Wang, Y. Deng, Z. Zhang, B. Luo, J. Yang, and Y. Xu, "Oriented growth of A2Te3 (A = Sb, Bi) films and their devices with enhanced thermoelectric performance," Sensors Actuators, A Phys., vol. 171, no. 2, pp. 252-259, 2011.

[58] X. F. Zheng, Y. Y. Yan, and K. Simpson, "A potential candidate for the sustainable and reliable domestic energy generation-Thermoelectric cogeneration system," Appl. Therm. Eng., vol. 53, no. 2, pp. 305-311, 2012.

[59] H.-K. Ma, C.-P. Lin, H.-P. Wu, C.-H. Peng, and C.-C. Hsu, "Waste heat recovery using a thermoelectric power generation system in a biomass gasifier," Appl. Therm. Eng., pp. 1-6, 2014.

[60] J. Eakburanawat and I. Boonyaroonate, "Development of a thermoelectric battery-charger with microcontroller-based maximum power point tracking technique," Appl. Energy, vol. 83, no. 7, pp. 687-704, 2006.

[61] C. E. Kinsella, S. M. O’Shaughnessy, M. J. Deasy, M. Duffy, and a. J. Robinson, "Battery charging considerations in small scale electricity generation from a thermoelectric module," Appl. Energy, vol. 114, pp. 80-90, 2014.

[62] A. Zachár, I. Farkas, M. Kálmán, and P. Odry, "Application of Thermopile Technology in the Automotive Industry."

[63] M. a. Karri, E. F. Thacher, and B. T. Helenbrook, "Exhaust energy conversion by thermoelectric generator: Two case studies," Energy Convers. Manag., vol. 52, no. 3, pp. 1596-1611, 2011.

[64] X. Liu, Y. D. Deng, Z. Li, and C. Q. Su, "Performance analysis of a waste heat recovery thermoelectric generation system for automotive application," Energy Convers. Manag., vol. 90, pp. 121-127, 2015.

[65] Y. Wang, C. Dai, and S. Wang, "Theoretical analysis of a thermoelectric generator using exhaust gas of vehicles as heat source," Appl. Energy, vol. 112, pp. 11711180, 2013. 
[66] I.-S. Suh, H. Cho, and M. Lee, "Feasibility study on thermoelectric device to energy storage system of an electric vehicle," Energy, vol. 76, pp. 436-444, 2014.

[67] C.-C. Weng and M.-J. Huang, "A study of using a thermoelectric generator to harvest energy from a table lamp," Energy, vol. 76, pp. 788-798, 2014.

[68] G. Casano and S. Piva, "Experimental investigation of the performance of a thermoelectric generator based on Peltier cells," Exp. Therm. Fluid Sci., vol. 35, no. 4, pp. 660-669, 2011.

[69] R. Chein and G. Huang, "Thermoelectric cooler application in electronic cooling," Appl. Therm. Eng., vol. 24, no. 14-15, pp. 2207-2217, 2004.

[70] X. F. Zheng, C. X. Liu, R. Boukhanouf, Y. Y. Yan, and W. Z. Li, "Experimental study of a domestic thermoelectric cogeneration system," Appl. Therm. Eng., vol. 62 , no. 1, pp. 69-79, 2014.

[71] W.-H. Chen, C.-C. Wang, and C.-I. Hung, "Geometric effect on cooling power and performance of an integrated thermoelectric generation-cooling system," Energy Convers. Manag., vol. 87, pp. 566-575, 2014.

[72] B. S. Yilbas and A. Z. Sahin, "Thermal characteristics of combined thermoelectric generator and refrigeration cycle," Energy Convers. Manag., vol. 83, pp. 42-47, 2014.

[73] J. L. Wang, J. Y. Wu, and C. Y. Zheng, "Simulation and evaluation of a CCHP system with exhaust gas deep-recovery and thermoelectric generator," Energy Convers. Manag., vol. 86, pp. 992-1000, 2014.

[74] A. Bitschi, "Modelling of Thermoelectric Devices for Electric Power Generation," no. $18441,2009$.

[75] D. N. Kossyvakis, C. G. Vossou, C. G. Provatidis, and E. V. Hristoforou, "Computational analysis and performance optimization of a solar thermoelectric generator,” Renew. Energy, vol. 81, pp. 150-161, 2015.

[76] C. Lertsatitthanakorn, J. Jamradloedluk, and M. Rungsiyopas, "Electricity Generation from a Solar Parabolic Concentrator Coupled to a Thermoelectric Module," Energy Procedia, vol. 52, pp. 150-158, 2014.

[77] K. Qiu and a. C. S. Hayden, "Development of a novel cascading TPV and TE power generation system,” Appl. Energy, vol. 91, no. 1, pp. 304-308, 2012.

[78] A. Bianchini, M. Pellegrini, and C. Saccani, "Thermoelectric cells cogeneration from biomass power plant," Energy Procedia, vol. 45, pp. 268-277, 2014.

[79] M. C. Barma, M. Riaz, R. Saidur, and B. D. Long, "Estimation of thermoelectric power generation by recovering waste heat from Biomass fired thermal oil heater," Energy Convers. Manag., vol. 98, pp. 303-313, 2015.

[80] Á. G. Miranda, T. S. Chen, and C. W. Hong, "Feasibility study of a green energy powered thermoelectric chip based air conditioner for electric vehicles," Energy, vol. 59, pp. 633-641, 2013.

[81] wikipedia, "Thermoelectric effect." [Online]. Available: https://en.wikipedia.org/wiki/Thermoelectric_effect\#Thomson_effect. [Accessed: 28-Aug-2015].

[82] Z. Ge, L. Jin, and C. Yang, "Microfluidic concentration of sample solutes using Joule heating effects under a combined AC and DC electric field," Int. J. Heat Mass Transf., vol. 85, pp. 158-165, 2015.

[83] K. S. Ravi Chandran, "Transient Joule heating of graphene, nanowires and 
filaments: Analytical model for current-induced temperature evolution including substrate and end effects," Int. J. Heat Mass Transf., vol. 88, pp. 14-19, 2015.

[84] a. Chakraborty, B. B. Saha, S. Koyama, and K. C. Ng, "Thermodynamic modelling of a solid state thermoelectric cooling device: Temperature-entropy analysis," Int. J. Heat Mass Transf., vol. 49, no. 19-20, pp. 3547-3554, 2006.

[85] G. Fraisse, J. Ramousse, D. Sgorlon, and C. Goupil, "Comparison of different modeling approaches for thermoelectric elements," Energy Convers. Manag., vol. 65, pp. 351-356, 2013.

[86] J. H. Meng, X. D. Wang, and X. X. Zhang, "Transient modeling and dynamic characteristics of thermoelectric cooler," Appl. Energy, vol. 108, pp. 340-348, 2013.

[87] S. C. Kaushik and S. Manikandan, "The influence of Thomson effect in the performance optimization of a two stage thermoelectric cooler," Cryogenics (Guildf)., vol. 72, pp. 57-64, 2015.

[88] G. Fraisse, C. Viardot, O. Lafabrie, and G. Achard, "Development of a simplified and accurate building model based on electrical analogy," Energy Build., vol. 34, no. 10, pp. 1017-1031, 2002.

[89] G. Fraisse, M. Lazard, C. Goupil, and J. Y. Serrat, "Study of a thermoelement's behaviour through a modelling based on electrical analogy," Int. J. Heat MasS Transf., vol. 53, no. 17-18, pp. 3503-3512, 2010.

[90] N. Wang, X. Li, and J. Mao, "Improvement of Thermal Environment by Thermoelectric Coolers and Numerical Optimization of Thermal Performance," vol. 62, no. 8, pp. 2579-2586, 2015.

[91] Y. Wu, T. Ming, X. Li, T. Pan, K. Peng, and X. Luo, "Numerical simulations on the temperature gradient and thermal stress of a thermoelectric power generator," Energy Convers. Manag., vol. 88, pp. 915-927, 2014.

[92] E. Massaguer, a. Massaguer, L. Montoro, and J. R. Gonzalez, "Development and validation of a new TRNSYS type for the simulation of thermoelectric generators," Appl. Energy, vol. 134, pp. 65-74, 2014.

[93] E. Massaguer, A. Massaguer, L. Montoro, and J. R. Gonzalez, "Modeling analysis of longitudinal thermoelectric energy harvester in low temperature waste heat recovery applications," Appl. Energy, vol. 140, pp. 184-195, 2015.

[94] W. He, S. Wang, C. Lu, X. Zhang, and Y. Li, "Influence of different cooling methods on thermoelectric performance of an engine exhaust gas waste heat recovery system," Appl. Energy, 2015.

[95] J.-Y. Jang, Y.-C. Tsai, and C.-W. Wu, "A study of 3-D numerical simulation and comparison with experimental results on turbulent flow of venting flue gas using thermoelectric generator modules and plate fin heat sink," Energy, vol. 53, no. 0, pp. 270-281, 2013.

[96] D. T. Crane and L. E. Bell, "Progress towards maximizing the performance of a thermoelectric power generator," Proc. Int. Conf. Thermoelectr. ICT, pp. 11-16, 2006.

[97] R. J. Stevens, S. J. Weinstein, and K. S. Koppula, "Theoretical limits of thermoelectric power generation from exhaust gases," Appl. Energy, vol. 133, pp. 80-88, 2014.

[98] B. V. K. Reddy, M. Barry, J. Li, and M. K. Chyu, "Thermoelectric-hydraulic performance of a multistage integrated thermoelectric power generator," Energy 
Convers. Manag., vol. 77, pp. 458-468, 2014.

[99] S. Bensaid, M. Brignone, A. Ziggiotti, and S. Specchia, "High efficiency ThermoElectric power generator," Int. J. Hydrogen Energy, vol. 37, no. 2, pp. 1385-1398, 2012.

[100] X. Gou, H. Ping, Q. Ou, H. Xiao, and S. Qing, "A novel thermoelectric generation system with thermal switch," Appl. Energy, 2014.

[101] a. Martínez, D. Astrain, and a. Rodríguez, "Experimental and analytical study on thermoelectric self cooling of devices," Energy, vol. 36, no. 8, pp. 5250-5260, 2011.

[102] R. Kiflemariam and C.-X. Lin, "Numerical simulation of integrated liquid cooling and thermoelectric generation for self-cooling of electronic devices," Int. J. Therm. Sci., vol. 94, pp. 193-203, 2015.

[103] C. Amaral, C. Brandão, É. V. Sempels, and F. J. Lesage, "Thermoelectric power enhancement by way of flow impedance for fixed thermal input conditions," $J$. Power Sources, vol. 272, pp. 672-680, 2014.

[104] M. Tan, Y. Deng, and Y. Hao, "Improved thermoelectric performance of a film device induced by densely columnar Cu electrode," Energy, vol. 70, pp. 143-148, 2014.

[105] B. V. K. Reddy, M. Barry, J. Li, and M. K. Chyu, "A fluid-thermo-electric coupled field analysis of a novel integrated thermoelectric device," Energy Procedia, vol. 14, no. December 2011, pp. 2088-2095, 2012.

[106] B. V. K. Reddy, M. Barry, J. Li, and M. K. Chyu, "Mathematical modeling and numerical characterization of composite thermoelectric devices," Int. J. Therm. Sci., vol. 67, pp. 53-63, 2013.

[107] W. H. Chen, C. Y. Liao, C. I. Hung, and W. L. Huang, "Experimental study on thermoelectric modules for power generation at various operating conditions," Energy, vol. 45, no. 1, pp. 874-881, 2012.

[108] B. T. Admasu, X. Luo, and J. Yao, "Effects of temperature non-uniformity over the heat spreader on the outputs of thermoelectric power generation system," Energy Convers. Manag., vol. 76, no. 0, pp. 533-540, Dec. 2013.

[109] a. a. Snarskii and I. V. Bezsudnov, "Rotating thermoelectric device in periodic steady state," Energy Convers. Manag., vol. 94, pp. 103-111, 2015.

[110] D. Dai, Y. Zhou, and J. Liu, "Liquid metal based thermoelectric generation system for waste heat recovery," Renew. Energy, vol. 36, no. 12, pp. 3530-3536, 2011.

[111] C. Liu, X. Pan, X. Zheng, Y. Yan, and W. Li, "An experimental study of a novel prototype for two-stage thermoelectric generator from vehicle exhaust," J. Energy Inst., vol. 86, pp. 1-11, 2015.

[112] C. Amaral, C. Brandão, É. V. Sempels, and F. J. Lesage, "Net thermoelectric generator power output using inner channel geometries with alternating flow impeding panels," Appl. Therm. Eng., vol. 65, no. 1-2, pp. 91-101, 2014.

[113] D. N. Kossyvakis, C. G. Vossou, C. G. Provatidis, and E. V. Hristoforou, "Computational and experimental analysis of a commercially available Seebeck module," Renew. Energy, vol. 74, pp. 1-10, 2015.

[114] X. D. Wang, Y. X. Huang, C. H. Cheng, D. Ta-Wei Lin, and C. H. Kang, "A threedimensional numerical modeling of thermoelectric device with consideration of coupling of temperature field and electric potential field," Energy, vol. 47, no. 1, pp. 488-497, 2012. 
[115] F. J. Lesage, R. Pelletier, L. Fournier, and É. V. Sempels, "Optimal electrical load for peak power of a thermoelectric module with a solar electric application," Energy Convers. Manag., vol. 74, pp. 51-59, 2013.

[116] M. F. Remeli, L. Tan, A. Date, B. Singh, and A. Akbarzadeh, "Simultaneous power generation and heat recovery using a heat pipe assisted thermoelectric generator system," Energy Convers. Manag., vol. 91, pp. 110-119, 2015.

[117] A. Abusorrah, M. M. Al-Hindawi, Y. Al-Turki, K. Mandal, D. Giaouris, S. Banerjee, S. Voutetakis, and S. Papadopoulou, "Stability of a boost converter fed from photovoltaic source," Sol. Energy, vol. 98, no. PC, pp. 458-471, 2013.

[118] K. Ishaque, Z. Salam, and G. Lauss, "The performance of perturb and observe and incremental conductance maximum power point tracking method under dynamic weather conditions," Appl. Energy, vol. 119, pp. 228-236, 2014.

[119] Y. M. Roshan and M. Moallem, "Maximum power point estimation and tracking using power converter input resistance control," Sol. Energy, vol. 96, pp. 177-186, 2013.

[120] M. H. Taghvaee, M. A. M. Radzi, S. M. Moosavain, H. Hizam, and M. H. Marhaban, "A current and future study on non-isolated DC - DC converters for photovoltaic applications," Renew. Sustain. Energy Rev., vol. 17, pp. 216-227, 2013.

[121] R. Kim, S. Member, J. Lai, and A. Abstract, "A Seamless Mode Transfer Maximum Power Point Tracking Controller For Thermoelectric Generator Applications," IEEE Trans. Power Electron., vol. 23, no. 5, pp. 2310-2318, 2008.

[122] J. H. Carstens and C. Gühmann, "Maximum Power Point Controller for Thermoelectric Generators to Support a Vehicle Power Supply," Mater. Today Proc., vol. 2, no. 2, pp. 790-803, 2015.

[123] C. Yu and K. T. Chau, "Thermoelectric automotive waste heat energy recovery using maximum power point tracking," Energy Convers. Manag., vol. 50, no. 6, pp. 1506-1512, 2009.

[124] M. Li, S. Xu, Q. Chen, and L. R. Zheng, "Thermoelectric-generator-based DC-DC conversion networks for automotive applications," J. Electron. Mater., vol. 40, no. 5, pp. 1136-1143, 2011.

[125] M. Li, "Thermoelectric-Generator-Based DC-DC Conversion Network for Automotive Applications," KTH Information and Communication Technology, 2011.

[126] J.-D. Park, H. Lee, and M. Bond, "Uninterrupted thermoelectric energy harvesting using temperature-sensor-based maximum power point tracking system,” Energy Convers. Manag., vol. 86, pp. 233-240, 2014.

[127] H. Kim and W. Kim, "A way of achieving a low \$/W and a decent power output from a thermoelectric device," Appl. Energy, vol. 139, pp. 205-211, 2015.

[128] H. Lu, T. Wu, S. Bai, K. Xu, Y. Huang, W. Gao, X. Yin, and L. Chen, "Experiment on thermal uniformity and pressure drop of exhaust heat exchanger for automotive thermoelectric generator," Energy, vol. 54, pp. 372-377, 2013.

[129] F. Wang, Y. Cao, and G. Wang, "Thermoelectric generation coupling methanol steam reforming characteristic in microreactor," Energy, vol. 80, pp. 642-653, 2015.

[130] X. Gou, S. Yang, H. Xiao, and Q. Ou, "A dynamic model for thermoelectric generator applied in waste heat recovery," Energy, vol. 52, pp. 201-209, 2013. 
[131] D. Enescu and E. O. Virjoghe, "A review on thermoelectric cooling parameters and performance," Renew. Sustain. Energy Rev., vol. 38, pp. 903-916, 2014.

[132] M. B. A. Bashir, S. Mohd Said, M. F. M. Sabri, D. A. Shnawah, and M. H. Elsheikh, "Recent advances on Mg2Si1-xSnx materials for thermoelectric generation," Renew. Sustain. Energy Rev., vol. 37, pp. 569-584, 2014.

[133] R. Saidur, M. Rezaei, W. K. Muzammil, M. H. Hassan, S. Paria, and M. Hasanuzzaman, "Technologies to recover exhaust heat from internal combustion engines," Renew. Sustain. Energy Rev., vol. 16, no. 8, pp. 5649-5659, 2012.

[134] A. Date, A. Date, C. Dixon, and A. Akbarzadeh, "Progress of thermoelectric power generation systems: Prospect for small to medium scale power generation," Renew. Sustain. Energy Rev., vol. 33, pp. 371-381, 2014.

[135] W. He, G. Zhang, X. Zhang, J. Ji, G. Li, and X. Zhao, "Recent development and application of thermoelectric generator and cooler," Appl. Energy, vol. 143, pp. 125, 2015. 